Portland State University

PDXScholar

4-16-1976

\title{
The Chemistry of Chromium (VI) And Chromium (V) Oxide Fluorides
}

Patrick Jay Green

Portland State University

Follow this and additional works at: https://pdxscholar.library.pdx.edu/open_access_etds

Part of the Chemistry Commons

Let us know how access to this document benefits you.

Recommended Citation

Green, Patrick Jay, "The Chemistry of Chromium (VI) And Chromium (V) Oxide Fluorides" (1976).

Dissertations and Theses. Paper 4039.

https://doi.org/10.15760/etd.5923

This Thesis is brought to you for free and open access. It has been accepted for inclusion in Dissertations and Theses by an authorized administrator of PDXScholar. Please contact us if we can make this document more accessible: pdxscholar@pdx.edu. 
AN ABSTRACT OF THE THESIS OF Patrick Jay Green For the Master of Science in Chemistry presented April 16, 1976.

Title: Chemistry of Chromium(VI) and Chromium(V) Oxide Fluarides. APPROVED BY MEMBERS DF THE THESIS COMITTEE;
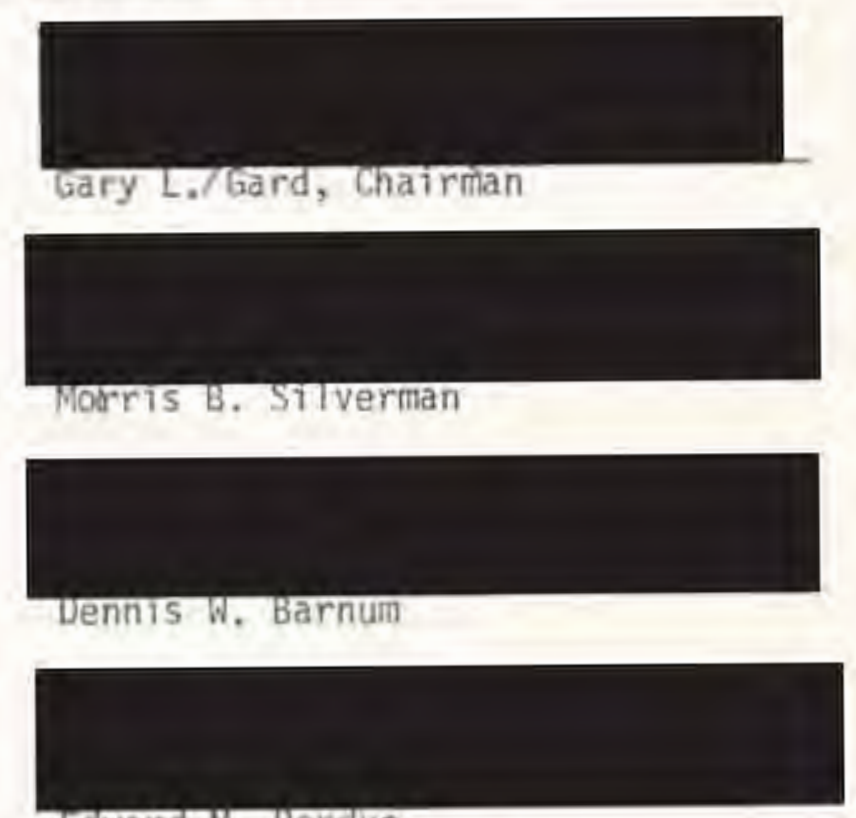

Eoward M. Perdue

New preparative routes to chromyl fluoride were sought. It was found that chlorine monofluoride reacts with chromium trioxide and chromyi chloride to produce chromy 1 fluoride. Attempts were made to define a mechanism for the reaction of $\mathrm{ClF}$ and $\mathrm{CrO}_{3}$ in light of by-products observed and previous investigations. Carbonyl fluoride and chromium trioxide react to form chronyl fluoride and carbon dioxide. A mechanism was also proposed for this reaction. Chromium trioxide with $\mathrm{MoF}_{6}$ or $\mathrm{WF}_{6}$ reacts to produce chromyl fluoride and the respective oxide tetrafluoride. 
Sulfur hexafluoride did not react with $\mathrm{CrO}_{3}$.

A limited study of the reaction chemistry of chromyl fluoride was undertaken. The interaction of $\mathrm{NO}_{2} \mathrm{~F}$ and $\mathrm{NOF}$ and $\mathrm{CrO}_{2} \mathrm{~F}_{2}$ leads to nitranium and nitrosonium trifluorochromate (Vi) saits, respectively. The structure of these compounds was assigned as a cisudioxo, fluorine bridged polymer on the basis of infrared spectral data and its similarity to previousiy reported work where the structures were confirmed by $x$-ray crystallography, The previously reported compound, $\mathrm{SO}_{2} \cdot 2 \mathrm{CrO}_{2} \mathrm{~F}_{2}$, was found to form a $1: 2$ adduct with acetonitrile which was shown from infrared spectral data to contain coordinated $\mathrm{CH}_{3} \mathrm{CN}$ groups. Chromyl fluoride was found to react with $n$-hexane to form an Etard complex of non-stoichiometric composition. The infrared spectrum of the complex displayed a band which was assigned to a carbonyl group coordinated to a chromium center. Hydrolysis of the complex produced ten different organic compounds, among which hexanoic acid, 2-hexanone, and 3-hexanone were identified. Tetrachloroethylene, trifluoroethylene, and 1,1-difluoroethylene were found to react with chromyl fluoride with only 1,1-difluoroethylene yielding a stoichiometric complex, $\mathrm{CF}_{2}: \mathrm{CH}_{2} \cdot 2 \mathrm{CrO}_{2} \mathrm{~F}_{2}$. The solid products of the reactions of all three olefins wi th $\mathrm{CrO}_{2} \mathrm{~F}_{2}$ show an infrared band which was assigned to a carbonyl group coordinated to chromium, Tike the n-hexane Etard complex. Hydrolysis of $\mathrm{CF}_{2}: \mathrm{CH}_{2} \cdot 2 \mathrm{CrO}_{2} \mathrm{~F}_{2}$ does not yield trifluoroethanol as had been reported.

It was found that $\mathrm{CrO}_{3}$ or $\mathrm{CrO}_{2} \mathrm{~F}_{2}$ react with excess $\mathrm{C} 1 \mathrm{~F}$ at $100^{\circ}$ to form a red-brown solid which was found to correspond to a composition of $\mathrm{CrOF}_{3} \cdot 0.14 \mathrm{ClF}$ to $\mathrm{CrO}_{2} \mathrm{~F}_{2} \cdot 0,21 \mathrm{ClF}$. Treatment of this solid with $\mathrm{F}_{2}$ at $120^{\circ}$ 
or reaction of $\mathrm{CIF}$ and $\mathrm{CrO}_{2} \mathrm{~F}_{2}$ at $250^{\circ}$ leads to a nonvolatile purple solid which was found to be greatly depleted in chlorine. This purple $\mathrm{CrOF}_{3}$ was assigned to be a fluorine-bridged polymer with terminal chromi um-oxygen double bonds from infrared and Raman spectral information. Chromium oxide trifluoride reacts with fiuorine at $180^{\circ}$ to form $\mathrm{CrF}_{5}$ and with antimony pentafiuoride to produce $\mathrm{CrOF}_{3} \cdot 2 \mathrm{SbF}_{5}$. 
THE CHEMISTRY OF CHROMIUM(VI) AND CHROMIUM(V) OXIDE FLUORIDES

by

PATRICK JAY GREEN

A thesis submitted in partial fulfillment of the requirements for the degree of

MASTER OF SCIENCE

in

CHEMISTRY

Portland State University

1976 
TO THE OFFICE OF GRADUATE STUDIES ANO RESEARCH:

The merbers of the Cormittee approve the thesis of

Patrick Jay Green presented Norl1 16, 1976.

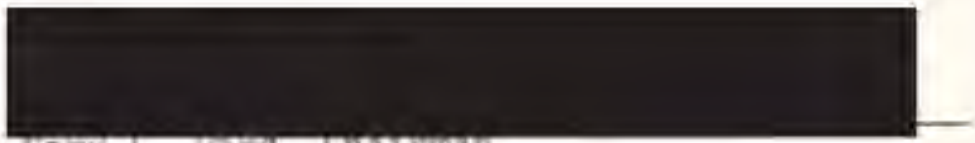

thery L. bard, Gramman

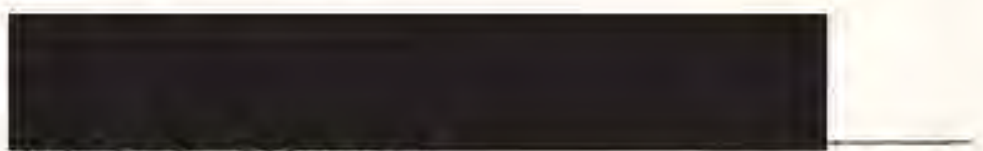

Morris B. Silverman

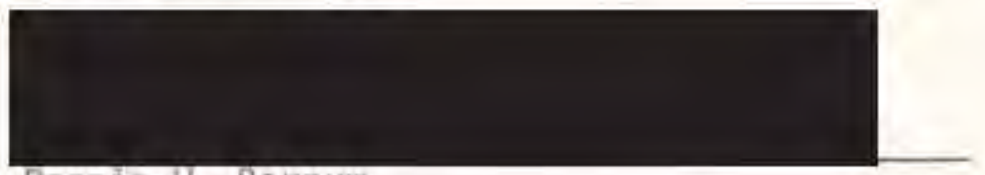

Dennis W. Barnumi

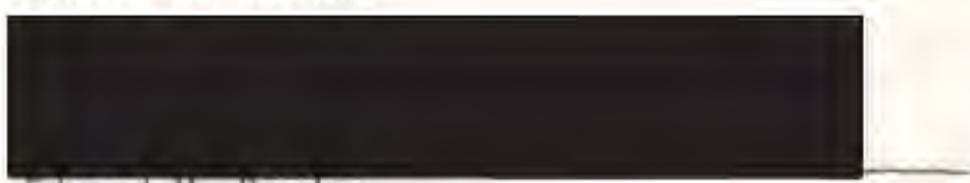

Edward M. Perdue

APPROVED:

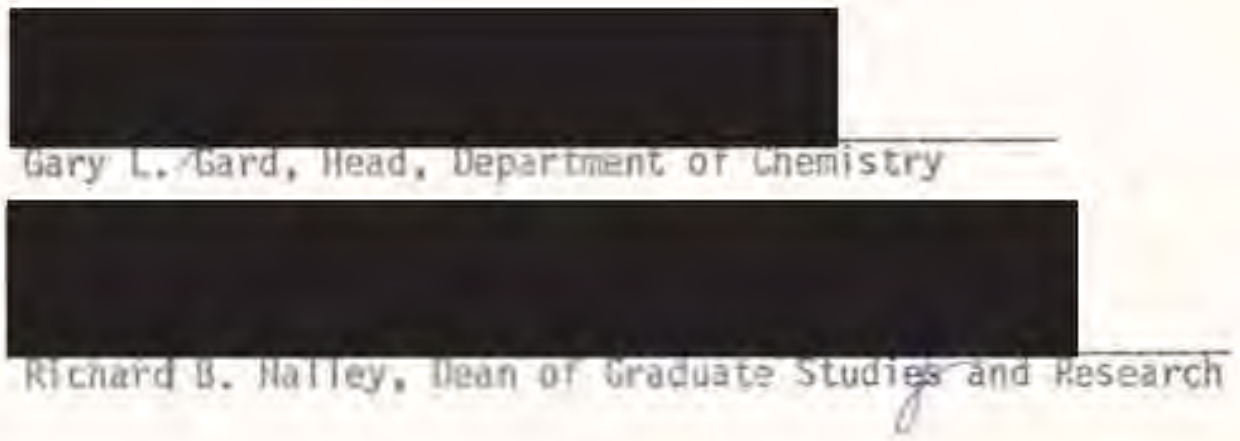


TABLE OF CONTENTS

PAGE

ACKNOWLEDGEMENTS $\ldots \ldots \ldots \ldots \ldots \ldots \ldots \ldots \ldots \ldots \ldots \ldots$, iti

LIST OF FIGURES $\ldots \ldots \ldots \ldots \ldots \ldots \ldots \ldots \ldots \ldots \ldots \ldots \ldots \ldots \ldots \ldots \ldots$ iv

LIST OF TABLES $\ldots \ldots \ldots \ldots \ldots \ldots \ldots \ldots \ldots \ldots \ldots \ldots \ldots \ldots \ldots \ldots \ldots$

CHAPTER

1 Experimental....................... 1

II New Preparations

of Chromyl Fluoride ................ 10

III Some Reaction Chemistry

of Chromyl Fluoride ............... 30

IV Preparation and Characterization

of Chromium(V) Oxide Trifluoride ......

BIBLIOGRAPHY $, \ldots \ldots, \ldots, \ldots, \ldots, \ldots, \ldots, \ldots, \ldots$, 


\section{ACKNOWLEOGEMENTS}

The author wishes to thank Mr. Steven Brown for assistance in obtaining Raman spectral data and for many productive discussions, Dr. Thomas Loehr of the Oregon Graduate Center for use of the Raman spectrometer, Ms. An McFarlane for typing the manuscript, Dr. Gary Gard for his patience, overall help and advice, and his wife, Susan, for her unvarying support. 


\section{LIST OF FIGURES}

F1GURE

PAGE,

1 Chromyl Fluoride Etard Reaction Apparatus .... 6

2 Proposed Mechanism of the Reaction of Chlorine Monofluoride and Chromium Trioxide at $0^{\circ}$.. 23

3. Proposed Mechanism of the Reaction of Carbonyl

Fluoride and Chromium Trioxide ............ 24

4 Structure of the $\mathrm{MO}_{2} \mathrm{~F}_{3}{ }^{-}$ion $(M=V, W, M o) \ldots \quad 45$

5 Structures of Metal oxide Trihalides ....... 82 


\section{LIST OF TABLES}

I Physical Properties of Chronyl Fluoride ........ 11

II Previousiy Reported Preparations of Chromyl Fluoride ............................. 11

III Ven Preparations of Chromyl Fluoride .......... 12

IV Reactions of Holybdenum and Tungsten Hexafluorides ........................... 15

$\checkmark$ Proposed Explanation of the Reaction of Chromfum Trioxide and Chlorine Nonofluoride at $0^{\circ} \mathrm{C} .$.

VI Infrared Absorbances (in $\mathrm{cm}^{-1}$ ) of Volatile Products of the Reaction of $\mathrm{CrO}_{3}$ and $\mathrm{CIF}$ at $0^{\circ} \mathrm{C} . \ldots$.

VII Bond Lengths and Angles of Chromyl Fluoride..... 31

VII Chromy1 Chloride Oxidation Products ........... 34

IX Infrared Vibrational Frequencies of $\mathrm{NO}_{2} \mathrm{CrO}_{2} \mathrm{~F}_{3}$ and

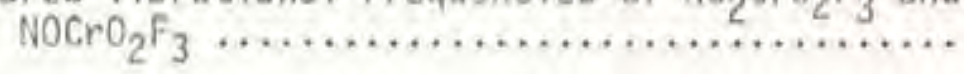

$x$ Infrared Vibrational Frequencies of $\mathrm{SO}_{2} \cdot 2 \mathrm{CrO}_{2} \mathrm{~F}_{2} \cdot$

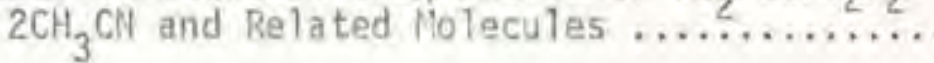

XI Vibrational Frequencies of the n-Hexane Etard

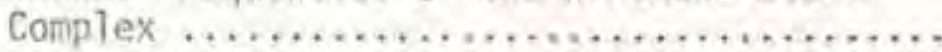

XIt Infrared Absorbances of $n$-Rexane Etard Hydra-

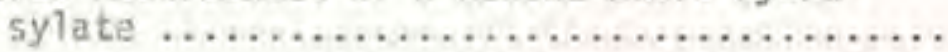

XIII Vibrational Frequencies of Chromy1 FluorideChlorofluaroolefin Reaction Products .......

XIY Vibration Frequencies of Selected Chlorine Ions

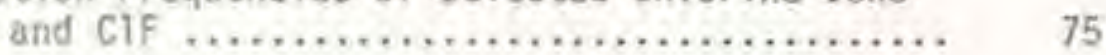

XV Observed Vibrational Frequencies of $\mathrm{CrOF}_{3} \cdot 0.21 \mathrm{ClF} \quad 76$

XyI X-Ray Powder Patterns of $\mathrm{CrOF}_{3}$ Prepared by Two hethods 
XVII X-Ray Powder Patterns of Products Obtained from Themint Decomposition of $\mathrm{CrDF}_{3}$ and Reaction of $\mathrm{CrO}_{3}$ and $\mathrm{ClF}$ at $285^{\circ} \ldots \ldots \ldots \ldots \ldots \ldots \ldots$

XVIII Netal-Oxygen Stretching Frequencies for Solid

Transition Metal Oxide Trihalides ..........

XIX Vibrational Frequencies of $\mathrm{CrOF}_{3}, \mathrm{YOF}_{3}$, and $\mathrm{MOOF}_{3} \quad 85$

XX Electronic Spectrum of the Product of $\mathrm{CrOF}_{3}$ and $\mathrm{SbF}_{5}$ and 0 ther $\mathrm{Cr}(\mathrm{V})$ Compounds $\ldots \ldots \ldots \ldots \ldots$

XXI Vibrational Frequencies of $\mathrm{CrO}_{2} \mathrm{FSb}_{2} \mathrm{~F}_{11}$ and 


\section{CHAPTER I}

\section{EXPERTMENTAL}

\section{Physical Methods}

Infrared Spectra. Infrared spectra reported in this work were recorded on Perkin-E1mer Mode1 467 infrared spectrophotometer over the range 4000 to $250 \mathrm{~cm}^{-1}$. Spectra of gases were obtained using a Monel gas cel1 (AgCl windows) with a path length of $8.25 \mathrm{~cm}$. The cell was equipped with a Whitey brass valve and metal $10 / 30 ;$ joint to adapt to the vacuum system. Solid product spectra were obtained either as mujol mulls or neat between CsBr or KRS-5 plates. A KBr minipress was aiso used for solid spectra. Infrared spectra were calibrated using polystyrene fiTm.

Raman Spectra. Raman spectra reported in this work were recorded on a Jarrel1 Ash 25-300 Raman spectrometer equipped with a Spectra-Physics 250 helium-neon laser for excitation at $5145 \AA$ and $5689 \AA$. The scattered radiation was detected at approximateiy $180^{\circ}$ geometry with a thermoelectrically cooled S-20 photomultiplier tube and photon counting system. Samples were sealed in $4 \pi m$ fused silica tubing.

U1traviolet/Visible spectra. Absorption spectra in the UV/visible region reported in this research were obtained using a Cary Model 14 recording spectrophotometer. The technique of 5. Brown (61) was used in order to obtain spectra of air-sensitive compounds. Cylindrical fused sfTica reaction vessels were used for such samples wfth $1.0 \mathrm{~cm}$ path length cells filled with water used in the reference beam. 
ported in the work were obtained using an XRD-5 Generat Electric Camera. Samples were contained in 0.5 m Lindemann glass capillaries which vere loaded in the dry box. Nickel-filtered copper Ka radiation was used with an exposure time varying between three and five hours.

Magnetic Susceptibility. Values for the magnetic susceptibility of the compounds reported in this work were obtained by the Gouy method. Keasurements were made using an A1pha AL 7500 water-cooled magnet with 4 in. pole faces and 1.5 inch air gap at field strength of $5 \mathrm{KG}$. The $4 \mathrm{~mm}$ OD sample tube was standardized with $\mathrm{CuSO}_{4} \cdot 5 \mathrm{H}_{2} \mathrm{O}$ using mercury(II) tetrathiocyanatocobattate(II) as the calibrant. Diamagnetic corrections were applied using Pascal's constants.

Gas Chromatography. Identification of organic products involved in this work was facilitated through the use of a llewlett-Packard Mode1 57508 gas chromatograph using a flame ionization detector. Solid support used in the six foot by $3 / 8$ inch columns was Chromasorb W with a $10 \%$ QF-1 11quid phase. Nitrogen was used as the carrier gas, Oven temperature was typical1y between 100-180' C.*

Chemical Analysis. Standard analys is of new compounds reported in the work were performed by the Beller Microanalytical Laboratory in Gattingen, West Germany. Analyses of chronyl fluoride were performed by the author by condensing a sample in a fused stlica vessel, hydrolysing the sample with boiled, distilled water, and diluting the solution in a volumetric flask. Hexavalent chromium was deteroined iodometrically, using standardized thiosulfate solution. Acidity was measured by titration with standard base using phenolphthalein indicator and ronorted as moles of actd. One mole of chromy? fluoride hydrolyses to yield four moles of pro-

* Unless otherwise stated, a11 temperatures reportad in this thesis are in degrees Celsius. 
tans in the form of two moles of HF and one mole of $\mathrm{H}_{2} \mathrm{CrO}_{4}$.

Molecular Meight Determinations. Molecular veight determinations of vapors were accomplished by the vapor density method. A calibrated $100 \mathrm{ml}$ Pyrex glass bulb fitted with an Eck and Krebs high vacuimi Teflon stópcock was used as the sample vessel. Molecular weights are reported in $9 /$ mole. Melting Points. Determinaton of melting points was accomplished through the use of a Mel-Temp apparatus equipped with a $400^{\circ}$ thermometer.

\section{Apparatus}

Vacuum Lines. Vacuum lines used in this research consisted of efther a metal or glass manifold evacuated through a 1iquid oftrogencooled trap by a Duo-Seat Model 1400 vacuum pump. Glass Iines were constructed of $22 \mathrm{~mm}$ Pyrex glass tubing and fitted with Eck and Krebs $2 \mathrm{~mm}$ high vacuum stopcocks attached to outer $10 / 30 \mathrm{3}$ ground glass joints. A dual leg mercury manometer constructed of $10 \mathrm{~mm}$ Pyrex glass tubing was also attached to the manifold. Pressure below $1 \mathrm{~mm}$ Hg was estimated by a Televac thermocouple vacuum gauge with a typical working vacuum of 2 to $4 \times 10^{-2}$ torr. The stopcocks vere Tubricated with Apiezon Type M grease while Dow Corning brand silicone grease was generally used on the ground glass joints.

The metal line used for the transfer of chromyl fluoride and chlorine monofluoride was constructed of 6 mn Mone1 tubing silver soldered with Monel connectors. VWR stainless-steal and Autoclave Engineering Space Saver valves were fitted to the line via Swagelock fittings. The surge vessel which comprised most of the 1ine's 1.81 1iters was made of copper. An ficco diaphram type vacuum gauge was used to monitor vacuutit from 1 min to 
$760 \mathrm{~mm}$ while high vacuum was estimated with a Kontes thermocouple vacuum gauge. Typical warking vacuum was 1 to $3 \times 10^{-2}$ torr. Brass $10 / 30 \bar{\xi}$ outer joints allowed attachment of yessels to the line.

The metal line used for the transfer of tungsten and molybdenum hexafluoride was constructed of $6 \mathrm{~mm}$ copper tubing soldered to brass connectors. VWR stainless-steel valves were attached via Swagelock fittings as were the brass outer $10 / 30 \overline{\mathbf{s}}$ joints. Vacuum was monitored through the use of a Televac thermocouple vacuum gauge.

Fluorine Line. Fluorine was dispensed in a 14 inch OD brass line fitted with a Ni helice filled, -78 cooled brass U-trap. WWR valves were connected through the use of a Swagelock fittings as were the brass $10 / 30 \overline{5}$ outer joints. Pressure was monitored on an Acco dial vacuum/ pressure gauge,

Reaction Vessels. Reaction vessels were composed of either Pyrex glass, fused silica, stainless-steel, or Mone1. The Pyrex glass vessels were constructed from a $100 \mathrm{mI}$ round bottom flask to which had been sealed a Kontes high vacuum stopcock fitted with an inner 10/30 $\bar{s}$ ground glass joint. The fused silica vessels were similarly outfitted but the body of the vessel was cylindrical, being constructed of 22,40 , or $54 \mathrm{~mm}$ tubing resulting in a vessel volume of 30,100 , or $250 \mathrm{ml}$, respectively. The body of the vessel was attached to the stopcock through a graded seal. The Pyrex glass and fused silica vessels were equipped with Teflon coated stirring bars.

The two sizes of stainless-5teel vessels were of a 35 mim diameter and had a valume of approximately 100 or $200 \mathrm{ml}$. These vessels were equipped with efther Hoke or VWR valves attached to metal 10/30 $\overline{\mathbf{s}}$ inner joints. The Monel reaction vessel was fitted with an Autoclave Engineering Space 
Saver valve attached to an inner 10/30 5 joint. The metal vessets were passivated by heating with the particular fluorinating agent before reactifons were rum. Frequently nickel metal shot (2 im diameter) was added to the ressels to facilitata cixing of reactants.

Dry Box. Handling of all air-sensitive reagents and products was done in a KSE dry box. Nitrogen used as the atmosphere in the box was dried by passing it through a column packed with phosphorous pentoxide and calcium chloride. Maintenance of a dry ervironment in the box was accomplished with an exposed contafner of phosphorous pentoxide left in the chamber.

Chromyl Fluoride Addition Yessel. The chromyl fluoride addition vessel was constructed of 52 m Pyrex glass tubing and fitted with one Kontes high vacuum stopcock and one Eck and Krebs vacuum stopcock. The volumie of the vessel was approximately $500 \mathrm{ml}$. The vessel, as used, is i11usstrated in Figure 1.

Vacuum Traps. Vacuum traps were constructed of $22 \mathrm{~mm}$ tubing and fitted with a concentric $10 \mathrm{~mm}$ inner tube. Kontes high vacuum stopcocks were fitted and $10 / 30 \mathrm{~s}$ ground glass joints allowed attachsient to the vacuum 1 ine and to other vessels.

\section{Reagents}

Chromium Trioxide. Chromium trioxide (Ma11inkrodt, Reagent Grade) $\mathrm{CrO}_{3}$ was dried for 24 hours in a $110^{2}$ oven and stored in a glass container in the dry box. The compound was transferred to the reaction vessel in the dry box before use,

Chlorine Monofluoride. Chlorine monofluoride (Ozark-Wahoning) - ClF was transferred from the commercial storage cylinder in a metal vacuum line described elsewhere. No purification was attempted. Infrared spectra agree with the literature (42) wi th no extraneous absorbances notud. 
FIGURE I

Chromyl Fluoride Etard Reaction Apparatus

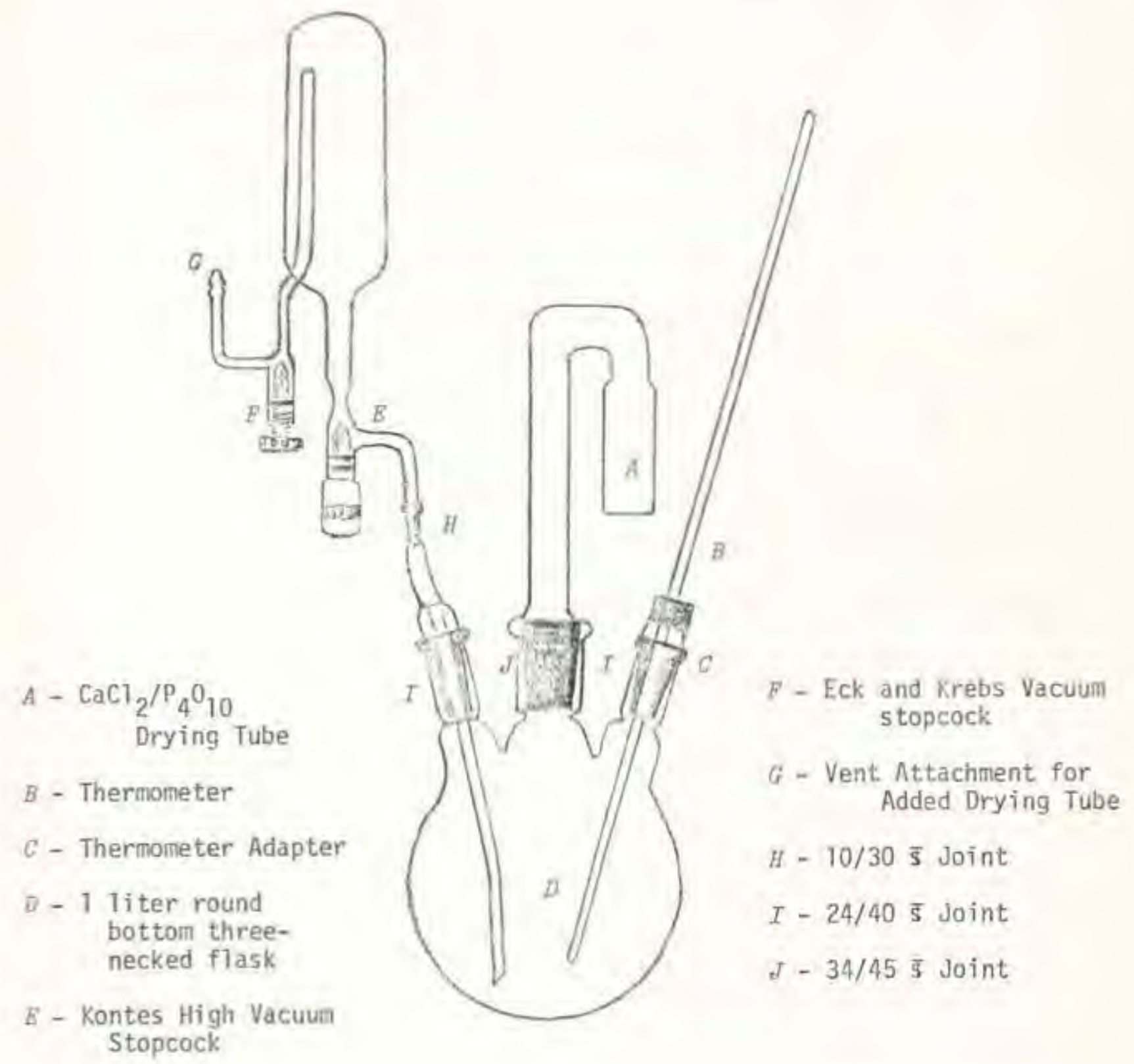


Chromyl Fluoride. $\mathrm{CrO}_{2} \mathrm{~F}_{2}$ used in this research was prepared by the methods described in Chapter 11. Chromy1 fluoride was stored over MaF in a stainless-steet vessel which was attached to a metal vacuur 1 ine described elsewhere. Before use, the $\mathrm{CrO}_{2} \mathrm{~F}_{2}$ was cooled to $-78^{\circ}$ and subjected to a dynamic vacuum to remove any residual HF or other volatile materiols. The compound was then transferred to the reaction vessel via vacuum distillation in the metal vacuum line.

Sodium Fluoride. Sodium fluoride (Mallinkrodt, Reagent Grade) Naf was fused in a nickel crucible and allowed to cool in the dry box where it was transferred to the vessel of interest.

Chromyl Chloride. Chromyl chloride (Alfa-Inorganies) - $\mathrm{CrO}_{2} \mathrm{Cl}_{2}$ was vacuum distilled from a vessel containing metallic mercury (to absorb residua $\mathrm{Cl}_{2}$ ) and condensed at $-195^{\circ}$.

Fluarine. Fluorine (Air Products, 98\%) - $F_{2}$ was passed through a $\mathrm{Ni}$ helice filled, $-78^{\circ}$ cooled trap before condensation at $-196^{\circ}$ on a metal line described elsewhere.

Tungsten Hexafluoride. Tungsten Hexafluoride (Ozark-Mahoning) IIF was ourified by first condensing a sample over NaF and then subjecting it to a dynamic vacuun at $-78^{\circ}$. The purified $W_{6}$ was stored over NaF in a glass container at room temperature before vacuum distillation at $-78^{\circ}$ into a reaction vesse1.

Molybdenum Hexafluoride. Molybdenum hexafluoride - MoF 6 was prepared using the method of Pitts and Jache (20). Povdered molybdenum (UCB, 99.95) was treated with excess C1F and allaved to stand at room temperature for 12 hours. Residual chlorine and C1F were remoyed at $-78^{\circ}$ resulting in pure MoF $_{6}$. The infrared spectrum agreed with the 1 iterature (62). The compound was handled in the same manner as $\mathrm{MF}_{5}$. 
Sulfur Haxafluoride. Sulfur hexafluoride (Matheson, 99.8\%) $-5 F_{6}$ was used as received. The infrared spectrum agreed with the ifterature (63).

Nitryl Fluoride. Nitryl fluorise (Ozark-liahoning) - $\mathrm{NO}_{2} F$ was vacuum distilled onto NaF contained in a metal vessel and then transferred at $-78^{\circ}$ to the reaction vesse1. The infrared spectrum agreed with the 1iterature $(54)$.

Witrosyl Fluoride. Nitrosyl fiuoride (PCR) - NOF was purified in a manner sfinilar to $\mathrm{NO}_{2} \mathrm{~F}$; however, due to the fact that it was very impure, $\left(\mathrm{NO}_{2}\right.$ and HF were the najor impurities) only repeated $-78^{\circ}$ distillations over NaF resulted in a pure starting material. The infrared spectrum agreed with the literature (64).

Carbony1 Fluoride. Carbonyl fluoride (PCR) - $\mathrm{COF}_{2}$ was condensed over NaF at $-196^{\circ}$ and then vacuum distilled into the reaction vessel. The infrared spectrum agreed with the literature (63).

Antimany Pentafluoride. Antinony pentafluoride (PCR) - SbF 5 was purified by condensing over NaF and subjecting it to a dvnamic vacuum at $0^{\circ}$. Every effort was made to completely degas the compound before vacuum distillation into the reaction vessel.

Freon-113. Freon-113 (Matheson) - 1,2,2 trichloro-1,1,2-trifluoroethane was dried over $\mathrm{P}_{4} \mathrm{O}_{10}$ and vacuum distilled.

Tetrachloroethylene. Tetrachloroethylene (B \& A, Reagent Grade) $\mathrm{Cl}_{2} \mathrm{C}: \mathrm{CCl}_{2}$ was dried over $\mathrm{P}_{4} \mathrm{O}_{10}$ and vacuum distilled.

1,1-Difluoroethylene. 1,1-Difluoroethylene (PCR) - $\mathrm{F}_{2} \mathrm{C}: \mathrm{CH}_{2}$ was used as received. The infrared spectrum agreed with the literature (53). Trifluoroethylene. Trifluoroethylene (PCR) - $\mathrm{F}_{2} \mathrm{C}$ :CHF vas used as received. The infrared spectrum agreed with the literature (63). 
Molecular Sieves. Molecular sieves (Linde Type 4A, MCB) - were used as received for final drying of organic solvents.

A11 other common reagents used were of the highest purity available. 


\section{CHAPTER I I}

MEU PREPARATIOIS OF CHROMYL FLUORIDE

Introduction

Chromium dioxide difluoride (chromyl fluoride) was first reported 148 years ago when German chemists noted the red vapors of what was found to be a chromium fluoride above a hot solution of fluorspar, chromates, and sulfuric acid (1). The positive identity of the compound was not known for some time although it was thought to be chronium hexafluoride (2). Fredenbagen (3) isolated a red-brown, easily condensable gas from the reaction between anhydrous HF and alkali chromates and speculated that it might be $\mathrm{CrO}_{2} \mathrm{~F}_{2}$ but he did not attempt to isolate the compound. In $1941, v$. Wartenberg (4) synthesized impure $\mathrm{CrO}_{2} \mathrm{~F}_{2}$ by treating chromyl chloride with elemental fluorine and reported it to be a strong fluorinating agent, a conclusion which is incorrect due to the fact that v. Wartenberg's chromyi fluoride was contaminated with free $\mathrm{F}_{2}$ (reaction with water yielded ozone). Engetbrecht and Grosse (5) were the first to prepare pure chronyl fluoride, using anhydrous $\mathrm{HF}$ and $\mathrm{CrO}_{3}$, and collected physical chemical data which are listed in Table I.

The recent 1iterature contains numerous methods of preparing chromy1 fluoride. These techniques most always involve the use of moderate to strong fluorinating agents and either chromium trioxide or chronyl chioride. $A$ 1ist of these preparations is found in Table II. Many of these methods suffer from problents in purifications of the product, in unwanted side reactions, or in requiring the use of elemental fluorine. 


\section{TABLE I}

\section{PINSICRL PROPERTIES OF CHPOMYL FLUORIJE}

$\begin{array}{lc}\text { Meiting Point } & 31.6^{\circ} \\ \text { Quasi Boiling Point } & 29.6 \% \\ \Delta H_{\text {fus }} \text { (kcal/mol) } & 5.6 \\ \lambda H_{\text {sub }} \text { (kcal/mol) } & 13.8 \\ \Delta H_{\text {vap }} \text { (kcal/mol) } & 8.2\end{array}$
*Temperature at which vapor pressure equats $760 \mathrm{~mm}$.

TABLE 11

PREVIOUSLY REPORTED PREPARATIOHS OF CHROMYL FLUORIDE

\begin{tabular}{|c|c|c|}
\hline $\mathrm{II}-\mathrm{A}$ & $\mathrm{CrO}_{3}+2 \mathrm{HF} \longrightarrow 25^{\circ} \longrightarrow$ & $\mathrm{CrO}_{2} \mathrm{~F}_{2}+\mathrm{H}_{2} \mathrm{O}$ \\
\hline $1 \mathrm{I}-\mathrm{B}$ & $\mathrm{CrO}_{2} \mathrm{Cl}_{2}+\mathrm{F}_{2} \longrightarrow$ & $\mathrm{CrO}_{2} \mathrm{~F}_{2}+\mathrm{Cl}_{2}$ \\
\hline $11-\tau$ & $\mathrm{CrO}_{3}+\mathrm{F}_{2} \longrightarrow$ & $\mathrm{CrO}_{2} \mathrm{~F}_{2}+y_{2} \mathrm{O}_{2}$ \\
\hline $\mathrm{II}-\mathrm{D}$ & $\mathrm{CrO}_{3}+\mathrm{SF}_{4} \longrightarrow 5^{\circ} \longrightarrow$ & $\mathrm{CrO}_{2} \mathrm{~F}_{2}+\mathrm{SOF}_{2}\left(+\mathrm{SO}_{2}\right)$ \\
\hline II -E & $\mathrm{CrO}_{3}+2 \mathrm{COF}_{3} \stackrel{200-3010^{\circ}}{\longrightarrow}$ & $\mathrm{CrO}_{2} \mathrm{~F}_{2}+2 \mathrm{CoF}_{2}+\mathrm{H}_{2} \mathrm{O}_{2}$ \\
\hline IIIF & $\mathrm{CrO}_{3}+\mathrm{IF}_{5} \longrightarrow$ & $\mathrm{CrO}_{2} \mathrm{~F}_{2}+10 \mathrm{~F}_{3}$ \\
\hline
\end{tabular}


Prior to the new methods of $\mathrm{CrO}_{2} \mathrm{~F}_{2}$ synthesis described in the following paragraphs, this 1aboratory used the method of Flesch and Svec (8), involving the reaction of cobalt trifluoride and chromium trioxide at temperetures up to $320^{\circ}$; to prepare chromyl ffuorite. This technique is useful for making sma11 quantities (less than five grams) but it is not practical for preparation of large quantities of $\mathrm{CrO}_{2} \mathrm{~F}_{2}$. In the metal flow system that is used, chromyl fluoride can easily solidify to block the flow, causing serious problems in keeping the moisture-sensitive product pure. The blockage is most 1 ikely to occur from $200-300^{\circ}$, once the chromium trioxide melts and the reaction is most vigorous.

Due to the fact that relatively large quantities of $\mathrm{CrO}_{2} \mathrm{~F}_{2}$ were needed for the study of its reaction chemistry, new preparative routes to chromyl fluoride were sought. A total of five new synthesis methods were found; amiong them are the most convenient and least expensive preparations thus far reported. These are listed in Table III.

TABLE III

NEM PREPARATIONS OF CHROMYL FLUORIDE

$$
\begin{aligned}
& \text { III-A } 2 \mathrm{CIF}+\mathrm{CrO}_{2} \mathrm{Cl}_{2}-78^{\circ} \longrightarrow \mathrm{CrO}_{2} \mathrm{~F}_{2}+\mathrm{Cl}_{2} \\
& \text { III-B } 2 \mathrm{CIF}+\mathrm{CrO}_{3} \longrightarrow \mathrm{O}^{\circ} \longrightarrow \mathrm{CrO}_{2} \mathrm{~F}_{2}+\mathrm{I}_{2} \mathrm{O}_{2}+\mathrm{Cl}_{2} \\
& \text { III-C } \mathrm{MF}_{6}+\mathrm{CrO}_{3} \longrightarrow \mathrm{I25}_{2} \longrightarrow \mathrm{CrO}_{2} \mathrm{~F}_{2}+\mathrm{WOF}_{4} \\
& \text { III-D } \mathrm{MaF}_{6}+\mathrm{CrO}_{3} \longrightarrow \mathrm{IrO}_{2} \mathrm{~F}_{2}+\mathrm{MOOF}_{4} \\
& \text { III-E } \mathrm{COF}_{2}+\mathrm{CrO}_{3} \longrightarrow \mathrm{Cr}^{\circ} \longrightarrow \mathrm{CrO}_{2} \mathrm{~F}_{2}+\mathrm{CO}_{2}
\end{aligned}
$$

Reaction Chemistry of Fluorinating Agents Used in the Preparation of Chronyl Fluoride

As a fluorinating agent, chlorine monofluoride has been assigned to be relatively less reactive than $\mathrm{F}_{2}, \mathrm{CIF}_{3}, \mathrm{BrF}_{5}$, and $\mathrm{IF}_{7}(10,11)$; 
however, CIF has found moderate use in preparative inorganic chemistry. It has been shown to react with perfluorinated ketones and alcohols to form perfluorinated hypochiorites (12):

$11-1$

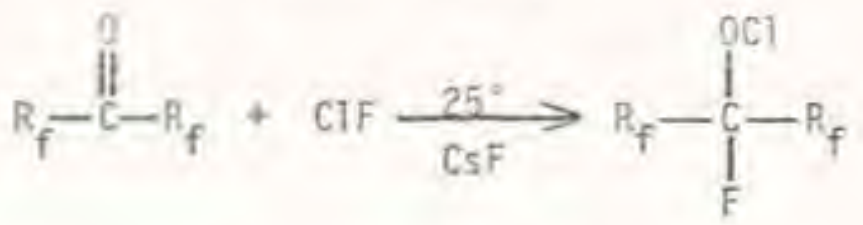

$1 \mathrm{I}-2$

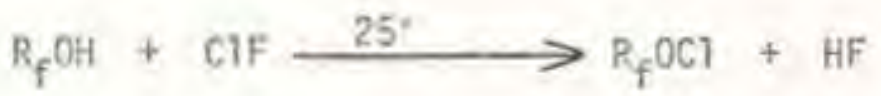

$R_{f}=$ perfluorinated alkyl group

Sulfur trioxide reacts with CIF to form chlorine fluorosulfate (13):

$\mathrm{II}-3 \quad \mathrm{SO}_{3}+\mathrm{ClF} \longrightarrow \mathrm{ClSO}_{3} \mathrm{~F}$

Chloryl fluoride can be prepared from oxygen and CIF (14):

$\mathrm{II}-4 \mathrm{O} \mathrm{O}_{2}+\mathrm{CIF} \longrightarrow \mathrm{IBO}^{\circ} \longrightarrow \mathrm{ClO}_{2} \mathrm{~F}$

In studying the complex reaction of excess $\mathrm{ClF}_{3}$ and $\mathrm{UO}_{2} \mathrm{~F}_{2}$, three groups $(15,16,17)$ concur that the overall reaction is:

II-5 $4 \mathrm{ClF}_{3}+3 \mathrm{UO}_{2} \mathrm{~F}_{2} \stackrel{77-165^{\circ}}{\longrightarrow} 3 \mathrm{O}_{2}+2 \mathrm{Cl}_{2}+3 \mathrm{UF}_{6}$

However, in side reactions where chlorine monofluoride is produced such as in equation II-5, CIF can also act as a fluorinating agent as shown in equation II-7.

$\mathrm{II}-6 \quad 2 \mathrm{ClF}_{3}+\mathrm{UO}_{2} \mathrm{~F}_{2} \longrightarrow \mathrm{ClO}_{2} \mathrm{~F}+\mathrm{ClF}^{2} \mathrm{UF}_{6}$

$\mathrm{II}-7 \quad 4 \mathrm{CIF}+\mathrm{UO}_{2} \mathrm{~F}_{2} \longrightarrow \mathrm{O}_{2}+2 \mathrm{Cl}_{2}+\mathrm{UF}_{6}$

Shrewsberry and Williamson (16) also studied the reaction of C1F and $\mathrm{UO}_{2} \mathrm{~F}_{2}$ and found it to be slower than the corresponding reaction of $\mathrm{ClF}_{3}$. It was discovered that chloryl fluoride was also a product of the reaction of both $\mathrm{ClF}$ and $\mathrm{ClF}_{3}$ with $\mathrm{UO}_{2} \mathrm{~F}_{2}$. This lessened the anount of oxygen and chlorine obtained as well as reducing the effectiveness of the fluorinating agent since a fluorine appears in something other than the intended product. 
It was assumed that equation II-8 described the reaction producing $\mathrm{C1O}_{2} \mathrm{~F}$ from chlorine monofluoride and uranyl fluoride and that the actual situation was a combination of equations II-7 and II-8 since $\mathrm{Cl}_{2}, \mathrm{O}_{2}, \mathrm{ClO}_{2} \mathrm{~F}$, II-8 $5 \mathrm{CIF}+\mathrm{HO}_{2} \mathrm{~F}_{2} \longrightarrow 2 \mathrm{Cl}_{2}+\mathrm{ClO}_{2} \mathrm{~F}+\mathrm{UF}_{6}$ and $U F_{6}$ were all found to be products of the reaction. The oxygen and chlorine were proposed to have come from the thermal decomposition of chloryl fluoride (18) which is described by the reverse of equation II- 4 . It appears that there is a high temperature equilibrium between oxygen, chlorine monofluoride, and chloryl fluoride. E11is and Forrest (15) also found $\mathrm{ClO}_{2}$ and $\mathrm{CT}_{2} \mathrm{O}$ as products of the reaction but these were attributed to wet apparatus by Luce and Hartmanshenn (17). It has since been shown that chloryl fluoride will react with $U F_{4}$ and $U F_{5}$ to form $\mathrm{ClO}_{2}$ and $U F_{6}(19)$ which would account for the presence of the chlorine dioxide.

Pitts and Jache (20) studied the reactions of CIF with some Group VI elements and compounds. The important reactions are listed in equations II -9 through II-14.

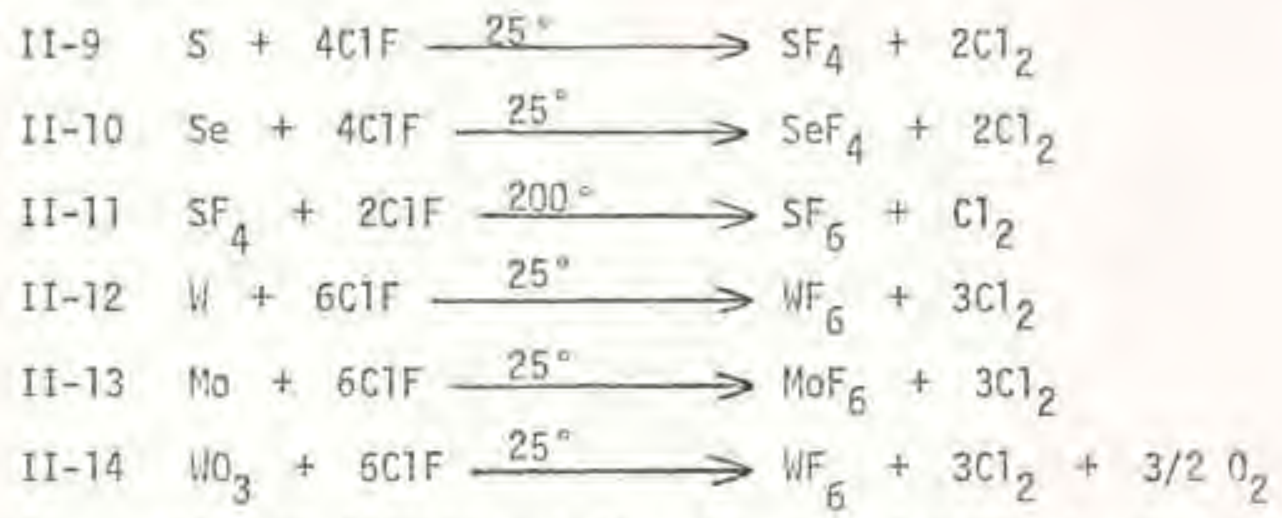
In reaction II-14, chloryl fluoride was also found among the volatile products of the reaction although no attempt was made to quantify the anount or to explain the mechanism of its origin.

The ahove mentioned work has recentiy been complimented with more study of the reactions between Group VIa compounds and chiorine monofluor- 
fde (21). It was found that suifur and selenium tetrachloride react with CIF at room temperature to form chlorine and $\mathrm{SF}_{4}$ and $\mathrm{SeF}_{4}$, respectively. Selenium dioxide, when treated with chlorine monofluoride, gave toxygen, chlorine, chlorine dioxide, and chloryl fluoride as well as $\mathrm{SeOF}_{2}$. Excess CIF produced $\mathrm{SeF}_{4}$ from $\mathrm{SeO}_{2}$ while $\mathrm{SeF}_{6}$ and $\mathrm{SeF}_{5} \mathrm{Cl}$ were formed from $\mathrm{SeOF}_{2}$ with similar side products. Analagous reactions have been observed for tellurium compounds (22).

It has been shown that $\mathrm{BrF}_{5}, \mathrm{BrF}_{3}$, and $\mathrm{ClF}_{3}$ react with chromium trioxide at or below room temperature to give chromium (V) oxyfluoride adducts of the fluorinating agents with the production of only a small amount of chromyl fluoride $(23,24,25)$. These reactions will be discussed in Chapter IV of this thesis.

The reaction chemistry of the hexafluorides of tungsten and molybdenum has not been widely studied. O'Donnell and Stewart (26) have investigated the relative reactivity of $\mathrm{MOF}_{6}$ and $\mathrm{WF}_{6}$ as outlined in Table IV.

TABLE IV

REACTIONS OF MOLYBDENUM AND TUNGSTEN HEXAFLUORIDES

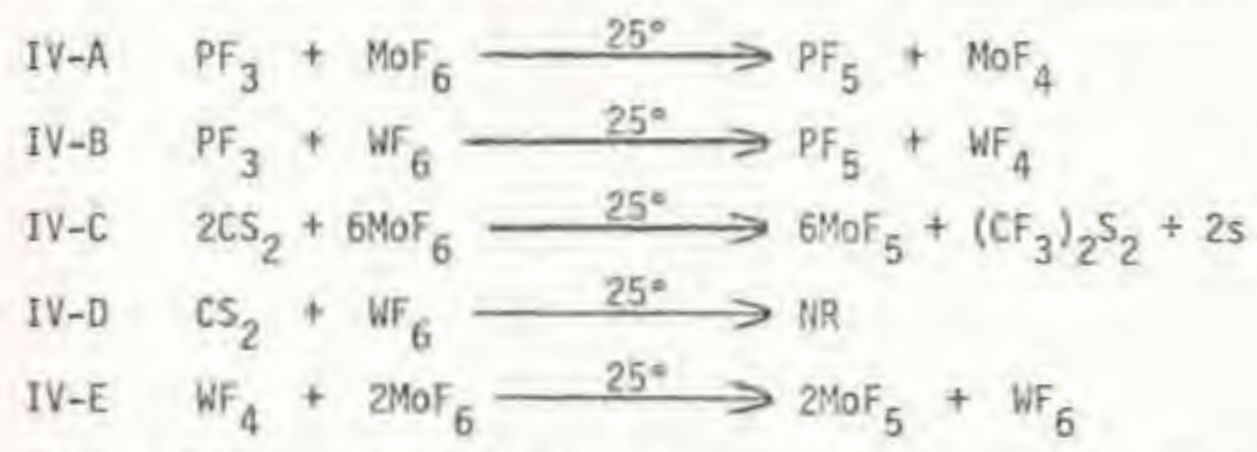

$\mathrm{MoF}_{6}$ and $\mathrm{WF}_{6}$ was found not to react with $\mathrm{AsF}_{3}, \mathrm{BiF}_{3}$, or $\mathrm{SbF}_{3}$. Molybdenum hexafluoride was found to be much more reactive than $\mathrm{WF}_{6}$ in halogen-exchange involving $\mathrm{PCl}_{3}, \mathrm{AsCl}_{3}, \mathrm{SbCl}_{3}$, and others to produce fluorinated substrates and $\mathrm{Mo}_{2} \mathrm{Cl}_{3} \mathrm{~F}_{6}$. No examples of oxygen-halogen exchange reactions involving $\mathrm{WF}_{6}$ nor $\mathrm{MaF}_{6}$ could be found in the literature. 
Fawcett has found carbonyl fluoride to be a novel fluorinating agent. The reaction of $\mathrm{COF}_{2}$ With $\mathrm{I}_{2} \mathrm{O}_{5}$ proceeds at $200^{\circ}$ to produce $\mathrm{IF}_{5}(27)$ :

II-15 $5 \mathrm{COF}_{2}+\mathrm{I}_{2} \mathrm{O}_{5} \longrightarrow 200^{\prime \prime} \longrightarrow 2 \mathrm{IF}_{5}+5 \mathrm{CO}_{2}$

Stannic fluoride can be prepared from $\operatorname{tin}(\mathrm{IV})$ oxide (28):

$\mathrm{II}-16 \mathrm{SnO}_{2}+2 \mathrm{COF}_{2} \longrightarrow \mathrm{SnF}_{4}+2 \mathrm{CO}_{2}$

Carbonyl fluoride, in the presence of a nitrogenous base, will fluorinate carbonyl groups, producing gem-difluorides, similar in reactivity to sulfur tetrafluoride (29). In the absence of base, fluorinated fluoroformates are produced. Similar transformations of carbonyl groups to produce chlorinated products have been reported using phosgene (30).

Chromyl chloride can be produced as a result of the reaction of hexavalent chromium with acid chlorides:

$\mathrm{II}-17 \mathrm{CrO}_{3}+(\mathrm{COCl})_{2} \stackrel{\text { reflux }}{\longrightarrow} \mathrm{CrO}_{2} \mathrm{Cl}_{2}+\mathrm{CO}_{2}+\mathrm{CO}$ (3I)

$\mathrm{II}-18 \mathrm{~K}_{2} \mathrm{CrO}_{4}+2 \mathrm{CH}_{3} \mathrm{COCl} \stackrel{25}{\longrightarrow} \mathrm{CrO}_{2} \mathrm{Cl}_{2}+2 \mathrm{CH}_{3} \mathrm{CO}_{2} \mathrm{~K}$

Sulfur hexafluoride has customarily been thought of as being relatively chemically inert; however, it has been shown that $\mathrm{SF}_{6}$ is an active fluorinating agent at elevated temperatures. Opalovsky and Lobkov (33) studied the interaction of $\mathrm{SF}_{5}$ with metals and metal oxides. From 500$600^{\circ}$ it was found that metals, such as the alkaline earths and rare earths, reacted with $\mathrm{SF}_{6}$ to form fluorides and sulphides. The oxides of the same metals formed fluorides with $S F_{6}$ at $600-700^{\circ}$. Sulfur trioxide reacts with $\mathrm{SF}_{6}$ at $250^{\circ}$ to form sulfuryi fluoride in 205 yield (34):

II-19 $\mathrm{SF}_{6}+2 \mathrm{SO}_{3} \stackrel{250^{\circ}}{\longrightarrow} 2 \mathrm{SO}_{2} \mathrm{~F}_{2}$

Recently, the thermal decomposition products of $\mathrm{SF}_{6}$ in glass have been worked out (35). It has been reported that between $700-900$, the products 
obtained are a result of reaction with the vessel. The equation proposed was:

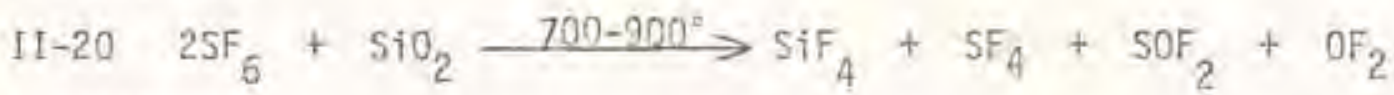
Exgerimental

Reaction of ChTorine Monofluoride and Chromy1 ChToride. To 31 mmoles $\mathrm{CrO}_{2} \mathrm{Cl}_{2}$ contained in a $100 \mathrm{~m}$ i stainless-steel reaction vessel was added 64 mmoles CIF at $-196^{\circ}$. The reaction mixture was warmed to $-78^{\circ}$ and this temperature was maintained for 24 hours after which time the volatile products (at $-78^{\circ}$ ) were removed. These vapors included the excess CIF and $\mathrm{Cl}_{2}$. The vessel was warmed to room temperature, then recooled to $-78^{\prime \prime}$ and re-evacuated. A small amount of $\mathrm{CT}_{2}$ was evident in the trap. The vessel was varmed again to room temperature and the product (31 motes $\mathrm{CrO}_{2} \mathrm{~F}_{2}$ ) was transferred to a storage vessel. The infrared spectrum of the product showed only $\mathrm{CrO}_{2} \mathrm{~F}_{2}(4 \mathrm{~T})$. Analysis: $\left(\mathrm{Cr}^{+6}\right.$; Requires: $42.62 \%$ Found: 42.7\% Acidity; Requires: 12.10 nmoles Found: 12.23 mmoles), Reaction of Chromium Trioxide and Chlorine Monofluoride at $0 . \mathrm{C}$. Dried $\mathrm{CrO}_{3}$ (45 mmoles) was added to a $100 \mathrm{ml}$ stainiess-steel reaction vessel in the dry box followed by the addition of 94 mmotes Cif at $-196^{\circ}$ via vacuum distillation. The reaction was then placed in $0^{\circ}$ bath for approximately 12 hours after which time the vessel was evacuated at $-196^{\circ}$. The only volatile product at this temperature was found to be $\mathrm{O}_{2}$, identified by its nolecular weight (Requires: 32,0 , Found: 32,1 ). At $-78^{\circ}$ the volatile products were $\mathrm{CIF}$ and $\mathrm{ClO}_{2} \mathrm{~F}$, as identified by their characteristic infrared absorhances (See Table $\mathrm{VI}$ ) and $\mathrm{Cl}_{2}$, identified by its molecular Weight (Requires: 71.0 Found: 74,8 , Note: Infrared spectruit of the molecular weight sample showed a small amount of $\mathrm{SiF}_{4}$ to be present) and its approximately $100 \mathrm{Im}$ i iquid vapor pressure at $-78^{2}$. At room temperature the only volatile product was $\mathrm{CrO}_{2} \mathrm{~F}_{2}$, identified by its infrared 
spectrum (41). The yield of $\mathrm{CrO}_{2} \mathrm{~F}_{2}$ was 45 mmoles or $100 \%$ based on $\mathrm{CrO}_{3}$. Anatysis ( $\mathrm{Cr}^{+6}$; Requires: $42.62 \%$ Found: $42.43 \%$, Acidity; Requires: 6. 364 moles Found: 6.304 moles).

Folfowing at proceclure similar to the atove-outhined nethod, 25 minoles of $\mathrm{CrO}_{3}$ and 24 mmoles of $\mathrm{CTF}$ were brought to $\mathrm{O}^{\circ}$ in a stainlesssteel reaction vesse1, Upon evacuation of the vessel at $-195^{\circ}$, oxygen was removed. At $-78^{\circ}$, an infrared spectrum of the volatile products was taken in an al1-metal vacuum line. The spectrum showed no $\mathrm{Cl} F$, only $\mathrm{ClO}_{2}$ (See Table VI). At room temperature the only volatile product was $\mathrm{CrO}_{2} \mathrm{~F}_{2}$ (24 monoles).

Peaction of Carbonyl Fluoride and Chromium Trioxide. To a $100 \mathrm{ml}$ stainless-steel reaction vessel equipped with a Hoke valve was added 9 moles of dried $\mathrm{CrO}_{3}$ in the dry box. Carbonyl fluoride (24 mmoles) previously condensed over NaF, was transferred into the vessel via vacuum distillation and the reaction mixture was heated to $185^{\circ}$ for 12 hours in a tube furrace. Upon cooting the vessel to $-78^{\circ}$ and opening it to an evacuated $-196^{\circ}$ trap, white bands formed irmediately in the 1iquid nitrogen-cooled receiver. The trap contents were shown to be $\mathrm{COF}_{2}$ and $\mathrm{CO}_{2}$ by infrared analysis. The room temperature volatiles consisted solely of $\mathrm{CrO}_{2} \mathrm{~F}_{2}$ as shown by its infrared spectrum (4T). The yield of chromyl fluoride was 100\% based on chromium trioxide. Analysis ( $\mathrm{Cr}^{+6}$; Requires: $42.62 \%$ Found: $42.71 \%$, Acidity; Requires: 4.157 mololes Found: 4.145 moles).

In another preparation, using the above-outined procedure, 12 moles of dried $\mathrm{CrO}_{3}$ and 9 moles of $\mathrm{COF}_{2}$ vere added to a reaction vessel and heated as above. When the vessel was evacuated at $-78^{\circ}$, the only volatile product observed in the infrared spectrum was $\mathrm{CO}_{2}$. A molecular weight: 
determination was performed on the -78 "volatile product: (Pequires 44.0 $\mathrm{g} / \mathrm{in}$, Found $43.9 \mathrm{~g} / \mathrm{m})$. After evacuation at room temperature which removed the product, $\mathrm{CrO}_{2} \mathrm{~F}_{2}$, the vessel was found to contain 3 moles of unreacted $\mathrm{CrO}_{3}$.

Reaction of Tungsten Hexafluoride with Chromium Trioxide. To a $200 \mathrm{ml}$ stainiess-steel vessel equipped with a VWR valve was added 28 moles dried $\mathrm{CrO}_{3}$ in the dry box. The vessel was then evacuated and 23 moles of $\mathrm{WF}_{6}$ was transferred at $-78^{\circ}$ via vacuum distillation. The reaction was heated to $125^{\circ}$ for 12 hours, after which tine the vessel was attached to a vacuuin line and the volatile product investigated. Upon opening the vessel to the vacuum 1 ine at room temperature, the only volatile material remaining in the vessel was found to be $\mathrm{CrO}_{2} \mathrm{~F}_{2}$, as identified by its infrared spectrum (4i) and subsequent analysis: ( $\mathrm{Cr}^{+5}$; Reguires: $42,62 \%$ Found $41.95 \%$, Acidity; Requires: 2.23 mmoles Found: 9.31 mmoles). The yield was $100 \%$ based on $\mathrm{WF}_{6}$.

In another run, 10.55 moles of dried $\mathrm{CrO}_{3}$ was placed in a $30 \mathrm{ml}$ fused silica reactor. The vessel was evacuated and 75.78 minoles of $\mathrm{WF}_{6}$ was transferred via vacuum distillation at $-78^{\circ}$. The reaction mixture was then Warned to $45^{\circ}$ where after one hour red-brown vapors appeared above the Tiquid $W_{6}$. The reaction was allowed to stir overnight. When evacuated the only volatile materials indicated in the infrared spectrum were $\mathrm{CrO}_{2} \mathrm{~F}_{2}$, $\mathrm{WF}_{6}$, and $\mathrm{SiF}_{4}$ leaving behind a grey-white solid. More dried $\mathrm{NF}_{6}$ was added to the vessel and the solution set to stir for two additional hours at $60^{\circ}$. Red-brown yapors became evident inmediately upon heating. The vessel was re-evacuated, leaving an off-white powder. The powder was subtimed and the White crystalline sublimate was found to melt from $102-104^{\circ}$. WOF 4 has a reported melting point of $105^{\circ}(39)$. Andysis: W(Requires: $56.54 \%$ Found: 66.75\%) F(Requires: 27.5\% Found: $27.7 \%$ ). 
Reaction of Molybdenum Hexafluoride and Chromium Trioxide. To 24 mmoles of $\mathrm{CrO}_{3}$ contained in a $200 \mathrm{ml}$ stainless-steel vessel fitted with a VWR valve was added 11 mmoles of $\mathrm{MoF}_{6}$ at $-78^{\circ}$ via vacuum distillation. The reaction vessel was heated to $125^{\circ}$ for 12 hours and then evacuated at room temperature. The only volatile product was found by infrared analysis to be chromyl fluoride (41). The weight loss indicated that the total $\mathrm{CrO}_{2} \mathrm{~F}_{2}$ produced was $1.4 \mathrm{~g}$ ( 11 mornoles). Analysis ( $\mathrm{Cr}^{+6}$; Requires: $42.62 \%$ Found $42.51 \%$, Acídity; Requires: 6.010 mnoles found: 5.915 mmoles). Sublimation of the nonvolatile residue yielded a white solid which had a melting point of $95-97^{\circ}$. The reported melting point of MoOF 4 is $97^{\circ}(40)$. Analysis (Mo; Requires: 40.4\% Found: 40.0\%, F; Requires $51.0 \%$ Found: $51.0 \%$ ). The yield was $100 \%$ based on $\mathrm{MoF}_{6}$.

In another reaction, 23.57 moles of $\mathrm{CrO}_{3}$ was placed in a $30 \mathrm{ml}$ fused silica reaction vessel. The vessel was evacuated and 9.623 moles of MoF 6 was vacuum distilled into the vessel at $-78^{\circ}$. The reaction mixture was allowed to warm to room temperature and reddish-brown vapors were evident immediately upon the melting of the $\mathrm{MoF}_{6}$. The reaction was allowed to stir for two hours at room temperature (22) and the reddish-brown color of the vapors became increasingly intense. The vessel was evacuated at room temperature and chromyl fluoride and silicon tetrafluoride were the only volatile components to be observed in the infrared spectrum.

Reaction of Chromium Trioxide and Sulfur Hexafluoride. To 27 mmoles of $\mathrm{CrO}_{3}$ contained in a $200 \mathrm{ml}$ stainless-steel reaction vessel equipped wi th a VWR valve was added 35 minoles of $\mathrm{SF}_{6}$ at $-196^{\circ}$. The reaction mixture was heated to $185^{\circ}$ for 24 hours after which time the vessel was evacuated at $-78^{\circ}$. The infrared spectrum of the $-78^{\circ}$ volatiles showed only $\mathrm{SF}_{6}$. There 
were no products volatile at room temperature. The reaction vassel was found to contain only unreactad $\mathrm{CrO}_{3}$.

A similar reaction was rut at $330^{\circ}$. No chromy1 fluoride was obtained.

Discussion

Reaction of $\mathrm{CrO}_{2} \mathrm{Cl}_{2}$ and $\mathrm{ClF}$

The reactivity of chlorine monafluoride can be best explained if one assumes the compound to be chlorine(I) fluoride, implying that the chlorine is on the positive end of a very polarized bond, In the reaction of ClF with $\mathrm{CrO}_{2} \mathrm{Cl}_{2}$ there is a simple halogen exchange, forming $\mathrm{CrO}_{2} \mathrm{~F}_{2}$, while the chlorine fragments, chloride and unipositive chlorine form molecular chtorine analagous to the $\mathrm{SeCl}_{4}$ reaction with $\mathrm{ClF}$ already mentioned. The balanced equation is given belor:

$\mathrm{II}-21 \mathrm{CrO}_{2} \mathrm{Cl}_{2}+2 \mathrm{ClF}--78^{\circ} \longrightarrow \mathrm{CrO}_{2} \mathrm{~F}_{2}+2 \mathrm{Cl}_{2}$

Reaction of $\mathrm{CrO}_{3}$ and $\mathrm{CTF}$

In the $\mathrm{CrO}_{3}$ reaction with CIF the situation is not so sinple. It has been shown, as was mentioned eariler, that ClF will add across a double bond to oxygen with the product having fluorine bonded to the central atom and the chlorine attached to oxygen in a hypochlorite structure. Examples of this behavior are the reactions of $\mathrm{SO}_{3}(13)$ and perfluorinated ketones and alcohols (12). In addition, CIF can also fluorinate oxides to form non-chlorine containing products. Examples of this sort of reactivity include the reactions of chlorine monofluoride with selenium dioxide, telurium dioxide, tungsten trioxide, and uranyi fluoride.

In all of the Tatter reactions chioryl fluoride $\left(\mathrm{ClO}_{2} \mathrm{~F}\right)$ has been reported as a product of the reaction. Christe (35) has shown that chlorine dioxide reacts with chlorine monofluoride to gtve chloryl fluorfde and chlorine. 


\section{$\mathrm{II}-22 \quad 2 \mathrm{Cl}_{2} \mathrm{O}+\mathrm{CIF} \stackrel{-78^{\circ}}{\longrightarrow} \mathrm{ClO}_{2} \mathrm{~F}+2 \mathrm{Cl}_{2}$}

This reaction has been assumed by others (21). A reasonable mechanism can be assigned for the reaction of CTF and $\mathrm{CrO}_{3}$ assuming chTorine monoxide to be the original co-product of the reaction. This is presented in Figure 2. The first step in the proposed mechanism involves addition of CIF across a chromium-oxygen double bond to form a hypochlorite intermediate which reacts with a second molecule of chlorine monofluoride to form chlorine monoxide and chromyl fluoride which separates from the $\mathrm{CrO}_{3}$ polymer. $\mathrm{Cl}_{2} \mathrm{O}$ would not survive long enough to be detected in the presence of $\mathrm{ClF}$ and would be converted to $\mathrm{ClO}_{2} \mathrm{~F}$ and $\mathrm{Cl}_{2}$.

Chloryt fluoride may also be formed as a result of the reaction of CIF with glass or with unpassivated metal surfaces $(20)\left(\mathrm{ClO}_{2}\right.$ is also reported as a product). Chlorine monofluoride will react with small amounts of water to produce $\mathrm{ClO}_{2} \mathrm{~F}(36)$. In addition, chToryl fluoride and chlorine are the products of the reaction of $\mathrm{CIF}$ and $\mathrm{ClO}_{2}(36)$. It becomes clear that $\mathrm{ClO}_{2} \mathrm{~F}$ is the most prevalent chlorine oxide to be found in the presence of oxides and excess chlorine monofluoride (or chlorine trifluoride) so that it seems reasonable to assume that $\mathrm{CrO}_{2} \mathrm{~F}$ may not be a direct product of the reactions involving $\mathrm{ClF}$ and oxides. It is assumed that the $\mathrm{ClO}_{2} \mathrm{~F}$ obtained in the reaction of $\mathrm{CrO}_{3}$ and $\mathrm{CTF}$ is not the product of hydrolysis or glass attack since anhydrous conditions were maintained throughout, and in addition, working in an all metal system still allowed the detection of chloryl fluoride.

This above-outlined assertion and the accompanying mechanisin are strengthened by the fact that in a reaction of $\mathrm{CIF}$ and $\mathrm{TeO}_{2}$ where excess tellurium dioxide was used, chloryl fluoride was not observed but rather chlorine dioxide (21). In addition, in this research when excess chromium 


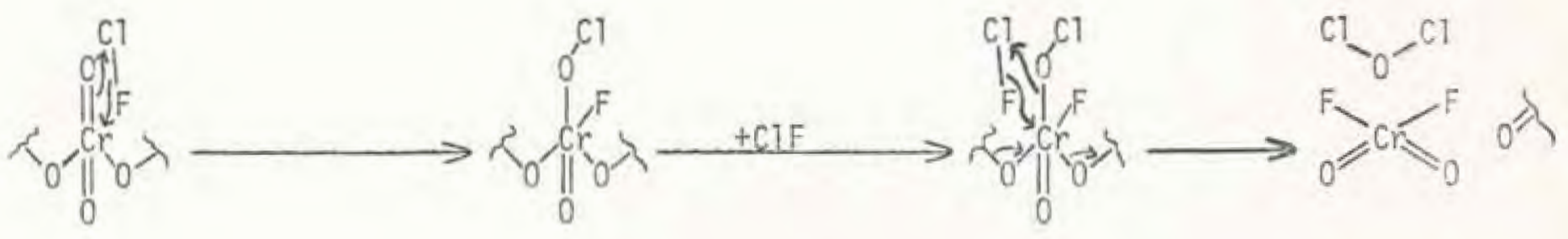

Figure 2. Proposed Mechanism of the Reaction of Chlorine Monofluoride and Chromium Trioxide at $0^{\circ}$ 


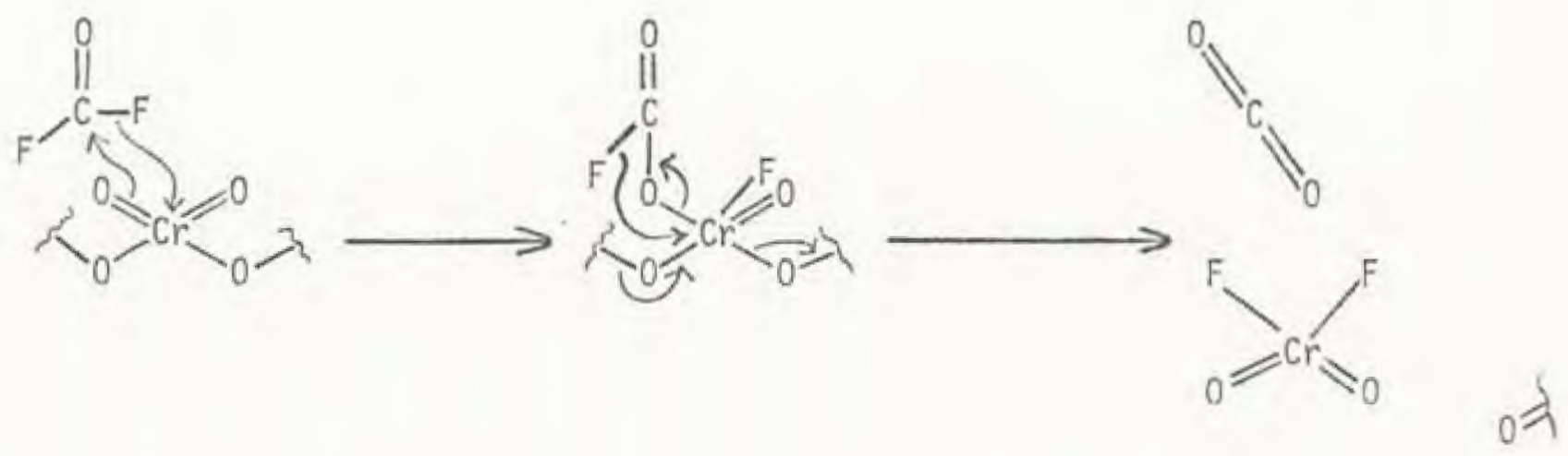

Figure 3. Proposed Mechanism of the Reaction of Chromium Trioxide and Carbonyl Fluoride 
trioxile was treated with chtorine monofluoride at $0^{*}$. only $\mathrm{ClO}_{2}$ was noted as a voletfle product in addition to $\mathrm{CrO}_{2} \mathrm{~F}_{2}, \mathrm{Cl}_{2}$, and $\mathrm{O}_{2}$. It has been reported (19) that chloryl fluoride can act as a fluorinating agent, giving UF 5 or $\mathrm{UF}_{\mathrm{f}}$ and $\mathrm{ClO}_{2}$ from $\mathrm{UF}_{4}$. Chloryl fluoride may also react with chromifum trioxide to give $\mathrm{ClO}_{2}$ and $\mathrm{CrO}_{2} \mathrm{~F}_{2}$ which would account for the presence of chlorine dioxide in the reaction where excess $\mathrm{CrO}_{3}$ was used.

The oxygen found as a product of the reaction can be explained in keeping with the proposed mechanism by taking into account that these chlorine oxides slowly decompose into their constituent elements slightiy above room temperature. A study of the explosive decomposition of chlorine dioxide revealed that the reaction is hastened as the pressure is increased (37). The pressure inside the reaction vessels is on the order of 10 atmospheres which would seen to be enough to at least partially decompose any chlorine dioxide that might form. Additionally, there is the possibility that chloryl fluoride may also undergo a pressure-induced decomposition to oxygen and chlorine monofluoride, analagous to $i$ ts theral decomposition. This, however, is not documented in the literature.

In sumary, the proposed explaration of the observed products are listed in Table V. A balanced overall reaction would be:

$\mathrm{II}-23 \mathrm{CrO}_{3}+2 \mathrm{CIF} \stackrel{\mathrm{O}^{*}}{\longrightarrow} \mathrm{CrO}_{2} \mathrm{~F}_{2}+\mathrm{Cl}_{2}+\mathrm{HO}_{2}$

This preparation is very useful since the product chromyl fluoride can be easily freed of all other products of the reaction by simply subjecting the vessel to a dynamic vacuum at $-78^{\circ}$. As much as fifteen grams of chromyl fluoride has been prepared using this method.

Reaction of $\mathrm{CrO}_{3}$ and $\mathrm{COF}_{2}$

The reaction of carbonyl fluoride and chromium trioxide goes quickiy to complation to form chromyl fluortde and carbon dioxide. As was noted in the introduction. Favicett found that $\mathrm{COF}_{2}$ would add across double bonds 
to carbon as though the compound was $\operatorname{COF}^{+} \mathrm{F}^{-}$, forming a fluorinated fluoroformate with carbonyl groups, for example. Assuming a mechanism similar to the one proposed for $\mathrm{ClF}^{2}$ and $\mathrm{CrO}_{3}$, a reasonable node of reactivity is outlined in Figure 3.

\section{TABLE $V$}

PROPOSED EXPLANATION OF THE REACTION OF CHROMIUY TRIOXIOE AND CHLORINE MONOFLUORIDE AT $0^{\circ} \mathrm{C}$

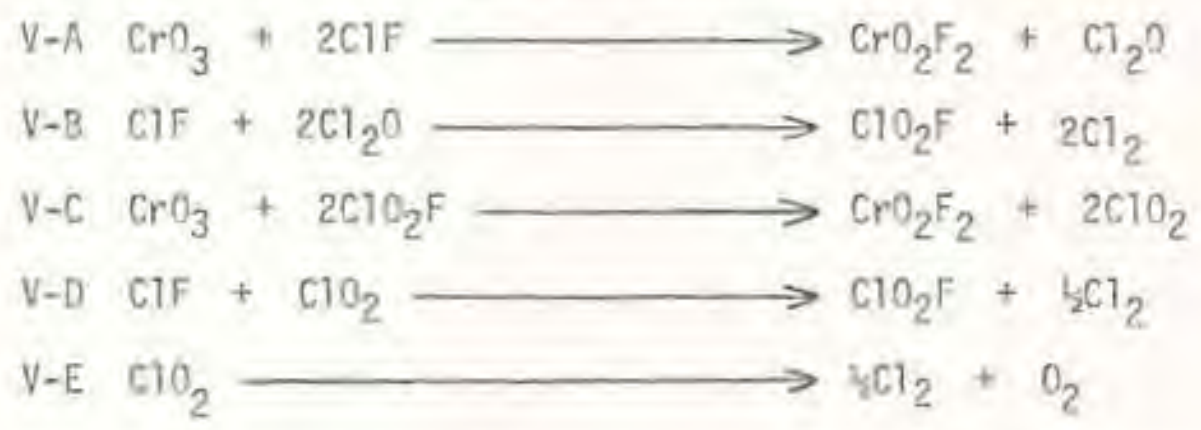

The fluoroformate intermediate would rapidly attack the chromium to form chronyl fluoride and carbon dioxide. This mechanism is analagous to the one proposed for the reaction of $\mathrm{SF}_{4}$ with carbonyl groups (38). This reactivity implies a decided necleopht11c character for the fluorine atoms of $\mathrm{COF}_{2}$ similar to the behavior of the chlorines of phosgene and acid chlorides $(30,31,32)$.

Reaction of $\mathrm{CrO}_{3}$ and $\mathrm{SF}_{6}$, MoF 6 , and $\mathrm{MF}_{6}$

The reaction of molybdenum hexafluoride and tungsten hexafluoride with chromfum trioxide oroceeds at a moderate temperature to form chromy1 fluoride while sulfur hexafluoride does not react even at elevated temperatures, above the decomposition temparature of chromium trioxide. It seems probable that, in light of the previous work on $\mathrm{SF}_{G}$, chronyl fluoride could be formed at perhaos even higher temparatures (up to $450^{\circ}$, the decomposition point of $\left.\mathrm{CrO}_{2} \mathrm{~F}_{2}\right)$ but this sort of synthes is would not be practical nor would it give high yields due to the decomposition of chromium 


\section{TABLE VI}

INFRARED ABSORBANCES (in $\mathrm{cm}^{-1}$ ) OF VOLATILE PRODUCTS

OF THE REACTION OF $\mathrm{CrO}_{3}$ AND CIF AT $0^{\circ}$

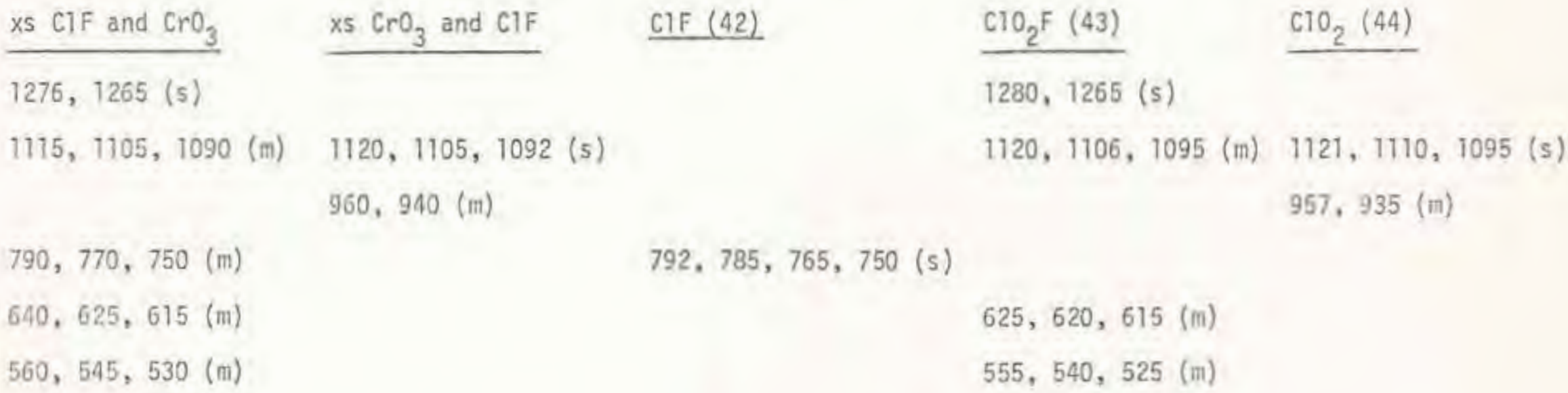


brloxide at far lower temperatures.

The production of chromyl fluoride from the hexafluorides of moiybdonum and tungsten and chronium trioxide provides the simplest and most convenient. route to $\mathrm{CrO}_{2} \mathrm{~F}_{2}$ thus diszovered. The resction will occur anly slawiy at room temperature, but elevated temperatures hasten the process and drive the reaction to completion. An added feature of these reactions Is that the use of a high pressure vessel is not required and small quantities can even be produced in a very dry fused silica vessel. Since the reactants consist of a nonvolatile reagent $\left(\mathrm{CrO}_{3}\right)$ and a volatile fluorinating agent $\left(\mathrm{MoF}_{6}, \mathrm{WF}_{6}\right)$ which form a volatile and nonvolatile product, $\mathrm{CrO}_{2} \mathrm{~F}_{2}$ and $\mathrm{MOOF}_{4}$ or $\mathrm{MOF}_{4}$, respectively; purification is greatiy simplified. In addition, this provides a straightforward synthesis of the oxide tetrafluorides of molybdenum and tungsten, which can be obtained pure via sublimation.

In line with the reported relative reactivities of the two hexafluorides (26), MoF 6 produced chromyl fluoride more readily than did $\mathrm{WF}_{6}$; the former at room temperature while the latter only conveniently when heated to at least $45^{\circ}$. Higher temneratures were used in the bulk synthes is of $\mathrm{CrO}_{2} \mathrm{~F}_{2}$ to insure complete reaction. Conclusion

Chlorine monofluoride, carbonyi fluoride, tungsten hexafluoride, and molybdenum hexafluoride have all been shown to be usefut in the preparation of chromyl fluorlde. These reactions proceed to comoletion with little or no problem in purffication of the product. An interesting factor concerning these reactions is the relative cost involved in the starting materials. The above mentioned methods are the last expensive ways of making $\mathrm{CrO}_{2} \mathrm{~F}_{2}$. perticularly those invalving $\mathrm{WF}_{6}$ and $\mathrm{MoF}_{5}$. 
The reaction of chromyl chloride and chlorine monofluoride is straight forward, but the other preparations are preferred due to the possibility of forming chromyl chlaride fluoride $\left(\mathrm{CrO}_{2} \mathrm{ClF}\right)$ as a conbieiount unless one is certatio excess clf is used.

The mechanisms proposed for the reactions of carbonyt fluoride and chlorine monofluoride with chromium trioxide are based solely on the previously reported reactivity of these reagents as well as attempts to explain the formation of products observed. Unfortunately, there was no way to verify the mechanism through the use of a mass balance of components. Teflon packed gas chromatographs have been used in similar work with chlorine fluoride reaction studies (16) and one would have been usefut here to quantify the product concentrations,

No mechanism was proposed for the reactions of $\mathrm{MF}_{6}$ and $\mathrm{MOF}_{6}$ with $\mathrm{CrO}_{3}$ but it seems 1ikely these involve an oxygen and/or fluorine bridged chromium-tungsten or molybdenuni species as an intermediate. In principle, these might be monitored using the characteristic infrared absorbances of these bridging modes since these absorbances have been relatively well characterized due to the ubiquity of fluorine and oxygen bridging in solid metal oxide fluorides. 


\section{CIIAPTER 111}

\section{SOME REACTION QUEUISTRY DF CHWOHYL FLUORIOE}

\section{Introduction}

Prior to the work done with $\mathrm{CrO}_{2} \mathrm{~F}_{2}$ in this laboratory, rather little was known of its reactivity, with most of the 1 iterature concerned with the more widely known analogue, chromyl chloride. It was reported that chromy? fluoride reacts with arsenic trioxide, forming chromium trioxide and arsenic fluorides as well as producing $\mathrm{BF}_{3}$ from boric oxide and $\mathrm{SiF}_{4}$ from glass (45). Engelbrecht and Grosse (5) found that methane and butane were ignited at elevated temperatures by $\mathrm{CrO}_{2} \mathrm{~F}_{2}$, but $\mathrm{KF}$ and $\mathrm{XaF}$ did not combine with chromyl fluoride at room temperature. Chronyt chloride was found to undergo a halogen exchange with $\mathrm{CrO}_{2} \mathrm{~F}_{2}$ to form $\mathrm{CrO}_{2} \mathrm{ClF}(8)$. These studies represent the total reported work on chromyl fivoride to be found in the modern, pre-1960 1iterature.

More recent studies proved chronyl fluoride to have a greater themal stability than chromyl chloride:

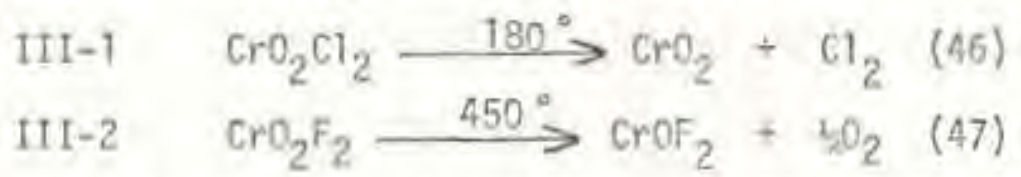

In addition, it is interesting to note that chromyl chloride undergoes photodecomposition readily to chromium dioxide and chiorine (46) while chromyl fluoride polymerizes under UV radiation with loss of oxygen (47).

The molecular structure of $\mathrm{CrO}_{2} \mathrm{~F}_{2}$ has recently been reported as a result of an electron diffraction study (48). It was found that the 
$D=C r=0$ tond angle was less than the $F-C r-F$ angle, which is just the opposite of an analagous compound, $\mathrm{SO}_{2} \mathrm{~F}_{2}$. It was proposed that Tigandligand interactions are more important than electron-pair repulsions in determining the stereochemistry of $\mathrm{CrO}_{2} \mathrm{~F}_{2}$. Results of the study are Tisted in Table VIt

\section{TABLE VIT}

BOHD LENGTHS AND RNGLES OF CHROMYL FLUORIDE

$\begin{array}{ll}\mathrm{Cr}=0 & 1.579 \AA \\ \mathrm{Cr}-\mathrm{F} & 1.739^{\circ} \\ <\mathrm{O}=\mathrm{Cr}=0 & 102.11^{\circ} \\ <\mathrm{F}-\mathrm{Cr}-\mathrm{F} & 118.91^{\circ}\end{array}$

The infrared spectrum of $\mathrm{CrO}_{2} \mathrm{~F}_{2}$ vapor has been recorded and assigned on the basis of $C_{2 v}$ symetry (41). An infrared and Raman study of solid and 1 iquid chromy 1 fluoride published recentiy from this laboratory (49) has shown the compound to be a polymer of cis-fluorine bridged tetrahedra, in accordance with an x-ray study (50).

A recent publication (51) contains nost of what is known of the reaction chemistry of chromyl fluoride. It was found that $\mathrm{CrO}_{2} \mathrm{~F}_{2}$ reacts with the Lewis acids $\mathrm{SO}_{3}, \mathrm{TaF}_{5}, \mathrm{SbF}_{5}$, and $\left(\mathrm{CF}_{3} \mathrm{CO}_{2} \mathrm{O}\right.$ to form the chromy1 compounds, $\mathrm{CrO}_{2}\left(\mathrm{SO}_{3} \mathrm{~F}\right)_{2}, \mathrm{CrO}_{2} \mathrm{~F}\left(\mathrm{TaF}_{6}\right), \mathrm{CrO}_{2} \mathrm{~F}\left(\mathrm{SbF}_{6}\right), \mathrm{CrO}_{2} \mathrm{~F}\left(\mathrm{Sb}_{2} \mathrm{~F} 11\right)$, and $\mathrm{CrO}_{2}\left(\mathrm{CF}_{3} \mathrm{COO}_{2}\right.$, respectively. Nitric oxide, nitrogen dioxide, and sulfur dioxide neact to produce the so-called inorganic Etard complexes, No. $\mathrm{CrO}_{2} \mathrm{~F}_{2}, 2 \mathrm{NO}_{2} \cdot \mathrm{CrO}_{2} \mathrm{~F}_{2}$, and $\mathrm{SO}_{2} \cdot 2 \mathrm{CrO}_{2} \mathrm{~F}_{2}$ which were shown to contain chromium in of ther a tetra- or pentavalent oxidotion state depending on the complex. Of particular interest is the discovery that $\mathrm{CrO}_{2} \mathrm{~F}_{2}$ reacts with alkali and alkalinc earth fluorides to give fluorochromates: 
III-3 2MF $+\mathrm{CrO}_{2} \mathrm{~F}_{2} \rightarrow \mathrm{H}_{2} \mathrm{CrO}_{2} \mathrm{~F}_{4} \quad \mathrm{H}=\mathrm{Na}, \mathrm{K}, \mathrm{CS}$
$111-4$
$\mathrm{MF}_{2}+\mathrm{CrO}_{2} \mathrm{~F}_{2} \rightarrow \mathrm{MCrO}_{2} \mathrm{~F}_{4}$
$\mathrm{M}=\mathrm{Ca}, \mathrm{N}_{9}$

The infrared spectra of the compounds was assigned assuning an octahedral, cis-dioxo configuration about the chromium center. This is the first example of an octahedrally coordinated hexavalent chromium atom. In another study (52) it was shown that chromyl nitrate, $\mathrm{CrO}_{2}\left(\mathrm{NO}_{3}\right)_{2}$ can be prepared from $\mathrm{CrO}_{2} \mathrm{~F}_{2}$ and $\mathrm{NaNO}_{3}$.

The previous work on the reaction chemistry of chronyl fluoride with inorganic reagents has been augmented in this thesis by the preparation of nitronium and nitrosonium trifluorochromate(VI) salts synthesized by the reaction of $\mathrm{NO}_{2} \mathrm{~F}$ and NOF, respectively, with $\mathrm{CrO}_{2} \mathrm{~F}_{2}$. In addition, a $1: 2$ adduct was isolated from the inorganic Etard product, $\mathrm{SO}_{2} \cdot 2 \mathrm{CrO}_{2} \mathrm{~F}_{2}$, and acetonitrile. This product is analagous to those found to form betmeen various solvents acting as Lewis bases and organic chromyl chloride Etard products (53).

The most widely known use of a chromyl compound has been in the oxfdation of organic compounds; a process which has come to be called the Etard reaction. Alexander Leon Etard found in 1877 that a mixture of toluene and chromyl chloride dissolved in an inert solvent such as carbon tetrachloride or carbon disulfide produced an amorphous, hygroscopic, brown material which was insaluble in most cormon solvents. When this solid, the Etard product, was hydrolysed and the solution extracted, benzaldehyde cauld be isoleted. Ftard studied the reaction of chromy? chloride Hith a nimber of other organic conoounds (54) but for the most part, this warle has not been repeated. 
In genera1, the Etard reaction involves, the reaction of chromy1 chioride with an alkane, an alkene, or an alkyl aromatic compound to produce a solid of composition varying between one to three moles of $\mathrm{CrO}_{2} \mathrm{Cl}_{2}$ per mole of hydrocarbon, depending on the particular organic substrate. The insolubility of the Etard product as well as its amorphous nature has haspered work on the elucidation of its structure; however. an ESR study of the $1: 2$ complex of diphenylmethane and chromyl chloride was interpreted as showing the presence of two different kinds of chromium atoms; one diamagnetic (hexavalent) and the other diamagnetic and probabiy quadravalent (57). This work has since been challenged (58). In one of the few other studies done on the complex, Nakhlja and stalrs (53) found that Etard's original complex (1 toluene; 2 chromyl chloride) fomed a 1:2 complex with donor solvents such as acetonitrile, pyridine, dioxane, and others. Their interpretation of magnetic susceptibilities taken of the original complex as well as the adducts suggest that both chromium atoms vere in the tetravalent oxidation state. This work was in agreement with a magnetic susceptibility study done by Wheeler (58) on the same complex. The proposal that both chromium atoms are in the tetravalent oxidation state also is consistent with the structure of the toluene complex originally postulated by Etard:

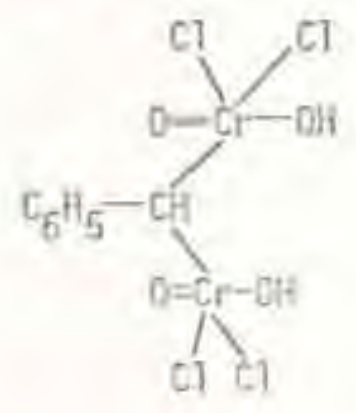


In practice, hydrolysis of the complex is done in the presence of a reducing solution containing sulfur dioxide or sodium sulfite to prevent further oxidation of the organic product. The oxidized product is most generally a ketone or an aldehyde but alcohols are also isolated. Chlorohydrins have also been found as products in the hydrolysis of alKene chromyt chloride complexes. A limited table of onganic substrates and their chromyl chloride oxidation products is found in Table VIII.

TABLE VIII

CHROMYL CHLORIDE OXIDATION PRODUCTS

\begin{tabular}{|c|c|c|}
\hline Reactant & Product & Ref. \\
\hline toluene & benzaldehyde & 54 \\
\hline n-hexane & 2-hexanone, 3-hexanone & 54 \\
\hline 2-methylpentane & 2-methyt-3-pentanone & 55 \\
\hline 1-hexene & $\begin{array}{l}\text { 2-chloro-1-hexanoi ( } 33 \%) \text {, 1-chloro- }- \\
\text { hexanol }(9 \%) \text {, 1-chloro-2-hexanone }(5 \%) \text {, } \\
\text { 2-chlorohexanal ( } 2 \%) \\
\text { (Percentages are of the total organic } \\
\text { materiat isolated.) }\end{array}$ & 56 \\
\hline cyclohexane & cyclohexanone & 55 \\
\hline methylcyclohexane & $\begin{array}{l}\text { 2-methylcyclohexanone, 2-chloro-2- } \\
\text { methylcyclohexanone }\end{array}$ & 55 \\
\hline
\end{tabular}

The reaction is characterized by relatively low yields (Overall yilelds based on amounts of original organic starting material are almost never reported.) and many side reaction products from substrates of lower reactivity. Hobbs and Houston (55) found that alkanes with a tertiary carbon-hydrogen bond reacted much more quickly then did an alYane without this feature. The Etard product obtainad from the tertiary $\mathrm{C}-\mathrm{H}$ containing compounds vere of comoosition $1 \mathrm{HC}: 2 \mathrm{CrO}_{2} \mathrm{Cl}_{2}$, while other alkanes 
complexes were analyzed as intermediate composition between $1: 2$ and $1: 4$, perhaps indicating a mixture af products.

Knunyants (59) has studied the reaction of chromyt chioride with various fluoroolefins and found the resulting products rather surprising. For example, vinytidene fluoride and $\mathrm{CrO}_{2} \mathrm{Cl}_{2}$ yielded monochloroacetic acid while trifluoroethylene reacted with chromyl chloride to give fluorochloroacetic acids. Trifluorochioroethylene also gave a mixture of chlorofluoracetic acids. Perfluoropropylene and isobutylene reacted with chromyl chloride to give the acid fiuorides of o-chloroperfiuoropropionic acid and a-chloroperfluoroisobutyric acid, respectively. In this work, no attenpt was made to isolate or characterize the intermediate product; in fact, in the latter two cases listed above it appears that there was a direct reaction, with no Etard product-1ike intermediate evident. No explanation for the odd reactivity was given.

In another study, chromyl fluoride formed in situ from chronium trioxide and hydrogen fluoride at $-78^{\circ}$ was allowed to react with vinylidene chloride and 1,1-difluoroethylene (70). The result of the reaction after hydrolysis was a hypofluorination of the starting materials, forming dichlorofluoroethanol and trifluoroethanol, respectively. Again no atteript was inade to isolave or characterize the intermediate product. It appears that chramyl chloride reacts via a different mechanism than chromyl fluoride.

In this research, the reaction of chromyl fluoride and hexane, 1.1difluoroethylene, trifluoroethylene, and tetrachloroethylene were studied. 
A11 these organic substrates yield an Etard product and attempts were made to identify structural features from the infrared spectra of the compounds. For the hexane and 1,1-difluoroethylene products, hydrolysis was performed and attempts at isolation of the resulting products were made.

\section{Experimenta1}

Preparation of $\mathrm{NO}_{2} \mathrm{~F}^{*} \mathrm{CrO}_{2} \mathrm{~F}_{2}$. To 9.16 mmoles of $\mathrm{CrO}_{2} \mathrm{~F}_{2}$ in a $250 \mathrm{ml}$ fused silica reaction vessel was added 20.1 imoles of purified $\mathrm{NO}_{2} \mathrm{~F}$ at $-196^{\circ}$. No reaction was evident upon warming to $-78^{\circ}$ nor upon placement of the vessel in a $0^{*}$ bath. The reaction was allowed to stand at 0 " for ten hours at which time there was sti11 no evidence of reaction: however, there were traces of glass attack. The reaction mixture was then placed in a $45^{\circ}$ water bath and after fifteen minutes, a yellow solid formed, The vessel was removed from the water bath after two hours and evacuated at $-78^{\circ}$ into a $-196^{\circ}$ trap. Infrared analysis of the volatile products at this temperature revealed the presence of $\mathrm{SiF}_{4}, \mathrm{NO}_{2}$, and $\mathrm{NO}_{2} \mathrm{~F}$. Upon evacuation at room temperature, no unreacted $\mathrm{CrO}_{2} \mathrm{~F}_{2}$ was found in the reaction vesse1. The weight pickup of $\mathrm{NO}_{2} \mathrm{~F}$ corresponded to 9.14 mmoles, making the apparent composition $1.00 \mathrm{NO}_{2} \mathrm{~F} \cdot 1.00 \mathrm{CrO}_{2} \mathrm{~F}_{2}$. The product is a pale yellow, very hygroscopic solid which darkens rapidly in the presence of moisture and dissolved in water to give an orange-yellow solution. Analysis (Cr; Requires: $27.82 \%$ found: 28.585, N; Requires: $7.49 \%$ Found: 7.22\%, F; Requires: $30.50 \%$ found: $29.5 \%$ ). The compound does not melt but decomposes above $130^{\circ} \mathrm{C}$ in a melting point capillary. giving off $\mathrm{NO}_{2}$. An $\mathrm{x}$-ray powder spectrum revealed to the compound to be amorphous. Infrared data are found in Table IX. Note: all tables are found in the "biscussion" soction. 
Preparation of $\mathrm{NOF} \cdot \mathrm{CrO}_{2} \mathrm{~F}_{2}$

To 12 moles of $\mathrm{CrO}_{2} \mathrm{~F}_{2}$ contained in a $200 \mathrm{mi}$ stainiess steel

reaction vessel was added 26 moles of purified NCF at $-195^{\circ}$ via vacuum distillation. The reaction was allowed to stand at room temperature (23) for approximately 36 hours after which time the volatile components of the mixture were removed. Infrared analysis showed the presence of NOF and a small amount of $\mathrm{NO}_{2}$. No $\mathrm{CrO}_{2} \mathrm{~F}_{2}$ was evident. The weight pickup of NOF corresponded to 12 moles, giving the adduct an apparent composition of 1,0:1.0. The product is a greenish-yellow powder which dissoives in water to give a yellow solution. Analysis ( $\mathrm{Cr}$; Requires: $30.4 \%$ Found; $32.5 \%$, N; Requires: $8.19 \%$ Found: $9.03 \%$, F; Requires: $33.3 \%$ Found: 33.68$)$. The solid doesn't melt but decomposes in a melting point capillary above $100^{\circ} \mathrm{C}$ to give a grey-green solid and $\mathrm{NO}_{2}$. An $\mathrm{x}$-ray powder spectrum showed the compound to be amorphous. Infrared data are found in Table IX.

Reaction of $\mathrm{SO}_{2} \cdot 2 \mathrm{CrO}_{2} \mathrm{~F}_{2}$ and Acetonitrile

To 1.43 moles of freshly prapared $\mathrm{SO}_{2} \cdot 2 \mathrm{CrO}_{2} \mathrm{~F}_{2}$ (51) in a $100 \mathrm{~m}$ ! Pyrex glass reaction vesset was added approximately 0.1 mole $\mathrm{CH}_{3} \mathrm{CH}$ via vacuum distillation from $\mathrm{P}_{4}{ }^{9} 10$. The mixture was allowed to stir for 24 hours without evidence of reaction followed by heating at 600 for 48 hours. During this time the reaction mixture took on a light green color. Upon evacuating the vessel at room temperature, a straw-colored solid precipitated which had a dry weight pickup of acetonitrile corresponding to 2.87 mmoles. Infrared analysis of the volatile groducts from the reaction showed only $\mathrm{CH}_{3} \mathrm{CN}$ and no $\mathrm{SO}_{2}$ or any other would-be deconposition product. Analysis for $5_{2} \cdot 2 \mathrm{CrO}_{2} \mathrm{~F}_{2} \cdot 2 \mathrm{CH}_{3} \mathrm{CN}$ ( $\mathrm{Cr}$; fiequires: 26.65: 
Fourid: 26.9\%, F; Requires: 19.5\% Found: 19.1\%, N; Requires: 7.2\%, Found: $7.08 \%$ C: Requires: $12.3 \%$ Found: $12.38 \mathrm{H}$; Requires: $1.51 \%$ found: $1.55 \%$. An $x$-ray powder spectrum revealed the adduct. to be amorplious. Infrared data are found in Table X. Reaction of $\mathrm{n}$-hexane and Chromyl Fluoride in Fused Silica

To a $200 \mathrm{mil}$ fused silica reaction vessel containing 38.9 mmoles of $n$-hexane and 70.7 mmoles of Freon-113 was added 23.2 moles chromy 1 fluoride at $-196^{\circ}$. The reaction mixture was warmed to $-78^{\circ}$ and kept at that temperature for approximately one hour after which the reaction was allowed to stir at $0^{\circ}$ for 24 hours. A brown solid was formed as soon as the liquids melted. Upon evacuation of the reaction vessel a small amount of unreacted $\mathrm{CrO}_{2} \mathrm{~F}_{2}$ was removed and trapped at $-196^{\circ}$ along with excess $n$-hexane and $F-113$. An infrared spectrum of the volatile materials of the reaction showed nothing other than n-hexane and F-113. The weight of the product corresponded to an n-hexane weight pickup of 4.85 moles making the apparent composition of the complex 4.85 moles n-hexane to 23.2 moles $\mathrm{CrO}_{2} \mathrm{~F}_{2}$ or $1.00: 4.78$. Analysis: $\mathrm{C}_{6} \mathrm{H}_{14}-4 \mathrm{CrO}_{2} \mathrm{~F}_{2}$ Requires: $\mathrm{Cr}: 36.2 \% \mathrm{~F}: 25.5 \%, \mathrm{C}: 12.5 \%, \mathrm{H}: 2.44 \%, \mathrm{C}_{6} \mathrm{H}_{14} \cdot 3 \mathrm{CrO}_{2} \mathrm{~F}_{2}$ Requires; Cr: $34.55, \mathrm{~F}: 25.2 \%, \mathrm{C}: 15.9 \%, \mathrm{H}: 3.09 \%$. Found; $\mathrm{Cr}$ : $35.19 \%, F: 26,4 \%, C: 11.07 \%, H: 2.52 \%$. The product is a hygroscopic very very fine brown powder which dissolves in water to give a yellow-green solution with a characteristic pungent odor. An x-ray powder spectrum sliowed the complex to be amorphous. Infrared data are found in Table XI. Reaction of n-hexane and Chromyl Fluoride in Giass Apparatus

In a typical rum, $9.1 \mathrm{q}$ ( 74 trales) of $\mathrm{CrO}_{2} \mathrm{~F}_{2}$ was transferred to the chromyl fluaride addition vessel (see Figure 2) via vacuun distillafiar at -78 . Imediately thareafter, Freon-113, dried oxer P $\mathrm{A}^{0} 10$. 
Wes drawn into the vessel using the vacuum of the addition vessel. It. was then yented to atmospheric pressure through a calcium chloride/ phosphorous pentoxide drying tube attached to the addition vessei. To a one Titer three-neck flask was added 16.59 (192 moles) of $n$-hexane and $351 \mathrm{~g}$ (1.87 moles) of F-113. The flask was then fitted with a thermometer, a calcium chloride/phosphorous pentoxide drying tube, and a $\$$ adapter for attachment of the addition vessel. When these were in place, the $n$-hexane and F-113 solution was cooled to $0^{\circ}$ with an ice bath. The solution of chromyl fluoride in F-113 was added over the course of approximately one haif hour such that the temperature of the hexanecontaining solution did not rise above $3^{\circ}$. Immediately after the $\mathrm{CrO}_{2} \mathrm{~F}_{2}$ solution came in contact with the hexane, a reddish-brown precipitate formed, During the course of the reaction, significant glass attack was evident on the addition vessel and the three-neck flask. After addition of chronyl fluoride, the reaction mixture was then filtered on a Schlenck-type pressure filtering apparatus equipped with a glass frit. The filter apparatus was then attached to a vacuum trap cooled to $-195^{\circ}$ and evacuated, with the complex being completely freed of any volatile materials. The trajp contents were allalyzed by infrared spectroscopy and gas chromatography with both methods revealing $n$-hexane and $\mathrm{F}-113$ to be the only volatile material from the complex. Similar analysis of the fittrate from the pressure filtering gave the same results. The dried complex $(9.6 \mathrm{~g})$ was then stored in the dry box until a large sample of the complex was prepared for hydrolysis. Analysis: $\mathrm{C}_{6} \mathrm{H}_{19} \cdot 4 \mathrm{Cr}_{2} \mathrm{~F}_{2}$ Pequires: $\mathrm{Cr}: 36.2 \%$, F: $26.5 \%, \mathrm{C}: 12.5 \%$ H: $2.44 \%, \mathrm{C}_{6} \mathrm{H}_{14} \cdot 3 \mathrm{CrO}_{2} \mathrm{~F}_{2}$ Requires; $\mathrm{Cr}: 34.5 \%, \mathrm{~F}: 25.28, \mathrm{C}: 15.9 \%$ 11: $3.09 \%$ Found; Cr: $37.7 \%$, F: $25.5 \%$, C: $9.85 \%$, 11: $2.20 \%$. 
Hydrolysis of the n-hexare Etard Comolex

To a $500 \mathrm{ml}$ Pyrex glass three neck flask equipped with Tefton stir bor litas added $730 \mathrm{~min}$ of a frestily preared saburated solution of $\mathrm{Na}_{2} \mathrm{SO}_{3}$. The solution was acidified to $\mathrm{pH} 2$ with concentrated $\mathrm{H}_{2} \mathrm{SO}_{4}$ and then cooled to $0^{\circ}$ with an ice bath and set to stir. The n-hexane Etard complex (21.6 g), prepared in glass apparatus, was added stow7y to the reducing solution such that the temperature did not rise above $5^{\circ}$. At this point the solution took on an intense, dark green color. Testing a smalt sample of the solution with $\mathrm{H}_{2} \mathrm{O}_{2}$ and extracting with ether yielded a negative test for Cr(VI). Stirring was continued overnight, after which ether was added and the solution vigorously extracted twice. Before the third extraction, NaC1 was added to saturate the solution. The collected ether extracts, totaling $70 \mathrm{ml}$, were pre-dried over $\mathrm{Na}_{2} \mathrm{SO}_{4}$ for one hour, followed by a 12 hour drying period over Linde AA modecular sieves.

The dried ether solution was subjected to fractional distillation on a Kontes adiabatic distilling colum packed with glass helices. The only fraction obtained was from $34.0^{\circ}$ to $35.0^{\circ}$ (ethyt echer) Teaving approximately $7 \mathrm{mi}(4 \mathrm{~g})$ of a yellow-brown liquid in the pot. The solution darkened as ether was removed down to the final 7 nit. A rancid, butterscotch-Tike odor was noted from the liquid in the flask. An infrared spectrum of the Tiquid showed major absorbances listed in Table XII. The sample was transferred to a short path, microdistillation apparatus and heated. Again, the only fraction distiliting over was ether, collected at $34.0^{\circ}$ while the pot residue grey more deeply colored and the presence of a precipitative coating on the inside of the flask became evident. 
lleating was stopped without collecting a non-ether fraction. Gas chromatagraphic analysis of the pat residue showed the presence of pther and at least ten otier compounds. Ether anounted to approximateiy $17 \%$ of the total sample. Among the ten components was found 2-hexanone, and/or 3-hexanone, and n-hexanoic acid as identified by comparison to authentic samples. The infrared spectrum of the hydroTysate is presented in Table XII.

The Reaction of Chromyl Fluoride and 1,1-Difluoroethylene

To a $200 \mathrm{ml}$ fused silica vessel was added 46.22 mmoles of $\mathrm{CrO}_{2} \mathrm{~F}_{2}$, followed by 103 moles F-113 and 38 moles of 1,1-difluoroethylene at $-196^{\circ}$. The reaction mixture was wamed to $-78^{\circ}$ and a chocolate brown solid became evident where $\mathrm{CrO}_{2} \mathrm{~F}_{2}$ had come in contact with the olefin. After about 30 minutes the yessel was transferred to a $0^{*}$ bath whereupon the solvent melted and the reaction went to completion within another 30 minutes of stirring as evidenced by the lack of $\mathrm{CrO}_{2} \mathrm{~F}_{2}$ vapors in the vessel. The vessel was then cooled to $-196^{\circ}$ and evacuated. An infrared spectrum of the volatile product at this temperature showed absorbances characteristic of carbon monoxide. A molecular weight of this gas agreed with the identity assumed from the infrared spectrum (Pequires: $28.0 \mathrm{~g} / \mathrm{m}$ Found; $27.0 \mathrm{~g} / \mathrm{m}$ ). The weight loss showed that the amount of Co was less than 3.6 moles. The vessel was then warned to $-78^{\circ}$ and evacuated into a $-196^{\circ}$ cooled trap. An infrared spectrum of the volatile materials showed $\mathrm{CF}_{2}: \mathrm{CH}_{2}, \mathrm{CO}_{2}, \mathrm{COF}_{2}$, and $\mathrm{F}-113$. The vessel was then evacuated at room temperature into a $-196^{\circ}$ cooled trap unti 1 constant weight was obtained. The raom temperature valatile products were $F-113$ and excess difluoroethylente. No chromyl fluoride was obtained. 
The veight pickup of olefin was 22.39 moles making the product an adduct of composition 1:2.05. Analysis for $\mathrm{CF}_{2}: \mathrm{CH}_{2} \cdot 2 \mathrm{CrO}_{2} \mathrm{~F}_{2}: \mathrm{Cr}$ : Requires: $33.8 \%$ Found: $36.38 \%$; F; Requires: $37.0 \%$ Found: $35.4 \%$, C: Requires: $7.79 \%$ Found: $6.72 \%$, H; Requires: $0.65 \%$ Found: $0.73 \%$.

The product is a brown powder which decomposed at $120^{\circ}$, giving off a colortess gas while the solid turned green. It is moderately hygroscopic; forming a black solid in moist air with a definite fluorocarbon odor above the solid. Hydrolysis in water gives a yellow-green solution. The magnetic susceptibility of the compound was found to be 3.73 Bohr Magnetons.

A tota1 $7.8 \mathrm{~g}$ of the complex was prepared and then hydrolyzed using a procedure and condtitions described for the hydrolysis of the n-hexane-chromyl fluoride Etard Complex. The solution was extracted with ether and dried first over $\mathrm{Na}_{2} \mathrm{SO}_{4}$ then over Linde $4 \mathrm{f}$ molecular sieves. Gas chromatographic analysis of the ether extract revealed the presence of on $7 y$ one compound. The compound in the ether extract was not triftuoroethanol as evidenced by the presence of two peaks resulting from a coinjection of the ether extract and an authentic sample of $\mathrm{CF}_{3} \mathrm{CH}_{2} \mathrm{OH}$.

The Reaction of Chromyl Fluoride and Trifluoroethylene

To 8.977 moles of $\mathrm{CrO}_{2} \mathrm{~F}_{2}(1.0954 \mathrm{~g})$ contained in a $200 \mathrm{~m}$ ) fused silica vessel was added 56.04 mmoles of Freon-113, and 5.899 mmoles of trifluoroethylene $(0.4837 \mathrm{~g})$ at $-196^{\circ}$. The vessel was then placed in a $-78^{\circ}$ bath and reaction was evident aimost immediately, with the formatian of a brown solid. The reaction was kept at -78 for thirty minutes and then transferred to a $0^{\circ}$. bath for overnight. Upan evacuation of the 
vessel at $-196^{\circ}$ there was a non-condensable gas (at -196.) evolved, identified as carbon ponoxide by its infrared spectrum and molecular weight (Requires: 28 Found: 26). The weight loss indicated that the c0 amounted to 1.19 mmoles $(0.0332 \mathrm{~g})$. The vessel was warmed to $-78^{\circ}$ and the volatile materials investigated by infrared anaiysis. Absorbances die to $\mathrm{CO}_{2}, \mathrm{COF}_{2}$, and a trace of $\mathrm{F}-113$ were observed with no evidence for the presence of trifluoroethylene. Upon evacuation at room temperature there was no $\mathrm{CrO}_{2} \mathrm{~F}_{2}$ among the volatile materials. The product weight of the brown non-volatile solid was $1.0497 \mathrm{~g}$, less than the weight of the $\mathrm{CrO}_{2} \mathrm{~F}_{2}$ added.

The reaction was repeated using 16.78 moles of $\mathrm{CrO}_{2} \mathrm{~F}_{2}$ and 37 minoles of trifluoroethylene without a solvent. The reaction mixture Was warmed from $-196^{\circ}$ to $-78^{\circ}$ and kept at that temperature for approximately 24 hours. The vessel was then placed in a $-45^{\circ}$ bath (chlorobenzene slush with dry ice) for approximately eight hours, after which the reaction was allowed to warm slowly to room temperature over the course of 12 hours. After the reaction vessel had warmed to room temperature, it was shaken and no vapors of $\mathrm{CrO}_{2} \mathrm{~F}_{2}$ were visible. However, while being shakan the reaction mixture detonated sharply, completely destroying the vessel. It is advised that future investigators use extreme caution in the further study of these reactions, Darticularly when no solvents are used. The Reaction of Chromy? Fluoride and Tetrachloroethylene

To 25.50 minoles of tetrachloroethylene was added 67.56 moles of Freon-113 and 11.01 moles of chromyl f7uoride $(1.3427 \mathrm{~g})$ at $-196^{\circ}$. The reaction mixture was placed in a $0^{\circ}$ bath where reaction was evident 
immediately upon melting of the olefin, forming a dark brown solid. Red-brown vapors were to be seen in the reaction vessel up to approxinately 20 hours after the addition of the reactants but there had been no glass attack at the graded seal of the vessel over this period. Upon evacuation of the vessel at $-196^{\circ}$, no volatile materials were noted but at $-78^{\circ}$ white and reddish-brown bands were observed in the $-196^{\circ}$ trap. These bands were found to be partial1y due to $\mathrm{F}-113, \mathrm{COCl}_{2}$, and possibiy $\mathrm{COClF}$ as identified by their infrared absorbances. Evacuation at room temperature yielded more F-113 and the deep reddish-brown compound alang with tetrachloroethylene, leaving a Tight brown solid with a weight of $1.2898 \mathrm{~g}$. The solution of $\mathrm{F}-113$, tetrachloroethylene, and the reddishbrown compound was thoroughly degassed and then a sample was extracted with water. To the aqueous extract was added $\mathrm{AgNO}_{3}$ solution which resulted in a white precipitate that dissolved in amonium hydroxide. Analys is for $\mathrm{CCl}_{2}: \mathrm{CCl}_{2} \cdot 2 \mathrm{CrO}_{2} \mathrm{~F}_{2}: \mathrm{Cr}$; Requires: $25.4 \%$ Found: $40.3 \%$, F; Requires: 18.5\% Found: 9.78\%, C; Requires: $5.85 \%$ Found: $1.73 \%$, C1; Requires: $34.6 \%$ Found: $25.4 \%$.

Discussion

$\mathrm{NO}_{2} \mathrm{CrO}_{2} \mathrm{~F}_{3}$ and $\mathrm{NOCrO}_{2} \mathrm{~F}_{3}$

Since chromyl fluoride has been shown to act as a lewis acid in its reaction with Group Ia and Group IIa fluorides to form tetrafluorochromate(VI) salts (5I), it seemed reasonable that formation of nitryl and nitrosonium salts from the strong Lewis bases $\mathrm{NO}_{2} \mathrm{~F}$ and NOF was likely. At $45^{\circ}$ in a fused silica vessel the reaction of $\mathrm{NO}_{2} \mathrm{~F}$ and $\mathrm{CrO}_{2} \mathrm{~F}_{2}$ leads to formation of a very hygroscopic, pale yellow solid which dissolves with vigor in water to give the familiar orange-yellow dichroniate solution. 
Reaction of nitrosyT fluoride and chromy fluoride occurs at room temperature to produce a greenish-yellow powder that behaves 1ike its nitronium analogue with water. The fact that $\mathrm{NO}_{2}$ was found among the volatile products of the reaction of $\mathrm{CrO}_{2} \mathrm{~F}_{2}$ and NOF indicates that there very probably was a side reaction occurring where the nitrosyl fluoride was oxidized by chromy? fluoride. A similar situation was noted in the reaction of $\mathrm{NO}$ with $\mathrm{CrO}_{2} \mathrm{~F}_{2}$ (51). Bath sa1ts decompose at elevated temperatures $\left(\mathrm{NO}_{2} \mathrm{CrO}_{2} \mathrm{~F}_{3}\right.$ at $130, \mathrm{NOCrO}_{2} \mathrm{~F}_{3}$ at 100$)$ to give off $\mathrm{NO}_{2}$. Lack of an X-ray powder pattern indicates both compounds are amorphous.

Dioxotrifluorometalate ions are known and have been well characterized as being isostructural for vanadium, tungsten, and molybdenum. The $\mathrm{VO}_{2} \mathrm{~F}_{3}{ }^{-2}$ ion has been studied in the form of its potassium, rubidium, and cesium salts and shown by $x$-ray studies to be a fluorine-bridged polymer, containing a cis-dioxo configuration coplanar with the bridging fluorines $(65,67)$. Vibrational spectral work on these compounds is in agreement with this structure. Publications on $\mathrm{WO}_{2} \mathrm{~F}_{3}^{-}$and $\mathrm{MoO}_{2} \mathrm{~F}_{3}^{-}$containing compounds report a similar structure, again using $x$-ray analysis and vibrational spectral data $(68,69)$. The structure of the $\mathrm{MO}_{2} \mathrm{~F}_{3}^{-n}$ ion is shown in Figure 5 :

Figure 5 - Structure of the $\mathrm{MO}_{2} \mathrm{~F}_{3}{ }^{-}$ion $(M=V, W, \mathrm{Mo})$

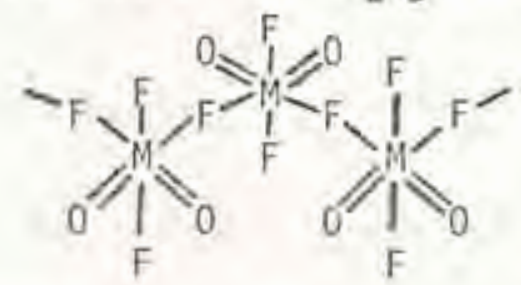

Metat jons containing a sis-dioxo configuration are well known (70) and have been shown to be present in compounds containing the $\mathrm{MO}_{2} \mathrm{~F}_{4}^{-n}$ ion, 
such as $\mathrm{Cs}_{2} \mathrm{CrO}_{2} \mathrm{~F}_{4}(51), \mathrm{Cs}_{2} \mathrm{HoO}_{2} \mathrm{~F}_{4}(68), \mathrm{Cs}_{2} \mathrm{WO}_{2} \mathrm{~F}_{4}(68)$ and $\mathrm{K}_{3} \mathrm{VO}_{2} \mathrm{~F}_{4}(67)$. The infrared viturational frequencies for $\mathrm{NO}_{2} \mathrm{CrO}_{2} \mathrm{~F}_{3}$ and $\mathrm{NOCrO}_{2} \mathrm{~F}_{3}$ are presented in Table IX. Comparison of the band positions of $\mathrm{NO}_{2} \mathrm{CrO}_{2} \mathrm{~F}_{3}$ with thase of $\mathrm{K}_{2} \mathrm{VO}_{2} \mathrm{~F}_{3}$, also in Table IX, shows good agreenent between the two spectra. Griffiths $(70)$ has presented evidence that all known transition metal do dioxo species tend to have cis oxygens. The microsyminetry is $C_{2 V}$ and thus the $0-17-0$ group shoutd display an infrared active symmetric and antisymetric metal oxygen stretch. In addition, the fluorine bridging in the polyrier makes the fluorine atoms nonequivalent so that there is a symmetric and antisymmetric stretch for each pair of similar $\mathrm{Cr}-\mathrm{F}$ bonds. These modes are readity assigned in $\mathrm{NO}_{2} \mathrm{CrO}_{2} \mathrm{~F}_{3}$. The absorisances at 1010 and $979 \mathrm{~cm}^{-1}$ represent the symmetric and antisymetric chromium-oxygen stretch, respectiveiy. The 720 and $510 \mathrm{~cm}^{-1}$ peaks are reasonabiy assigned to antisymetric $\mathrm{Cr}-\mathrm{F}$ stretch while the $635 \mathrm{~cm}^{-1}$ band is given to one symmetric $\mathrm{Cr}-\mathrm{F}$ stretching mode. It is not possible to assign the ather $\mathrm{Cr}-\mathrm{F}$ symmetric stretch definitely because it appears to fal1 in about the same region as that of the bending mode of the $\mathrm{MO}_{2}{ }^{\mathrm{*}}$ ion. This wi17 be discussed in the next paragraph. The shoulder at $490 \mathrm{~cm}^{-1}$ remains unassigned; it is possibly an avertone. The absorbances belo: $350 \mathrm{~cm}^{-1}$ are in the region usually ascribed to metal-oxygen and meta1-fluoride deformations, but definite assigniment of these is tenuous and w/171 not be attempted. The spectrum of $\mathrm{NOCrO}_{2} \mathrm{~F}_{3}$ is much Tess well defined so on $1 y$ the gross features can be interpreted. The band at $1900 \mathrm{~cm}^{-1}$ is unambiguousiy a terminal chromiumoxygen double bond stretch but the fact that it is not split into a dnublet seems to raise toubt atout the cormpound having the same structure 
Table IX - Infrared Vibrationat Frequencies of $\mathrm{NO}_{2} \mathrm{CrO}_{2} \mathrm{~F}_{3}$ and $\mathrm{NOCrO}_{2} \mathrm{~F}_{3}$, in $\mathrm{cm}^{-1}$

\begin{tabular}{|c|c|c|c|}
\hline $\mathrm{NO}_{2} \mathrm{CrO}_{2} \mathrm{~F}_{3}$ & $\mathrm{NOCrO}_{2} \mathrm{~F}_{3}$ & Probable Assignment & $\mathrm{K}_{2} \mathrm{VO}_{2} \mathrm{~F}_{3}(67)$ \\
\hline $3780 \mathrm{w}$ & & $v_{1}+v_{3}\left(\mathrm{NO}_{2}^{+}\right)$ & \\
\hline \multirow[t]{3}{*}{$2389 \pi$} & & $v_{3}\left(\mathrm{NO}_{2}^{+}\right)$ & \\
\hline & $2290 \mathrm{~m}$ & $v\left(\mathrm{NO}^{+}\right)$ & \\
\hline & $1505 \pi$ & & \\
\hline $1380 \mathrm{~m}$ & $1380 \mathrm{~m}$ & $v_{1}\left(\mathrm{NO}_{2}^{+}\right)$ & \\
\hline $1295 \mathrm{~m}$ & $1295 \mathrm{~m}$ & $(720+590=1300)$ & \\
\hline $1010 \mathrm{~s}$ & $1000 s, 6$ & $v_{s}(0=C r=0)$ & 922 \\
\hline $970 \mathrm{~s}$ & & $v_{d}(0=c r=0)$ & 898 \\
\hline \multicolumn{4}{|l|}{$880 w$} \\
\hline $720 \mathrm{~m}$ & $730 \mathrm{~m}$ & $v_{a} C r-F$ & 570 \\
\hline $635 \mathrm{~s}$ & & $\mathrm{v}_{5} \mathrm{Cr}-\mathrm{F}$ & 550 \\
\hline $610 \mathrm{~s}$ & & $v_{a} C r_{r}-F^{\prime}$ & 529 \\
\hline $580 \mathrm{~s}$ & & $v_{5} \mathrm{Cr}-\mathrm{F}^{7}$ & 431 \\
\hline $550 \mathrm{~s}$ & $550 \mathrm{~s}, 6$ & $\mathrm{~N}_{2}\left(\mathrm{MO}_{2}^{+}\right)$ & \\
\hline \multicolumn{4}{|l|}{$590 \mathrm{w}, \mathrm{sh}$} \\
\hline $350 \mathrm{w}$ & & $\mathrm{vCr}-\mathrm{F}-\mathrm{Cr}$ & 345 \\
\hline $370 \mathrm{w}$ & & $\therefore \quad F-C r=0$ & 305 \\
\hline $260 \mathrm{w}$ & $240 \mathrm{~W}$ & $8 \mathrm{~F}-\mathrm{Cr}-\mathrm{F}$ & 223 \\
\hline & & $0=C r=0$ & \\
\hline
\end{tabular}


as shown in Figure 5. However, it coutd simply be that the doublet is not resolved. The bands at 730 and $55 \mathrm{~cm}^{-1}$ are rgasonably assigned to $\mathrm{Cr}-\mathrm{F}$ stretching modes but again there is not the good agreement with previously published spectra that was found in $\mathrm{NO}_{2} \mathrm{CrO}_{2} \mathrm{~F}_{3}$.

Salts containing the nitryl and nitrosonium ions are well known and characterized. The linear $\mathrm{NO}_{2}{ }^{+}$species displays two infrared active bands; the bending node, $v_{2}$, and the antisymetric stretch, $v_{3}$ produce these absorbarces. The symetric stretch, $v_{1}$, is Raman Active. In a typical $\mathrm{NO}_{2}^{+}$salt such as nitryt verchlorate (71), the $v_{1}$ mode was observed at $1396 \mathrm{~cm}^{-1}$ while the $v_{2}$ fundamental is found at $570 \mathrm{~cm}^{-1}$ and $v_{3}$ at $2360 \mathrm{~cm}^{-1}$. For $\mathrm{NO}_{2} \mathrm{CrO}_{2} \mathrm{~F}_{3}$, the $\mathrm{v}_{3}$ mode is located at $2380 \mathrm{~cm}^{-1}$ in the infrared. The $v_{2}$ band falls in the region of chromium-fluorine stretch but is probably represented by either the peak at 580 or $550 \mathrm{~cm}^{-1}$ with the other absorbance being a symetric $\mathrm{Cr}-\mathrm{F}$ stretch. The $\mathrm{D}-\mathrm{N}-\mathrm{O}$ luending víbration was observed at $538 \mathrm{con}^{-1}$ in solid $\mathrm{N}_{2} \mathrm{O}_{3}\left(\mathrm{NO}_{2}{ }^{+} \mathrm{NO}_{3}{ }^{-}\right)$(72). As was mentioned earlier, the $v_{1}$ symetric stretch is Raman active only; however, often it can be estimated by the infrared allowed combination band $v_{1}+v_{3}$ which comonly occurs in nitryl salts. In $\mathrm{NO}_{2} \mathrm{P} t \mathrm{~F}_{6}(73)$, this combination band occurred at $2362 \mathrm{~cm}^{-1}$ which was in good agreement for the sum of $v_{1}$ and $v_{3}$ values. If the peak at $3780 \mathrm{~cm}^{-1}$ for $\mathrm{NO}_{2} \mathrm{CrO}_{2} \mathrm{~F}_{3}$ is taken to be the $v_{1}+v_{3}$ mode, then the difference between 3780 and 2380 , the value for $y_{3}$, gives $1490 \mathrm{~cm}^{-1}$ which is surprisingly coincident with a prominent absorbance in the spectrum. The Paman-active $v_{2}$ mode has been observed at $1400 \mathrm{~cm}^{-1}$ in solid $\mathrm{N}_{2} \mathrm{O}_{5}$ (72) and at $1396 \mathrm{~cm}^{-1}$ in $\mathrm{HO}_{2} \mathrm{ClO}_{4}$ (7T). A possible explanktian for the Raman active mode becoming 
infrared active could be that the normalty 1 inear $\mathrm{NO}_{2}{ }^{+}$ion is bent through sone sort of Tatifice effect. A bent nitryl ion would then be of $\mathrm{C}_{2 v}$ symmetry instead of $\mathrm{D}_{\text {inh }}$ and would display three absorbances, all infrared active. These infrared bands would be coincident with three peaks in the Raman effect but unfortunately, attempts to obtain a Raman spectrum for $\mathrm{NO}_{2} \mathrm{CrO}_{2} \mathrm{~F}_{3}$ failed.

The absorbance at $2290 \mathrm{~cm}^{-1}$ for $\mathrm{NOCrO}_{2} \mathrm{~F}_{3}$ is the NO ${ }^{+}$stretching mode. It has been observed at $2340 \mathrm{~cm}^{-1}$ in NOAsF ${ }_{6}, 2331 \mathrm{~cm}^{-1}$ in NOMoF ${ }_{6}$, and $2377 \mathrm{~cm}^{-1}$ for $\mathrm{NOSO}_{3} \mathrm{~F}(108)$.

In sumary, there is good evidence that $\mathrm{NO}_{2} \mathrm{CrO}_{2} \mathrm{~F}_{3}$ contains a fluorinebridged, cis-dioxo trifluorochromate(VI) ion, similar to the corresponding vanadium, molybdenum, and tungsten anions. It appears that the $\mathrm{NO}_{2}{ }^{+}$ion $\mathrm{NO}_{2} \mathrm{CrO}_{2} \mathrm{~F}_{3}$ may be bent as interpreted from infrared spectral evidence but. this is not conclusive due to the lack of Raman data. The IR spectrum of $\mathrm{NOCrO}_{2} \mathrm{~F}_{3}$ is 117 -defined and 11 ttle information can be obtained from it except to say that the $\mathrm{NO}^{+}$ion is present.

$\mathrm{SO}_{2} \cdot 2 \mathrm{CrO}_{2} \mathrm{~F}_{2} \cdot 2 \mathrm{CH}_{3} \mathrm{CN}$

Makhija and Stairs (53) found that certain solvents such as acetonitrile, dioxane, pyridine, and tetrahydrofuran will react with the Etard complex formed between chromyl chloride and toluene. The composition of the products was found to be $\mathrm{C}_{6} \mathrm{H}_{5} \mathrm{CH}_{3} \cdot 2 \mathrm{CrO}_{2} \mathrm{Cl}_{2} \cdot 2 \mathrm{D}$, where $\mathrm{D}$ represents the organic solvent apparentiy acting as a Lewis base. It was assumed that the donor solvent nolecules were coordinated directly to the tetravalent chromium centers which resulted in the depolymerization of the Etard complex. The previously known inorganic Etard complex $\mathrm{SO}_{2} \cdot 2 \mathrm{CrO}_{2} \mathrm{~F}_{2}$ (51) was found to also react with acetonitrils to give an adduct with composition 
$\mathrm{SO}_{2} \cdot 2 \mathrm{CrO}_{2} \mathrm{~F}_{2} \cdot 2 \mathrm{CH}_{3} \mathrm{CN}$. No compound other than $\mathrm{CH}_{3} \mathrm{CON}$ was found annong the yolatile materials of the reaction. The non-yolatile product, a light green solid, is hysroscopic, but less so than the original comolex, $\mathrm{SO}_{2} \cdot 2 \mathrm{CrO}_{2} \mathrm{~F}_{2}$. A hydrolyzed solution of the adduct does not give a precipitate when $\mathrm{BaCl}_{2}$ solution is added, but will yield an insoluble solid with $\mathrm{Ba}^{++}$after treatment with $\mathrm{H}_{2} \mathrm{O}_{2}$. This provides evidence for the sulfur probably being present in the tetravalent state in the complex. Upon hydrolysis, the sulfur in the complex may well dissolve as the sulfite ion which can be oxidized to sulfate by $\mathrm{H}_{2} \mathrm{O}_{2}$ and thus precipitated as $\mathrm{BaSO}_{4}$.

The infrared spectrum of $\mathrm{SO}_{2} \cdot 2 \mathrm{CrO}_{2} \mathrm{~F}_{2} \cdot 2 \mathrm{CH}_{3} \mathrm{CH}$ is tabutated in Table $x$. Prior spectroscopic work done on compounds containing coordinated acetonitrile are abundant in the literature. Hyhoin and Kepert (74) reported infrared frequencies of acetonitrile coordinated to tantalum and niobium pentachlorides and pentabromides and found a very important band to be the symetric c-il stretch $\left(v_{2}\right)$ since upon coordination this absorbance has been shown to be increased to higher wavenumbers. In Nyholm and Kepert's study, the change in $v_{2}$ upon coordination ranged from 29 to $36 \mathrm{~cm}^{-1}$ which is similar to the $38 \mathrm{~cm}^{-1}$ found in $\Delta v_{2}$ for $\mathrm{SO}_{2} \cdot 2 \mathrm{CrC}_{2} \mathrm{~F}_{2} \cdot 2 \mathrm{CH}_{3} \mathrm{CN}$. Other vibrations of acetonitrfie can be assigned from the spectrum and are Tisted in the table. Since most of these bands for acetonitrile occur in a region of the spectrum that is free of inorganic absorbances, the assignments can be made with confidence. It was proposed in another study (75) that since a certain $\mathrm{Ta}(\mathrm{III})$ compound, $\left[\left(\mathrm{TaCl}_{3}\left(\mathrm{CH}_{3} \mathrm{Ca}\right)_{2}\right)_{2}\right]$, displayed a relatively comolex $1 \mathrm{R}$ spectrum in the region 
Tabie X - Infrared Vibrational Frequencies of $\mathrm{SO}_{2} \cdot 2 \mathrm{CrO}_{2} \mathrm{~F}_{2} \cdot 2 \mathrm{CH}_{3} \mathrm{Cr}$ and Related Molecules, in $\mathrm{cm}^{-1}$

\begin{tabular}{|c|c|c|c|}
\hline $\mathrm{SO}_{2} \cdot 2 \mathrm{CrO}_{2} \mathrm{~F}_{2} \cdot 2 \mathrm{CH}_{3} \mathrm{CN}$ & Probable Assignment & $\mathrm{SO}_{2} \cdot 2 \mathrm{CrO}_{2} \mathrm{~F}_{2}$ (51) & $\mathrm{CH}_{3} \mathrm{CN}(114)$ \\
\hline $2995 \mathrm{WW}$ & $v_{5}$ (deg. C-H stretch) & & $2995 \mathrm{~m}$ \\
\hline $2930 \mathrm{w}$ & $v_{1}$ (sym, $C-H$ stretch) & & $2940 \mathrm{~m}$ \\
\hline $2318 \mathrm{~m}$ & $v_{3}+v_{4}$ & & $2285 \mathrm{~m}$ \\
\hline $2292 \mathrm{~m}$ & $v_{2}$ (sym. CN streteh) & & 22545 \\
\hline $1660 \mathrm{~m}$ & & & \multirow[t]{2}{*}{$1630 w$} \\
\hline $1560 \mathrm{in}$ & & & \\
\hline $1450 \mathrm{w}$ & \multirow[t]{2}{*}{$v_{6}$ (deg. $\mathrm{CH}_{3}$ def.) } & & \multirow[t]{2}{*}{$1440 \mathrm{~m}$} \\
\hline $1410 \mathrm{w}$ & & & \\
\hline $1365 \mathrm{w}$ & \multirow[t]{2}{*}{$v_{3}$ (sym. $\mathrm{CH}_{3}$ def.) } & $1360 \mathrm{~m}$ & \multirow[t]{2}{*}{$1375=$} \\
\hline 1287 m & & $1310 \mathrm{~m}$ & \\
\hline $1130 \mathrm{w}$, sh & $v_{s} 0=s=0$ & $1130 \mathrm{~s}$ & \multirow{2}{*}{$\begin{array}{l}1090 \mathrm{~m} \\
1035 \mathrm{~s}\end{array}$} \\
\hline $1040 \mathrm{~s}, \mathrm{~b}$ & $\begin{array}{l}v_{a} O=s=0 \text { or } \\
\left.v_{7} \text { (deg. } \mathrm{CH}_{3} \text { rock }\right)\end{array}$ & $1050 \mathrm{~s}$ & \\
\hline
\end{tabular}


TABLE X - CONTINUED

\begin{tabular}{|c|c|c|c|}
\hline $\mathrm{SO}_{2} \cdot 2 \mathrm{CrO}_{2} \mathrm{~F}_{2} \cdot 2 \mathrm{CH}_{3} \mathrm{CN}$ & Probable Assignment & $\mathrm{SO}_{2} \cdot 2 \mathrm{CrO}_{2} \mathrm{~F}_{2}$ (51) & $\mathrm{CH}_{3} \mathrm{CN}$ (114) \\
\hline $955 \mathrm{w}, \mathrm{sh}$ & $\begin{array}{l}v \mathrm{Cr}=0 \text { or } \\
v_{4} \text { (sym. C - C stretch) }\end{array}$ & $974 \mathrm{~s}$ & $915 \mathrm{~s}$ \\
\hline $890 \mathrm{w}$ & & $838 \mathrm{~m}$ & \\
\hline $\begin{array}{l}765 w \\
632 w, \text { sh }\end{array}$ & & $765 \mathrm{w}$ & $745 \mathrm{~m}$ \\
\hline $\begin{array}{l}550 \mathrm{~s}, \mathrm{~b} \\
415 \mathrm{w}\end{array}$ & $v \mathrm{Cr}-\mathrm{F}$ & $550 \mathrm{~s}, \mathrm{~b}$ & \\
\hline $360 \mathrm{w}$ & $v \mathrm{Cr}-\mathrm{F}-\mathrm{Cr}$ & $330 \mathrm{w}, \mathrm{b}$ & \\
\hline
\end{tabular}


3000 to $2000 \mathrm{~cm}^{-1}$, it revealed the acetonitrile ligands to be in significantly different environments. If in fact the absorbances of the acutonititie Tigands are as sensitive as was proposed; it can be taken that the $\mathrm{CH}_{3} \mathrm{CN}$ groups in $\mathrm{SO}_{2} \cdot 2 \mathrm{CrO}_{2} \mathrm{~F}_{2} \cdot 2 \mathrm{CH}_{3} \mathrm{CN}$ are identical due to the simplicity of the infrared spectrum. The fact that the acetonitrile absorbances are exactly where one would predict for coordinated $\mathrm{CH}_{3} \mathrm{CM}$. coupled with the very good chemical analysis, tends to exclude the possibility of oxidation of acetonitrile by the pentavatent chromium found in $\mathrm{SO}_{2} \cdot 2 \mathrm{CrO}_{2} \mathrm{~F}_{2}$. Unfortunately, very $7 \mathrm{ittle}$ else can be said about the structure of the complex. n-Hexane - Chromy1 Fuoride Etard Reaction

It was originatly anticipated that chromyl fluoride would prove to be a more active oxidant than chromyl chioride toward relativeiy non-reactive hydrocarbons such as Hexane. Hobbs and Houston (54) found the yield of the Etard Conplex forted between chromyl chloride and nhexane to be onty $31.5 \%$. Subsequent hydrotysis yielded 2-hexanone, 3hexanone, and what was reported as higher boiling unsaturated ketones. Chromyl fluoride bas been found in this research to react quantitatively with $n$-hexane at room temperature but due to the fact that $\mathrm{CrO}_{2} \mathrm{~F}_{2}$ will attack glass, a major problem was finding a vessel capable of containing this potentialiy vigorous reaction during the synthesis of an adequate quantity of product. After testing a number of different apparatus assembities, the set-up shown in Figure 2 was deened the best available. The chromyl fiuoride was contained in the addition vessepl, to which the Freon-173 solvent was added. Reaction was immediate upon mixing the $\mathrm{CrO}_{2} \mathrm{~F}_{2}$ with the $n$-hexane in Freon-113 solution, but during the course 
of the addition, there was appreciable glass attack. In Hobbs and Houston's work, no identifiable organic hydrolysate was found when 38 grams of chromyl chioride-2,2-direthylbutane Etard complex was hydrolyzed. To get 8 grams of 2-hexanone and 3-hexanone, they hydroTyzed $150 \mathrm{~g}$ of hexane-chromyl chloride Etard complex. As is evident. from these last statements, the chromy1 chloride-alkane Etard reaction does not give high yields. It was found that the same can be said for the chromyl fluoride Etard reaction with hexane.

The infrared absorbances of the n-hexane Etard complex with chromyl fluoride are listed in Table XI. The spectrum is of moderate quality despite repeated attempts to resolve some of the broad, featureless peaks to a greater extent; however, a few significant features are identifiable. The strong absorbance at $1640 \mathrm{~cm}^{-1}$ is in the same region where peaks assigned to coordinated carbonyl groups have been reported, Duffin and Tucker (76) have proposed that the toluenechromyl chloride Etard complex consists of benzaldehyde coordinated to reduced $\mathrm{CrO}_{2} \mathrm{Cl}_{2}$, implying that oxidation of the organic substrate by chromium is essentially complete upon formation of the Etard complex and the toluene oxidation product, benzaldehyde, stabilizes the finternediate oxidation state of the chromium via coordination through the carbony1 group. In their study, Duffin and Tucker compared infrared spectra of Etard complexes of $\mathrm{CrO}_{2} \mathrm{Cl}_{2}$ and toluene, benzyl alcohol, and benzyl chloride with liquid benzaldehyde and a Cr(III) complex isolated by refluxing $\mathrm{CrCl}_{3}$ in benzaldehyde of the composition, $\mathrm{CrCl}_{3}\left(\mathrm{C}_{6} \mathrm{H}_{5} \mathrm{CHO}\right)_{3}$. The Etard complexes and the $\operatorname{Cr}$ (III) adduct all displayed similar bands In the region 1640 to $1615 \mathrm{~cm}^{-1}$ which were assigned to the stretching 
Table XI - Vibrational frequencies of the n-Hexane Etard Complex

\begin{tabular}{|c|c|}
\hline $\mathrm{C}_{6} \mathrm{H}_{14}+\mathrm{CrO}_{2} \mathrm{~F}_{2}$ & Probable Assigniment \\
\hline $3200-3000 \mathrm{~s}, \mathrm{~b}$ & $\vee \mathrm{O}-\mathrm{H}$ \\
\hline $2950 \mathrm{~m}$, sh & $\sim \mathrm{C}-\mathrm{H}$ \\
\hline $1640 \mathrm{~s}, \mathrm{~b}$ & $\sim C=0--11$ \\
\hline \multicolumn{2}{|l|}{$1440 \mathrm{w}$} \\
\hline \multicolumn{2}{|l|}{$1360 \mathrm{w}$} \\
\hline $1200 \mathrm{w}$ & $\checkmark \mathrm{C}-\mathrm{H}$ def \\
\hline $1150 \mathrm{~W}$ & v C-H def \\
\hline \multicolumn{2}{|l|}{$1010 \mathrm{w}$} \\
\hline $980 \mathrm{~m}$ & $v C_{r}=0$ \\
\hline $950 \mathrm{~m}$ & $\sim \mathrm{Cr}=0$ \\
\hline \multicolumn{2}{|l|}{$945 \mathrm{w}$, sh } \\
\hline $885 w$ & $\checkmark \mathrm{Cr}-0-\mathrm{Cr}$ \\
\hline $740 \mathrm{w}, \mathrm{sh}$ & $v \mathrm{Cr}-\mathrm{F}$ \\
\hline $530 \mathrm{~s}, \mathrm{~b}$ & $v \mathrm{Cr}-\mathrm{F}$ \\
\hline
\end{tabular}


mode of the coordinated carbonyl group in benzaldehyde. The free car bonyl in benzaldehyde absorbs at $1701 \mathrm{cor}^{-1}$. This proposal describing the structure of the Etard complex bas been used to define the product: obtained in the oxidation of phenols to quinones by chromy chloride (77). In the chronyl fluoride oxidation of n-hexane, the hexanone isomers obtained anong the products have carbonyl absorptions at 1717 $\mathrm{cm}^{-1}$ for 2-hexanone (109) and $1710 \mathrm{~cm}^{-1}$ for 3-hexanone (110). Assuming the $1649 \mathrm{~cm}^{-1}$ band in the n-hexane Etard comblex to be due to a coordinated carbonyl group, this would represent a shift of 70 to $77 \mathrm{~cm}^{-1}$ which seems reasonable in light of Huffin and Tucker's data. The peaks at 980 and $960 \mathrm{~cm}^{-1}$ are in the region of teminal, metal oxygen double bond stretch while the weak absorbance at $885 \mathrm{~cm}^{-1}$ is assigned to a $\mathrm{Cr}-0-\mathrm{Cr}$ bridge stretch (93). (See Chapter IV for an explanation of termina) versus bridging matal-oxygen bond stretching frequencies.) If the contplex is a polymer as has been suggested $(46)$, one would expect the presence of a metal-oxygen bridges. The peaks at 740 and $530 \mathrm{~cm}^{-1} \mathrm{fall}$ into the region of metal-fluoride stretch (94). The strong, broad absorbance from 3200 to $3200 \mathrm{~cm}^{-1}$ is assigned to $\mathrm{O}-\mathrm{H}$ stretch. This could represent a protonated oxygen bound singly to chromium or a hydroxyl group bridging between two chromium centers in the polymer. The results of the chemtcal analysis of the compound suggest that this complex, like that obtained in the analogous reaction with $\mathrm{CrO}_{2} \mathrm{Cl}_{2}$, is a non-5toichiometric product and therefore an atterupt at a detailed anatys is of the spectrum is not possible.

Controlled hydrolysis of the n-hexane-chroityl fluaride Etard complex vas accomplished in a saturated sodium sulfite solution at 
less than $3^{\circ}$. Ether extraction and subsequent concentration yielded a relotively small quantity of organic material (4 g) which tended to darken rapidly upon heating to give a brown precipitate coating the inside of the vesse1. Gas chronatographic analysis of this concentrated sample revealed the presence of ethyl ether, which made up $17 \%$ of the solution, and at least ten other different compounds. By comparison of retention tines of authentic samples to that of components of the hydroTysate, hexanoic acid and 2-hexanone and/or 3-hexanone could be identified as being products of the reaction. No distinction could be made between the two hexanone isomers under the conditions that were employed. The darkening of the solution with formation of a precipitate was probabiy due to air-oxidation and polymerization of the hydrolysis products.

The tabulated infrared spectrum of the hydrosylate is presented in Table XIL. The broad peak from 3450 to $3250 \mathrm{~cm}^{-1}$ is assigned to the oxygen-hydrogen stretch of a carboxylate group with the carbonyl of this group absorbing at $1702 \mathrm{~cm}^{-1}$. The carbon-hydrogen stretching Frequencies are found at 2982,2960 , and $2940 \mathrm{~cm}^{-1}$. Since the hydrosylate is a complex mixture, the "fingerprint" region is obscurred, but the overal1 spectrum is very siailar to that of hexanoic acid.

In sumary, it has been found that chromyl fluoride reacts with n-hexane below $3^{\circ}$ to form an Etard cortiplex of apparently non-stoichiometric composition similar to that produced from $\mathrm{CrO}_{2} \mathrm{Cl}_{2}$ and n-hexane. The solid displays an infrared spectrum which suggests that oxidation of the organic substrate is essentially complete due to the presence of what is assigned as the absorbance of a coordinated cerbonyl group. 
Table XII - Infrared Absorbances of n-Hexane Etard React1on Hydrolysate in $\mathrm{Ci}^{-1}$

Absorbance

$3450-3250 \mathrm{s,b}$

$2982,2960,2940 \mathrm{~s}$

$1702 \mathrm{~s}$

$1450 \mathrm{~m}$

$1405 \mathrm{~m}$

$1375 \mathrm{~m}$

$1270 \mathrm{w}$

$1082 \mathrm{~s}$

1045 s

878 s
Probable Assignment

0-H stretch

$\mathrm{C}-\mathrm{H}$ stretch

$C=0$ stretch 
Controlled hydrolysis of the complex leads to formation of at least ten different organic products in low yields.

Reactian of Chromyl FTuoride with Haloolefins

Chromyt chloride has often been used as an oxidizing agent for alkenes (54) but it was reported that tetrachloroethylene and trichloroethylene do not react with $\mathrm{CrO}_{2} \mathrm{Cl}_{2}$ (111). As was mentioned in the introduction, Knunyants (59) has found that chromy1 chloride does react with a number of fluoroolefins and chiorofluoroolefins. In addition, chromyl fluoride formed in situ from HF and $\mathrm{CrO}_{3}$ at $-78^{\circ}$ reacted with 1,1-diffuoroethylene and trifluoroethylene (60). In this research, it was found that trifluoroethylene, tetrachloroethylene, and 1,i-difiuroethylene react with chronyt fluoride at or beTow rom temperature to give Etard products.

Chromy 1 fluoride and 1,1-diftuoroethylene react to form a brown product of apparent composition. $\mathrm{CF}_{2}: \mathrm{CH}_{2}-2 \mathrm{CrO}_{2} \mathrm{~F}_{2}$. There is a smal1 amount of destructive cxidation of the organic substrate leading to formation of $\mathrm{CO}$ and $\mathrm{COF}_{2}$. This fragmentation occurs to a much greater extent in the reaction of $\mathrm{CF}_{2}$ : $\mathrm{CHF}$ and $\mathrm{CrO}_{2} \mathrm{~F}_{2}$ with $10.0 \%$ of the totat carbon weight lost as carbon monoxide. Destruction of the olefin was such that after reaction and removal of volatile meterials, the weight: of the brown product was less than that of the amount of chromyl fluoride added. Carbonyl fluoride and carbon dioxide were found to be the other products of the fragmentation of trifluoroethylene but the exact amount: of these by-products could not be quantified because the presence of the volatile solvent, Freon-113, did not allow a nleaningful weight to 
taken after remoyal of the $-78^{\circ}$ volatile materials.

An attempt was made to minimize the destructive oxidation of trifluoroethylene by chromyl fluoride by running the reaction at low temperature over the course of a few days. Unfortunately, no suitable solvent was available which would be a liquid at that temperature. The reactants were added into a fused silica vessel at $-195^{\circ}$ with the olefin present in a greater than twofold molar excess. The vessel was kept at $-78^{\circ}$ for about one full day and was then warmed slowiy to room temperature during the following day. There definitely had been a reaction as evidenced by the formation of a dark brown solid almost immediately where the chromyl fiuoride had been condensed in the reaction vesse1. When the vesset had warmed to room temperature on the third day, there were no vapors of chromy1 fluoride visible which was interpreted as an indication of the reaction's completion. However, upon shaking the vessel (as had been done on the previous two days) the product detonated, completely destroying the fused silica container. Explosions have been reported with the chronyi chloride Etard reactions (54), particutarly in concentrated solutions or solventiess systems. It is advised that future investigators use caution in the further study of these reactions and avoid whenever possible, a chromyl fluoride reaction run without a solvent.

Tetrachloroethylene reacts with chromyl fluoride rapidiy but. what at first appeared to be incompletely. After 20 hours reaction tine, red vapors sti11 appeared in the vesse1, even though the olefin was present in excess. Particularly puzzling was the fact that over 
this extended period of time there was no glass attack upon the graded seal of the fused silica vessel which is very unusual for $\mathrm{CrO}_{2} \mathrm{~F}_{2}$ reactions mu for this length of tise. Upon renovel of the volatile materials, including $\mathrm{COCl}_{2}$ but no $\mathrm{CO}$, a light brown solid remained. A deep red solute which did not attack glass vas found in the Freon-113 solution removed from the product. A thoroughly degassed sample of this solution was extracted with water and tested for chloride ion with silver nitrote solution. The positive test for chloride together with the nonglass attacking proberties and color of the solute, led to the assumption that this was chronyl chloride. Isolation of the pure compound from the solution was not possible due to the very similar volatilities of tetrachloroethylene and chromyl chioride. It is well known that chromyl chloride and chromyl fluoride exchange halide atoms quite rapidly at room temperature $(8,112)$ but no examples of ligand exchange with compounds such as tetrachloroethylene appear to be found in the literature. A more likely candidate for the source of chioride could be phosgene (carbonyl chloride) produced by the destruction of the olefin. Acid chlorides such as $(\mathrm{COCl})_{2}$ and $\mathrm{CH}_{3} \mathrm{COCl}$ can be used to produce chromyl chloride from chromates or chromfum trioxide $(3), 32)$ so is seems reasonable that the chloride atoms in $\mathrm{CoCl}_{2}$ might have sufficiently ionic character to exchange with chromyl fluoride to produce $\mathrm{CrO}_{2} \mathrm{Cl}_{2}$ and $\mathrm{COF}_{2}$ or $\mathrm{COClF}$. As with the reaction involving trifluorcethylene, the weight of the product obtained from reaction of chrofyl fluorfde and tetrachloroethylene was less than the weight of $\mathrm{CrO}_{2} \mathrm{~F}_{2}$ used due to the removal of the volatile carban-containing compounds fomed in the destruction of the olefin. 
The magnetic susceptibility of $\mathrm{Cr}_{2}: \mathrm{CH}_{2} \cdot 2 \mathrm{Crl}_{2} \mathrm{~F}_{2}$, obtained by the Cusoy method, was found to be 3.73 Bohr Magnetons. The spin-only value for two unpaired electrons is 2.83 B.A. white that for three unpaired electrons is 3.88 B.M. The presence of a small amount of reduced chronfun from the oxidative destruction of the olefin would tend to give a larger value for the magnetic susceptibility so it seams unlikely that the complex possesses three unpaired electrons but rather that a representative value would 1 ie somewhere betiveen the values for two and three unpaired electrons. Leigh and Strickson (77) found intermediate values for the magnetic susceptibilities of the Etard complexes formed from chronyl chioride and various phenols but provided no explanation for these odd magnetic moments.

The tabulated values for the infrared vibrational frequencies of the products obtained in the reactions of chromyl fluoride with the three haloolefins are presented in Table XIII. Without information concerning the structure of the complex it is not possibie to make many definite assigniments. The striking feature of the three spectra is their simitarity despite the fact that only the 1,1-difluoroethylene product is a stoichiometric complex with the other two containing an apparently large amount of reduced chromium. In looking for the fnorganic features of the complexes, the familiar Cra0 stretch would appear to be Found at 970,990 , and $985 \mathrm{~cm}^{-1}$ in the chromy fluoride complex of 1,1difluorcethylene, tetrachioroethylene, and trifluoroethylene, respectively. As with n-hexane Etard complex discussed earlier in this chapter, if ano assumes these comounds to be polyners, it would be expected to 
Table XIII - Vibration Frequencies of Chromy1 Fluoride - Chlorofluoroolefin Reaction Products

\begin{tabular}{|c|c|c|}
\hline $\mathrm{CF}_{2}: \mathrm{CH}_{2} \cdot 2 \mathrm{CrO}_{2} \mathrm{~F}_{2}$ & $\mathrm{CCl}_{2}: \mathrm{CCl}_{2}+\mathrm{CrO}_{2} \mathrm{~F}_{2}$ & $\mathrm{CF}_{2}: \mathrm{CFH}+\mathrm{Cr}$ \\
\hline $3300-2700 \mathrm{~m}, \mathrm{~b}$ & & $3300-2800$ \\
\hline $2910-2800 \mathrm{~s}, \mathrm{~b}$ & & \\
\hline $1850 \mathrm{~W}$ & & \\
\hline $1620 \mathrm{~m}$ & $1600 \mathrm{~s}$ & $1610 \mathrm{~s}$ \\
\hline $1560 \mathrm{w}, \mathrm{sh}$ & & \\
\hline $1450 \mathrm{~s}$ & & $1470 \mathrm{w}$ \\
\hline & $1380 \mathrm{~W}$ & \\
\hline $1270 \mathrm{~W}$ & & $1290 \mathrm{w}$ \\
\hline $1230 \mathrm{~W}$ & & $1235 \mathrm{w}$, sh \\
\hline $1198 \mathrm{~m}$ & $1203 \mathrm{~W}$ & $1200 \mathrm{~m}$ \\
\hline $1165 \mathrm{~m}$ & $1165 \mathrm{~m}$ & $1185 \mathrm{~m}$ \\
\hline $1100 \mathrm{w}$ & $1105 \mathrm{w}$ & $1100 \mathrm{~m}$ \\
\hline $1025 \mathrm{w}$ & $1025 \mathrm{w}, \mathrm{sh}$ & $1030 \mathrm{w}$ \\
\hline
\end{tabular}

Approximate Assignment

V $\mathrm{O}-\mathrm{H}$

v $C=0-M$

CONTINUED ON NEXT PAGE 
TABLE XIII - CONTINUED

\begin{tabular}{llll}
$\mathrm{CF}_{2}: \mathrm{CH}_{2} \cdot 2 \mathrm{CrO}_{2} \mathrm{~F}_{2}$ & & $\frac{\mathrm{CF}_{2}: \mathrm{CFH}+\mathrm{CrO}_{2}: \mathrm{CCl}_{2}}{2}+\mathrm{CrO}_{2} \mathrm{~F}_{2}$ & Approximate Assignment \\
\cline { 2 - 3 } $970 \mathrm{~m}$ & $990 \mathrm{~s}$ & $985 \mathrm{~m}$ & $v \mathrm{Cr}=0$ \\
$895 \mathrm{w}$ & $900 \mathrm{w}$ & $900 \mathrm{w}$ & \\
& $860 \mathrm{w}$ & $865 \mathrm{w}$ & $v \mathrm{Cr}-\mathrm{O}-\mathrm{Cr}$ \\
$800 \mathrm{w}$ & $800 \mathrm{w}$ & $805 \mathrm{w}$ & $v \mathrm{Cr}-\mathrm{F}$ \\
$712 \mathrm{~m}$ & $712 \mathrm{~s}$ & $700 \mathrm{~m}, \mathrm{sh}$ & $v \mathrm{Cr}-\mathrm{F}$ \\
$550 \mathrm{~s}, \mathrm{~b}$ & $540 \mathrm{~s}, \mathrm{~b}$ & $550 \mathrm{~s}, \mathrm{~b}$ &
\end{tabular}


find bridging as well as teminal axygens bound to chromium. The absorbances found at about $800 \mathrm{~cm}^{-1}$ in the three complexes are in the proper region for $\mathrm{Cr}-0-\mathrm{Cr}$ stretch (93). Chromiun fluoride stretches are assigned to the peaks occurring at about $710-712$ and $540-550 \mathrm{~cm}^{-1}$. The broad bands from 2700 to $3300 \mathrm{~cm}^{-1}$ found in the trifluoroethylene and 1,1-difluoroethylene complexes are assigned to $0-1 /$ stretch. Again as in the n-hexane Etard complex, it seems possible that it could be efther the result of a protonated, singly bound oxygen or a hydroxyl group bridging between chromium centers. Carbon-halogen stretching absorbances usually can occur from approximately 800 to $1350 \mathrm{~cm}^{-1}$ (113). This region of the three spectra is complex as one would expect, but definite assignments are not possibie. The praminant peaks at $1620 \mathrm{~cm}^{-1}$ in the $1,1-$ difluoroethylene complex, $1600 \mathrm{~cm}^{-1}$ in tetrachloroethylone complex, and $1610 \mathrm{~cm}^{-1}$ in the trifluoroethylene complex are similar to those observed by Huffin and Tueker (76) in the infrared spectra of chronyt chloride Etard complex and also to that observed in the $n$-hexane-chromyl fluoride Etard complex reported earlier in this chapter. These bands have been assigned to the stretching vibration of a coordinated carbonyt group Where the oxidized product formed upon hydrolysis was either an aldehyde or a ketone. This evidence is in aoparent disagreement with the results of Knunyants (60) who reported trifluoroethanol as the hydrolysis product of chrozyl fluoride and 1,1-difluoroethyiene. AT though a reducing agent $\left(\mathrm{SO}_{2}\right)$ was added to the hydrolysis mixture, tetravalent sulfur is not capable of reducing carbonyl groups to alcohols. Knunyants did not isolate the intermediate complex but simply hydrolyzed the reaction product directiy after it was formed. In this research, enough 1,1-difluoro- 
ethylene-chromyl fluoride conplex was prepared to hydrolyze in $\mathrm{WaHSO}_{3}$ solution. An ether extract of the hydrolysate showed only one product peak upon gas chromatographic analysis. This peak was found not to be due to trifluoroethanol upon compartson to an authentic sample of $\mathrm{CF}_{3} \mathrm{CH}_{2} \mathrm{OH}$. The compound produced in the hydrolys is of $\mathrm{CF}_{2}: \mathrm{CH}_{2} \cdot 2 \mathrm{CrO}_{2} \mathrm{~F}_{2}$ could not be identified, but it definitely was not trifluoroethanol. In surmary, it was found that 1,1-difluoroethylene, trifluoroethylene, and tetrachloroethylene al1 react with chronyl fluoride to give Etard products. Only 1,1-difluoroethylene gave a stoichionetric complex, having a composition of $\mathrm{CF}_{2}: \mathrm{CH}_{2} \cdot 2 \mathrm{CrO}_{2} \mathrm{~F}_{2}$. The other two olefins undervent destructive oxidation to produce $\mathrm{CO}$ and carbonyl hoi ides and tetrachloroethylene a1so yielded chromyl chloride as a result of some sort of halogen exchange, probably with $\mathrm{CoCl}_{2}$. The magnetic susceptibility of $\mathrm{CF}_{2}: \mathrm{CH}_{2} \cdot 2 \mathrm{CrO}_{2} \mathrm{~F}_{2}$ was found to be 3.79 B.M., a value which would have to te considered inconciusive toward assigning the oxidation state of chromfum in the complex. Infrared spectral data suggests that both terminat and bridging oxygen-chromium bonds are found in the complexes as well as the fact that it appears that the oxidized organic substrates found in the complexes contain carbonyl groups coordinated to the chromfum centers. Hydrolys is of $\mathrm{CF}_{2}: \mathrm{CH}_{2} \cdot 2 \mathrm{CrO}_{2} \mathrm{~F}_{2}$ in this research did not yield trifluoroethanol as had been published earlier. 


\title{
CHAPTER IV
}

\author{
Preparation and Characterization \\ nf Chromium(V) Oxide Trifluoride
}

Introduction

Although the most common higher oxidation state of chromfum is Cr(VI), the pentavalent and tetravalent state has been shown to exist in a number of compounds. Chromium pentafluoride and chromium tetrafluoride were first prepared in 1941 (4). Tetrahedral alkali metal chromate (V) salts have been isolated from strongiy basic solutions and characterized via x-ray studies (78), ESR spectra (79), and magnetic susceptibility measurements (80). From concentrated HCl solutions, octahedral salts of $\mathrm{CrOCl}_{5}{ }^{2-}$ have been prepared and studied (81). Witlis has produced a $\mathrm{Cr}(\mathrm{V})$ ion through the reaction of chromate ion and perfluoropinacol which was characterized by its electronic spectrum and magnetic susceptfbitity measurements (82). Krauss (82, 63, 84) synthesized chromium(V) oxide trichloride using chromiun trioxide and either thionyl chloride or sulfuryl chloride. The co-products of the reaction were found to be chlorine and sulfur dioxide or suifur trioxide, depending on the starting material. The major product of the reaction is chromyl chloride but the less volatile $\mathrm{CrOCl}_{3}$. can be isolated in two percent yield via sublimation of the reaction residue. The magnetic susceptibtlity of the compound at $23^{\circ}$ was deteruined to be 1.81 Eohr Nagnetons. Chromfum(V) oxide trichloride is unstable at roon temperature, disproportionating to $\mathrm{CrO}_{2} \mathrm{Cl}_{2}$ and presumably $\mathrm{CrCl}_{3}$. No vibrational spectra data or physical cheoical information was gtven. 
It is interesting that with chromium under extreme fluorinating conditions: ie; high temperature and high pressure of $\mathrm{F}_{2}$, chromium pentafluoride is the major product and not a hexavalent chromiun species. This is sue to the fact that CrF 6 apparantly is unstable above upgroximately $-80^{\prime}$, decomposing to $\mathrm{CrF}_{5}$ and $\mathrm{F}_{2}(35)$. Chromium pentafiuoride can be produced by high temperature fluorination of $\mathrm{Cr}$ metal (4), $\mathrm{CrF}_{3}$ (87), or $\mathrm{CrO}_{3}(6)$. In the latter example, Edwards showed the reaction of fluorine and chronium trioxide to be a stepwise process. At a reaction temperature of $150^{\circ}, \mathrm{CrO}_{2} \mathrm{~F}_{2}$ was found to be the predominant product while at $220 \%$, chromium oxide tetrafluoride proved the major species. Above $250 \%, \mathrm{CrF}_{5}$ was obtained. It was assumed that fluorination of chromium trioxide proceeds by successive replacement of oxygen leading to formation of $\mathrm{CrF}_{6}$, which decomposes yielding chromium pentafluoride.

With certain other potent fluorinating agents a similar situation has been found to exist; that is, reaction of a hexavalent chromium compound yields a product reduced to the pentavalent oxidation state. The reaction of bromine trifiuoride with chromium trioxide and potassium dichromate yields $\mathrm{CrOF}_{3} \cdot 0.25 \mathrm{BrF}_{3}(23,24)$ end $\mathrm{KCrOF}_{4}(25)$, respectively, while reactions of $\mathrm{CrO}_{3}$ with $\mathrm{ClF}_{3}$ and $\mathrm{BrF}_{5}$ produce $\mathrm{CrOF}_{3} \cdot 0.30 \mathrm{ClF}_{3}$ and $\mathrm{CrOF}_{3} \cdot 0.25 \mathrm{BrF}_{5}(23,24)$. The $\mathrm{CrOF}_{3}$ adducts are al1 red solids while $\mathrm{KCrOF}_{4}$ is reported as a purple powder. In all cases, the chromium has been reduced to the pentavalent oxidation state as identified by magnetic susceptibility measurements. No significant amounts of other chromium fluorides or oxide fluorides were found to be present among the products. Only very small quantities of $\mathrm{CrO}_{2} \mathrm{~F}_{2}$ could be isolated.

Clark and Sadana $(23,24)$ found a.11 attempts to remove residual amounts of the interhalogen fluorinating agent resulted in decomposition 
of the $\mathrm{CrOF}_{3}$ to Tover valent chromiun fluorides, probably $\mathrm{Cr}$ (III).

This is compared to the fact that $\mathrm{KCOOF}_{4} \cdot 0.5 \mathrm{BrF}_{3}$, the inftial product isolated from the reaction of $\mathrm{BrF}_{3}$ and $\mathrm{K}_{2} \mathrm{Cr}_{2} \mathrm{O}_{7}$, was freed of $\mathrm{BrF}_{3}$ to yheld $\mathrm{KCOOF}_{4}$ by heating the samaio to $150^{\circ}$ under vacuris.

Chronium (VI) is unique here in its reactivfty since reaction with the interhalogen fluorides leads to reduction of the metal. Titanium dioxide reacts with $\mathrm{BrF}_{3}$ to give $\mathrm{TFF}_{4}$ while $\mathrm{V}_{2} \mathrm{O}_{5}$ appears to undergo a partial loss of oxygen in reaction with bromine trifluoride to give a mixture of vanadium pentafluoride and vanadium oxide fluorides (88). Vanadium pentoxide is reported to react with $\mathrm{ClF}_{3}$ to form $\mathrm{VOF}_{3}(89)$. As was mentioned in Chapter II, $\mathrm{CTF}_{3}$ and $\mathrm{CIF}$ react wi th a number of Group VI oxides and oxide fluorides, in all cases yielding fluorinated products with the oxidation state of the metal center unchanged.

\section{Experimental}

Preparation of Chromium oxide Trifiuoride

To a passivated $100 \mathrm{ml}$ Monel metal reaction vessel was added 14 moles of $\mathrm{CrO}_{2} \mathrm{~F}_{2}$ and 35 moles of $\mathrm{ClF}$ via vacuum distillation. The reactants were then heated to $100^{\circ}$ in a tube furnace for 12 hours after which time the vessel was evacuated at $-196^{\circ},-78^{\circ}$, and room temperature. The $-196^{\circ}$ volatile product was oxygen as identified by its molecular weight (Requires: 32.0 found: 31.9$)$. At $-78^{\circ}$, the volatile materials consisted of $\mathrm{CTF}$ and $\mathrm{ClO}_{2} \mathrm{~F}$, identified by their respective infrared spectra $(42,43)$ and $\mathrm{Cl}_{2}$, identified as a yellow-green liquid at $-78^{\circ}$ with a vaoor pressure of approximately $100 \mathrm{~m}$ at that tenperature. No vacuum line transferrable material was noted at room temperature. Jpon opening the vessel in the dry box, a brick-red, non-volatile powder was found coating the walls of the metal reactor. This solid darkens rapidiy on exposure to the dry box 
atmosphere. The sample vas subjected to a fuoy neasurement of magnetic susceptibility which yielded a value of 1.83 Bohr Magnetons, corresponding to one unpaired electron. The solid reacts violently with water to give a yellow-green solution and witl ignite ocetone upon contact. An aqueous solution of the hydrolyzed solid does nos give a precipitate with $\mathrm{AgIO}_{3}$ solution nor does pretreatment of the hydrolysate with $\mathrm{Na}_{2} \mathrm{O}_{2}$ give a precipitate. Infrared and Raman spectral data are listed in Table XV. Analysis for $\mathrm{CrOF}_{3}$ (Cr: requires: $41.6 \%$ found: $39.7 \%, 37.3 \%, F$; requires: $45.6 \%$ found: $38.95,39.9 \%, \mathrm{Cl}$; Found: $3.82 \%$, 5. 52\%).

To 16 mmoles of chlorine-containing $\mathrm{CrOF}_{3}$ prepared by the above outlined procedure was added 20 mmioles of $F_{2}$ at $-196^{\circ}$. The reaction mifxture was heated to $120^{\circ}$ for 4 hours. After removal of the excess fluorine at $-196^{\circ}$, the $-78^{\circ}$ volatile products were investigated. The only compound evident in the infrared spectrum was identified as $\mathrm{CTO}_{2} \mathrm{~F}$ (43). There were no room temperature volatile products. The non-volatile product was found to be a bright purple solid which darkens much iess quickly than the sample not treated with $\mathrm{F}_{2}$. Analysis $(\mathrm{Cr}$; reguires: 41.6\% found: $41.6 \%, \mathrm{~F}$ : requires: $45.6 \%$ found: $431 . \%, \mathrm{Cl}$ : found: $0.72 \%)$. To verify the pentavalent nature of the cornoound, a sample was hydrolyzed, quantitatively diluted in a volumetric flask, and an aliquot titrated iodometrically with standardized thiosulfate solution. Apparent Cr(VI) Requires: $27.73 \%$ found: $27.64 \%$. To another aliquot solution was added excess $\mathrm{Na}_{2} \mathrm{O}_{2}$, then the solution was heated to $40^{\circ}$ for 30 ainutes and to bolling for 20 minutes. The solution was then titrated iodometrically. Requires: $41.50 \%$ found; $41.62 \%$. In a glass capillary the compound did not attack glass apprectably below $200^{\circ}$ but there was a suddent attack with apparent melting from $300-304^{\circ}$. The melt bubbles vigorously, turning 
to a grey-green solid. An alternetive preparative procedure of purple $\mathrm{CrOF}_{3}$ was found to involve heating an excess ClF with $\mathrm{CrO}_{2} \mathrm{~F}_{2}$ to $250^{\circ}$ for 5 hours. The purple product obtained gives the same $x$-ray powder pattern as the material prepared using $F_{2}$ (see Table XVI). Infrared and Raman spectral data are 1 isted in Table XIX.

Reaction of Chromium Trioxide and Chlorine Monofluoride at 250"

To 26 mmoles of $\mathrm{CrO}_{3}$ contained in a passivated $100 \mathrm{~m}$ M Monel metal reaction vessel was added 114 moles of $\mathrm{CTF}$ at $-196^{\circ}$. The vessel was al Towed to warm to room temperature, then placed in an oven and heated to $285^{\circ}$ for five hours. The reaction vessel was evacuated at $-196^{\circ}$ and a molecular weight determination performed on the volatile materials at that temperature. The gas was found to be oxygen. Requires: 32.0 , found: 32.4 . The vessel was then evacuated at $-78^{\circ}$ and an infrared spectrum taken of the products at that temperature revea $1 e d \mathrm{ClO}_{2} \mathrm{~F}$ and $\mathrm{C} \mathrm{CO}_{2}$ to be present. There were no room temperature volatile materials. The vessel contained a 1ime-green poider which was not the least bit kygroscopic nor air sensitive. This solid was insoluble in water and displayed only $\mathrm{Cr}-\mathrm{F}$ stretching modes in its infrared spectrum. The product weight corresponded to 20 moles of $\mathrm{CrF}_{3}$. Analysis $(\mathrm{Cr}$; requires: $47.7 \%$ found: $44.5 \%$, F; requires: $52.3 \%$ found: $45.5 \%$ ). The $x$-ray powder pattern for the product is listed in Table XVII.

Thermal Decomposition of Chromium Oxide Trifluoride

A freshiy prepared sample of $\mathrm{CrOF}_{3}$ ( 5.6 mimoles), contained in a stainless steel reaction vessel was placed in a tube furnace and heated to $350^{\circ}$ for four hours. The vessel was allowed to cool to room temperature and evacuated. A molecular weight of the gaseous contents revealed the presence of oxygen. Requires: 32.0 found: 31.9 . The nonvolatile solid 
product was a light-greenish tan povider which was not hygroscopic or atherwise air-sensitive. This powder was insoluble in water, $\mathrm{CCl}_{4}$, and DMSO. The infrared spectrum of the compound was similar to that of $\mathrm{CrF}_{3}$, with an absorbance due to $\mathrm{Cr}=0$ completeiy lacking. Analysis ( $\mathrm{Cr}$; requires: $47.7 \%$ found: $46.2 \%$, F; requires: $52.3 \%$ found: $40.7 \%$ ). The x-ray powder pattern is listed in Table XVII. Reaction of Chromium Oxide Trifiuoride and Antimony Pentafluoride

In a typical reaction, freshly prepared $\mathrm{CrOF}_{3}$ (6.69 moles) was transferred directly from the preparation vessel to a $30 \mathrm{ml}$ fused silica vesse1. The $\mathrm{SbF}_{5}$ ( 43.6 mmoles) was vacuum distilled from NaF at $-78^{\circ}$. Upon me7ting of the $\mathrm{SbF}_{5}$ and heating to $60^{*}$ for 20 ininutes with stirring, the mixture formed a deep, red-wine colored solution which turned more purple as time passed. Upon evacuation of the reaction vessel, only white bands (due to $\mathrm{SbF}_{5}$ ) were found in the trap; however, as evacuation was continued, a yellow-orange band appeared and grew as time passed. The reaction mixture was evacuated to constant weight, leaving a fine, bright purpie powder which had a corresponding weight pickup of 12.8 introles of $\mathrm{SbF}_{5}$ or $25.5 \%$ of that expected for a $1: 2$ adduct. The product melts from $120-125^{\circ}$ to a reddish brown mass which bubbles vigorous $1 y$ above $130^{\circ}$, The magnetic susceptibility of the adduct was found to be 2.27 Bolir Magnetons at $21^{\circ}$. The compound is very hydroscopic and reacts vigorously with water to give a yellow-green solution. Analysis: calculated for $\mathrm{CrOF}_{3} \cdot 2 \mathrm{SbF}_{5}$, requitres; $\mathrm{F}: 44.2 \%$ found: $41.5 \%$.

An absorption spectrum of the reaction mixture and of the yelloworange volatile product was taken using the $30 \mathrm{~m}$ f fused silica reaction vessels as sample cells. The resultant data are listed in Tabie XX. Infrared data are presented in Table XXI. 
Preparation of Chromiun Pentafluoride from Chromium Oxide Trifluoride

To a freshly prepared sample of $\mathrm{CrOF}_{3}$ (29 moles) contained in a C1F-passivated stainless steel vessel was added 45 moles of $F_{2}$ at $-196^{\circ}$. The vessel was allowed to come to rogm temperature, than was heated to $180^{\circ}$ for five hours. The excess fluorine was renoved at $-78^{\circ}$. Upon evacuation of the vessel at room temperature, a small, deep red band appeared in the $-196^{\circ}$ trap and grew only very slowly with time. The weight pickup corresponded to 27 rmoles of $\mathrm{CrF}_{5}$. Opening the vessel in the dry box revealed a deep reddish coating throughout. An infrared spectrum of this red compound agreed with that of $\mathrm{CrF}_{5}$ (61). Discussion

Chromium oxide trifluoride was first noted in this research as a side reaction product of the interaction of $\mathrm{ClF}$ and $\mathrm{CrO}_{3}$ at room temperature. Production of $\mathrm{CrOF}_{3}$ reduced the yield of chromyl fluoride but it vas found that running the reaction at $0^{\circ}$ minimized the amount of the oxide trifluoride obtained as long as a large excess of chlorine monofluoride was avoided. The first samples of $\mathrm{CrOF}_{3}$ obtained were brick-red solids which darkened rapidly in the dry box to a black solid and attacked glass readily. This product could be obtained from the reaction of either $\mathrm{CrO}_{3}$ or $\mathrm{CrO}_{2} \mathrm{~F}_{2}$ and $\mathrm{ClF}$ from $25^{\circ}$ to $100^{\circ}$ with the yield increasing with temperature. Chemical analysis of the compound showed the presence of from 3.32 to $5.52 \%$ chlorine, making the apparent composition $\mathrm{CrOF}_{3} \cdot 0.14 \mathrm{ClF}$ to $\mathrm{CrOF}_{3} \cdot 0.21 \mathrm{ClF}$. This is compared to the adducts of composition $\mathrm{CrOF}_{3} \cdot 0.25$ $\mathrm{BrF}_{3}, \mathrm{CrOF}_{3} \cdot 0.25 \mathrm{BrF}_{5}$, and $\mathrm{CrOF}_{3} \cdot 0.30 \mathrm{ClF}_{3}$ formed from the reaction of chromium trioxide and the respective inter-halogen fluorides $(23,24,25)$. Similar to what was experienced with these other $\mathrm{CrOF}_{3}$ adducts, an x-ray powder pattern could not be obtained from $\mathrm{CrOF}_{3}{ }^{\circ} 0.21 \mathrm{clF}$ because the capil- 
laries exploded shortly after being loaded, presumably as a result of glass attack. Heating a sampie in a melting point capillary resulted in almost itmediate glass attack with the tube becoming completely opaque at $60-80^{\circ}$. A magnetic susceptibility measurement of the compound at $17 \%$ yielded a value of 1.82 Bohr Magnetons, consistent with a $d^{1} \mathrm{Cr}(V)$ species (theoretical spin-only value: 1.77 B.4.). $\mathrm{CrOF}_{3} \cdot 0.21 \mathrm{ClF}$ reacts vigorously with water to give a yellow-green solution while acetone is ignited by the compound.

It is of interest to speculate on the nature of the contaminating chlorine species in $\mathrm{CrOF}_{3}-0.21 \mathrm{CIF}$. It is unlikely that the adduct is one that contains a discrete ClF species, especially in light of the recent work done on synthesis and characterization of inter-halogen ions. The interaction of $\mathrm{ClF}_{3}$ with strong Lewis acids such as $\mathrm{SbF}_{5}, \mathrm{AsF}_{5}$, and $\mathrm{BF}_{3}$ leads to formation of the $\mathrm{CTF}_{2}{ }^{+}$ion $(90)$ as counterion for $\mathrm{SbF}_{6}{ }^{-}, \mathrm{AsF}_{6}{ }^{-}$, and $\mathrm{BF}_{4}{ }^{-}$, respectively. Reaction of alkali metal fluorides with chlorine monofluoride leads to compounds containing the $\mathrm{ClF}_{2}$ - ion which deconpose above -78 - (91). Christe has shown that chloryl fluoride reacts with strong Lewis acids to form saits contoining the $\mathrm{ClO}_{2}{ }^{+}$ion (92). Pertinent vibrational spectral data for those compounds are listed in Table XIV.

The Raman and infrared spectral data for $\mathrm{CrOF}_{3} \cdot 0.21 \mathrm{ClF}$ are tabulated in Table XV. Bands at $1068 \mathrm{~cm}^{-1}$ in the infrared and $1065 \mathrm{~cm}^{-1}$ in the Raman effect fall in the region of $\mathrm{ClO}_{2}^{+}$symetric stretch while the infrared absorbance at $1255 \mathrm{~cm}^{-1}$ can reasonably be assigned to an antisvrmetric chloryl ion stretch. The $\mathrm{ClO}_{2}^{+}$antisymetric stretching band should be Raman active but was not observed. The very weak, Raman peaks at 1395 and $1325 \mathrm{~cm}^{-1}$ are about 150 to 200 wave numbers too high to be safeTy assigned to the chloryl antisymmetric stretch; these remain unassigned. The band 
TABLE XIV

Vibrationat Frequencies of Selected Chlorine lans and CIF. in or ${ }^{-1}$

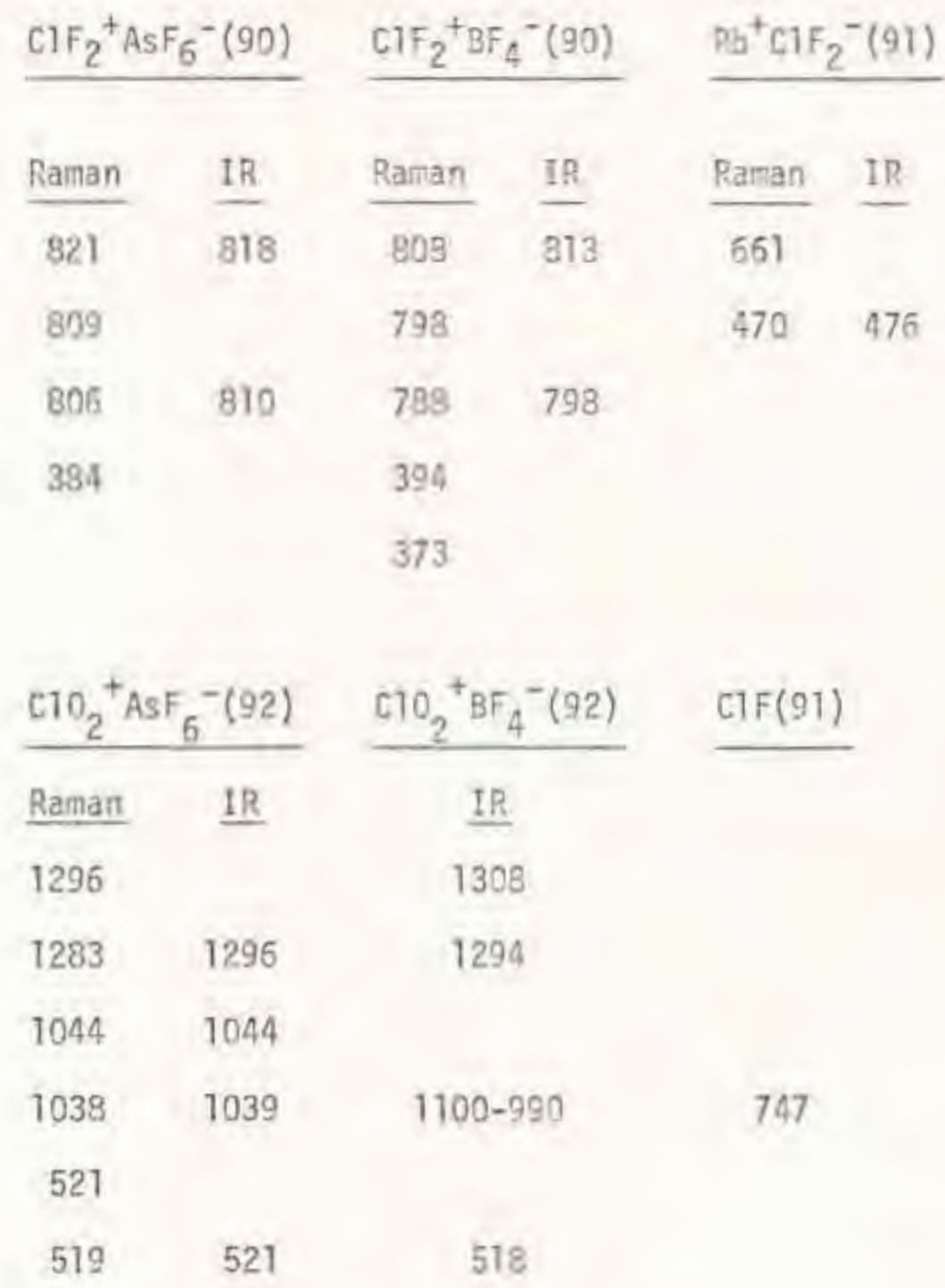


TABLE XV

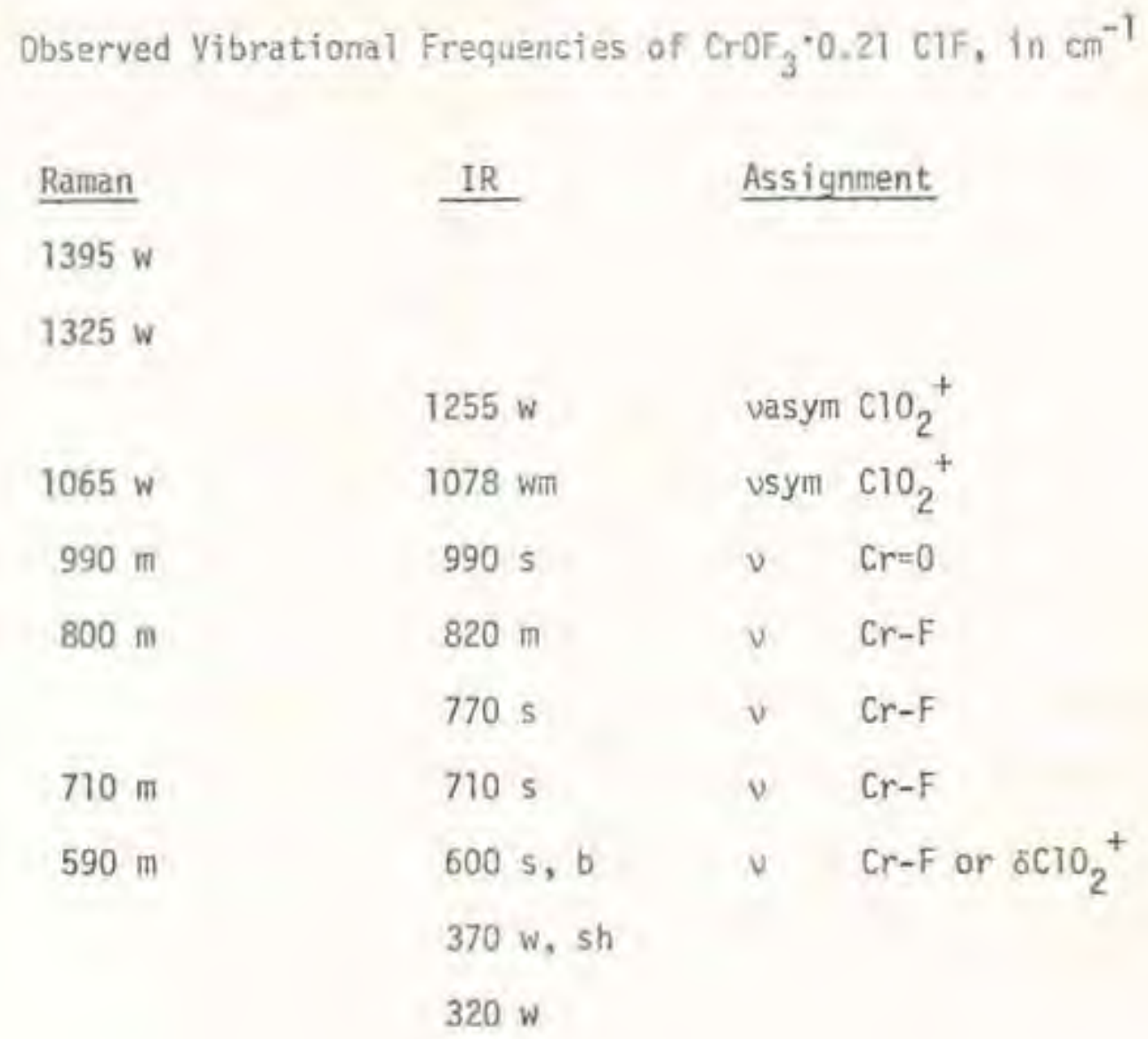


corresponding to the $\mathrm{CrO}_{2}{ }^{+}$bending mode is in the sana region as the chromium-fluorine stretching region $\left(\sim 500-800 \mathrm{~cm}^{-1}\right)$. The remaining bands can be assigned to $\mathrm{Cr}=0$ stretch: $990 \mathrm{~cm}^{-1}$ in the Ranan and infrared; $\mathrm{Cr}-\mathrm{F}$ stretch: 830 to $500 \mathrm{~cm}^{-1}$; and defomations: 370 and $320 \mathrm{~cm}^{-1}$. The assertion that chlorine is present in $\mathrm{CrOF}_{3} \cdot 0.21 \mathrm{CIF}$ as the $\mathrm{ClO}_{2}{ }^{+}$ion is strengthened by the fact that the logical counterion, $\mathrm{CrOF}_{4}^{-}$, is known (23) although no vibrational spectra are available. The $\mathrm{ClO}_{2}{ }^{+} \mathrm{CrOF}_{4}{ }^{*}$ could be produced from $\mathrm{CrOF}_{3}$ reacting with $\mathrm{ClO}_{2} \mathrm{~F}$ formed in the reaction of $\mathrm{ClF}$ and $\mathrm{CrO}_{3}$ or $\mathrm{CrO}_{2} \mathrm{~F}_{2}$.

It was found while attempting to prepare $\mathrm{CrOF}_{4}$, that treatment of chlorine-containing $\mathrm{CrOF}_{3}$ with fluorine at $120^{\circ}$ leads to a non-volatile purple product which has a lowered chlorine content. Analysis of the volatile materials from the reaction revealed $\mathrm{ClO}_{2} \mathrm{~F}$ to be the only species giving an infrared spectrum. Subsequent work revealed that purple CrOF $_{3}$ could also be prepared by the reaction of $\mathrm{CrO}_{2} \mathrm{~F}_{2}$ and $\mathrm{C} 1 \mathrm{~F}$ at $259^{\circ}$. The compound does not attack glass or fused silica quickly and this fact allowed $x$-ray powder patterns to be taken. These showed the $\mathrm{CrOF}_{3}$ prepared via the two different methods to be the same. (see Table XVI) Rapid heating of a sample of purple $\mathrm{CrOF}_{3}$ in a melting point capillary results in little change below $200^{\circ}$ but above that temperature glass attack becomes evident. At $300^{\circ}$ there is a sudden, extensive attack with the appearance of melting. The melt bubbles vigorously, apparently giving off a gas, Further study showed that a sample of $\mathrm{CrOF}_{3}$ heated to $350^{\circ}$ in a metal vessel decomposes to give off $\mathrm{O}_{2}$. This is analogotus to the behavior of $\mathrm{CrO}_{2} \mathrm{~F}_{2}$ which decomposes to $\mathrm{CrOF}_{2}$ and $\mathrm{O}_{2}$ above $550^{\circ}(47)$. The non-volatile decomposition product would logical1y be $\mathrm{CrF}_{3}$ but the analysis for this compound was very poor and the $x$-ray powder pattern does not agree with that of $\mathrm{CrF}_{3}$. It is possible that thermal decomposition of $\mathrm{CrOF}_{3}$ leads 


\section{TABLE XVI}

X-Pay Powder Patterns of $\mathrm{CrOF}_{3}$ Prepared by Two Nethods

$$
\mathrm{CrO}_{3}+\mathrm{CHF} \stackrel{100^{\circ}}{\longrightarrow} \stackrel{\mathrm{F}_{2} \quad 120^{\circ}}{\longrightarrow} \mathrm{CrOF}_{3} \quad \mathrm{CrO}_{3}+\mathrm{CHF} \stackrel{250^{\circ}}{\longrightarrow} \mathrm{CrOF}_{3}
$$

$\underline{d}(\AA)$

Intensity

4.43

III

3.63

m

3.35

S

2.59

2.51

2.26

2.06

1.94

1.89

1.81

1.58

1.53

1.49

1.47

1.43

1.42

1.20
W

III

m

W

W

w

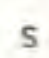

5

w

W

w

W

w

III

m d( $(\AA)$

4.43

3.63

3.38

2.58

2.49

2.23

2.05

1.95

1.89

1.82

1.59

1.53

1.48

1.46

1.43

1.41

1.20
Intensity

m

In

s

w

m

s

W

W

w

5

m

w

w

W

W

W

(T) 
to a previously unknown, complex Gr(III) oxide fluoride. A mixture of chromfum oxides and $\mathrm{CrF}_{3}$ as a decomposition product of $\mathrm{CrOF}_{3}$ is seemingly ruled out because of the lack of agreement in the $x$-ray powder patterns with known oxides and fluorides (see Teble XVII).

Chronium oxide trifluoride does not dissolve in Freon-113 or perfluoroheptane. It does dissolve with decomposition in dry glacial acetic acid, $100 \% \mathrm{H}_{3} \mathrm{PO}_{4}$, and DMSO. A11 attempts to obtain a visible/UV spectrum failed.

When chromium trioxide was treated with chlorine monofluoride and heated to $285^{\circ}$, a non-hygroscopic lime-green solid was obtained which was found to be very similar to the compound produced by the thermal decomposition of $\mathrm{CrOF}_{3}$. As with the $\mathrm{CrOF}_{3}$ thermal decomposition product, a poor analysis and unique $x$-ray powder pattern was obtained (see Table XV11).

Pentavalent chromium disproportionates to $\mathrm{Cr}$ (III) and $\mathrm{Cr}$ (VI) in water as described in Equation IV-1:

IV $-1 \quad 3 \mathrm{Cr}(\mathrm{V}) \rightarrow 2 \mathrm{Cr}(\mathrm{VI})+\mathrm{Cr}(\mathrm{III})$

This fact provided an additional way of proving the pentavalent nature of the compound. A sample was hydrolyzed after weighing and quantitatively diluted in a volumetric flask. A comparison was made of aliquots treated with $\mathrm{Na}_{2} \mathrm{O}_{2}$ before iodometric titration with aliquots titrated dírectly from the hydrolyzed sample solution. In the peroxide-treated aliquots, $\operatorname{Cr}$ (III) was oxidized to $\mathrm{Cr}$ (VI) so these samoles analyzed for $50 \%$ more chromium than the untreated solutions, as would be expected for a pentavalent chromium species.

In light of the veritable renaissance of inorganic chemistry brought about by vibrational spectroscopy in the past decade and a half, metal oxide trihalides have received 1 imited attention. There has been nuch 
TABLE XVII

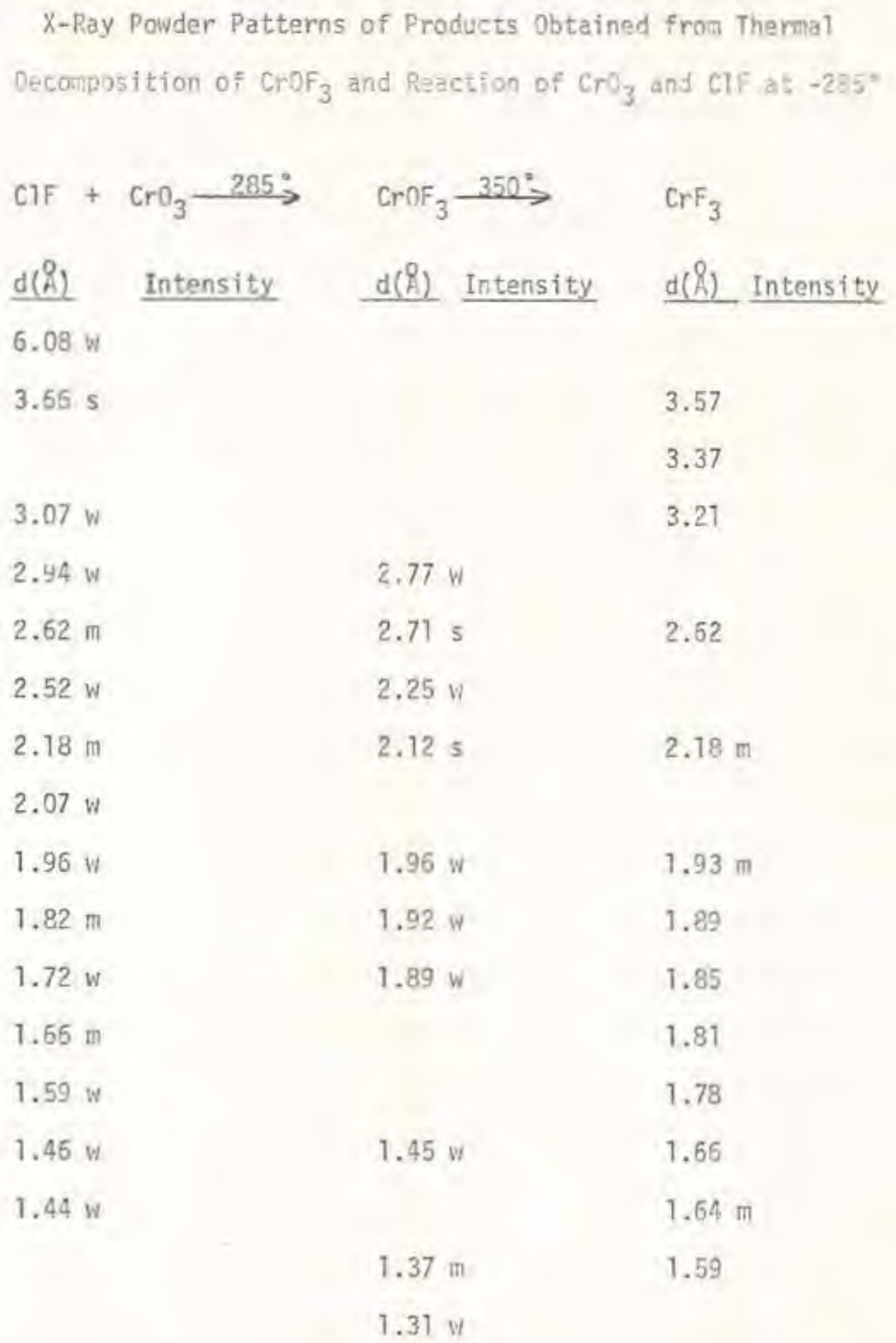


interest in correlating metal-oxygen stretching frequencies to bond order, that is, identifying the double bond character of a terminal oxygen-metal bond compared to the single bond character of a bridging oxygen. There appears to be general agreement that strong Raman or infrores bands in the 1100 to $950 \mathrm{~cm}^{-1}$ region are indicative of terminal $M=0$ bonds while the 650 to $850 \mathrm{~cm}^{-1}$ region is characteristic of the $\mathrm{M}-0-\mathrm{H}$ antisymetric stretch $(93,94)$. Table XVIII lists the reported metal-oxygen stretching frequencies for fifteen transition netal oxide trihalide solids, each placed in its respective group depending on the position of the $\mathrm{N}-\mathrm{O}$ stretching band.

An $x$-ray study of niobium oxide trichloride (101) revealed the structure of the compound to be di- $\mu$-chloro bridged $\mathrm{NIb}_{2} \mathrm{Cl}_{2}$ units connected by niobium-oxygen bridges (see Figure 5) giving the niobium ators a distorted octahedral coordination. $\mathrm{MOOBr}_{3}, \mathrm{NOCl}_{3}$, and $! 0 \mathrm{OB} \mathrm{r}_{3}$ have $\mathrm{x}$-ray powder patterns similar to $\mathrm{NbOCl}_{3}$ and it has been proposed that they are isomorphous (102). X-ray studies on $\mathrm{MoCCl}_{3}$ have shown there are two stable solid structures; one is a low temperature form isostructural with $\mathrm{NbOCl}_{3}$ (103) and the other a higher temperature form containing terminal oxygens and $d i-\mu$-chlorobridges (104). The only infrared data which seems to be available for either form is the teminal oxygen stretching value of $1007 \mathrm{~cm}^{-1}$ for the high temperature form (93). The relative non-volatility of these compounds has been the suggested result of their extensive polymerization (105). Ozin and Reynolds (106) found the gas phase Raman spectrum of $\mathrm{NbOCl}_{3}$ at $350^{\circ}$ to be very similar to that of $\mathrm{VOCl}_{3}$ at $130^{\circ}$. indicating at $\mathrm{C}_{3 \mathrm{y}}$ structure for gaseous $\mathrm{NbOCI}_{3}$, like $\mathrm{VOCI}_{3}$. Solld $\mathrm{VOCl}_{3}$ contains terminal oxygens (95) and presumably chlorine bridges. 
Figure 5 - Structures of Metal Oxide Trihalides

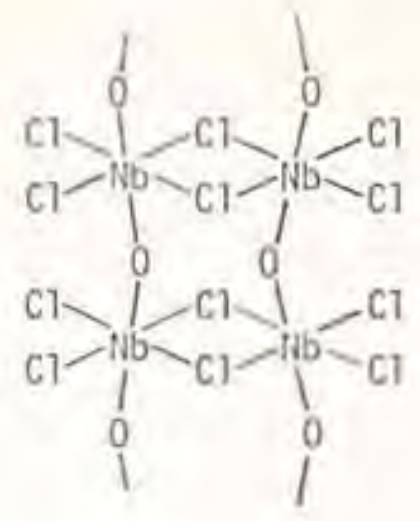<smiles>[Mg][GeH3]</smiles><smiles>CO[Si](Cl)(Cl)[Si](Cl)(Cl)[Si](Cl)(Cl)[Si](Cl)(Cl)[Si](=O)(Cl)(Cl)Cl</smiles><smiles>[GeH3]</smiles><smiles>CP(F)(F)(F)P(=O)(F)P(F)(F)(F)F</smiles>

$\mathrm{VOF}_{3}(50)$

Bond Lengths

$$
\begin{aligned}
& a=1.57 \AA \\
& b=1.70 \AA \\
& c=1.93 \AA \\
& d=1.95 \AA \\
& e=2.34 \AA
\end{aligned}
$$


Meta1-0xygen Stretching Freguencies (in $\mathrm{cm}^{-1}$ )

For Solid Transition letal Oxide Trihalides

\begin{tabular}{lcclll} 
& \multicolumn{3}{c}{ Terminal Oxygen } & & \multicolumn{3}{c}{ Bridging } & Oxyqen \\
& & Ref. & & & Ref \\
$\mathrm{VOF}_{3}$ & 1039 & 94 & $\mathrm{MbCCl}_{3}$ & 757 & 99 \\
$\mathrm{VOCl}_{3}$ & 1022 & 95 & $\mathrm{NbOBr}_{3}$ & 732 & 93 \\
$\mathrm{VOBr}_{3}$ & 1009 & 95 & $\mathrm{MoOBr}_{3}$ & 810 & 93 \\
$\mathrm{MoOF}_{3}$ & 1000 & 96 & $\mathrm{WOCl}_{3}$ & 796 & 98 \\
$\mathrm{MoOCl}_{3}$ & 1007 & 93 & $\mathrm{WOBr}_{3}$ & 722 & 98 \\
$\mathrm{ReOCl}_{3}$ & 1018 & 97 & $\mathrm{TCOBr}_{3}$ & 770 & 93 \\
$\mathrm{ReOBr}_{3}$ & 1018 & 93 & $\mathrm{TaOCl}_{3}$ & 837 & 100 \\
$\mathrm{TCOCl}_{3}$ & 1017 & 93 & & &
\end{tabular}


Unfortunately, rather little attention has been paid to the ralide stretching and bending bands of the solid molecules, oddly, there are no assignsients for any halide bridging which one would expect if the strut ture of these comnounds was sizilar to that of $\mathrm{VOF}_{3}$ or $\mathrm{NODCl}_{3}$. An unassigned infrared spectrun of $\mathrm{MoOF}_{3}$ has appeared in the Russian 11 terature $(95)$ and definitely appears to contain the terminal oxygen stretching mode. An oriented single-crystal Raman study of $7 b 01_{3}$ (94) has assigned a strong, sharp bond at $770 \mathrm{~cm}^{-1}$ to an $\mathrm{Nb}-0-\mathrm{Nb}$ antisymetric stretch, a vibration also active in the infrared. Bridging chlorine stretches were assigned to bands at 293,287 , and $223 \mathrm{~cm}^{-1}$ while tenminal chlorine stretches wore found at 421 and $337 \mathrm{~cm}^{-1}$.

The values for the infrared and Raman spectra of $\mathrm{CrOF}_{3}$ are 1 isted in Table XIX. The infrared spectrum is of very high quality and the intensities and positions are identical and reproducible using either a nujol mull or $\mathrm{KBr}$ disc. It has been reported that a $\mathrm{KBr}$ disc can present distorted bands in the infrared (107) but this does not anpear to be the case here. The Raman spectrum is of rather poor quality, partially due to the fact that the samples ssemed to fluoresce. In general, fluorides do not tend to be good Raman scatterers. Comparing the infrared and Raman spectrum results in the unambiguous assignment of the band at $1000 \mathrm{~cm}^{-1}$ to a terminal, chromium-oxygen double bond stretch. Definite assignments for the rest of the bands are not possible without having information on the structure of the compound; however, certain generalizations can be made based on accepted trends in the vibrational spectra of metal fluorides. The physical properties of the compound (non-volatility, insolubility in non-polar solvents) tends to suggest that $\mathrm{CrOF}_{3}$ is extensively polymerized and this adds to the problem of assignment without a 
TABLE XIX

Vibrational Frequencies of $\mathrm{CrOF}_{3}, \mathrm{VOF}_{3}(94)$, and $\mathrm{MoOF}_{3}(95)$, in $\mathrm{cm}^{-1}$

\begin{tabular}{|c|c|c|c|c|}
\hline & & & $\mathrm{VOF}_{3}$ & $\because a / F_{3}$ \\
\hline$\underline{\mathrm{IR}}$ & Raman & Assignment & Raman & IR \\
\hline $1090 \mathrm{~s}$ & $1002 \mathrm{~s}$ & $U C r=0$ & 1039 vs & $1000 \mathrm{~s}$ \\
\hline $718 \mathrm{~s}$ & 790 in & $v C r-F$ & & \\
\hline $680 \mathrm{~s}$ & $720 \mathrm{~m}$ & $U C r-F$ & 7415 & \\
\hline $600 \mathrm{~s}$ & $685 \mathrm{~m}$ & $u C r-F$ & 678 w & 680 \\
\hline $565 \mathrm{~s}$ & $600 \mathrm{~m}$ & $u C r-F$ & $520 \mathrm{~m}$ & 625 \\
\hline $512 \mathrm{~m}$ & $545 \mathrm{~m}$ & $u C r-F-C r$ & $530 \mathrm{in}$ & 545 \\
\hline $478 \mathrm{~m}$ & & $v C r-F-C r$ & & \\
\hline & 485 W & $6^{\circ}$ & & 490 \\
\hline $378 w$ & $440 \mathrm{~W}$ & $\mathrm{~F}-\mathrm{Cr}-\mathrm{F}$ & $408 \mathrm{rw}$ & \\
\hline $350 \mathrm{vw}$ & $380 \mathrm{vl}$ & $\mathrm{O}-\mathrm{Cr}-\mathrm{F}$ & & \\
\hline $330 \mathrm{w}$ & & 8 & $358 \mathrm{~m}$ & \\
\hline & $310 \mathrm{w}$ & $\delta$ & 3265 & \\
\hline $288 \pi$ & & $\delta$ & $312 \mathrm{vw}$ & \\
\hline & & & $232 \mathrm{~s}$ & \\
\hline & & & $215 \mathrm{~s}$ & \\
\hline
\end{tabular}


structural determination. Although the structure of $\mathrm{VOF}_{3}$ is known (50) and a Raman spectrum has been reported (94), no assignaents vere made. In comparing the spectra of $\mathrm{VOF}_{3}$ and $\mathrm{NoOF}_{3}$ with those presented for $\mathrm{CrOF}_{3}$ in Table XI\%, one seas thers is a rcespnably good similarity to be found between the spectra. Especially important is the metal-fluoride stretching region ( 800 to $550 \mathrm{~cm}^{-1}$ ). The complexity of the spectra in this region lends evidence for the presence of different types of metal-fivortde bonds, eliminating the possiblity of a simple monomeric $C_{3 V}$ species which would display only two IR and Raman active bands in this region. Edward's work on $\mathrm{VOF}_{3}$ revealed the presence of four different bond lengths to the vanadium center (see Figure 5). These different metal-fluorine bond lengths would be expected to display a complex spectrum in the stretching region due to the resultant low symetry and in fact, the Raman spectrum of $\mathrm{VOF}_{3}$ is very similar to that of $\mathrm{CrOF}_{3}$ except for the band at $790 \mathrm{~cm}^{-1}$. The peaks found between 790 and $545 \mathrm{~cm}^{-1}$ in $\mathrm{CrOF}_{3}$ can be reasonably assigned to $\mathrm{Cr}-\mathrm{F}$ stretching modes, but more detailed assignments are not possible. The $790 \mathrm{~cm}^{-1}$ band in $\mathrm{CrOF}_{3}$ would appear to be troublesome toward showing chromfum and vanadium oxide trifluorides to be structurally similar. The peak is too intense to be an overtone $\left(485 \div 310=795 \mathrm{~cm}^{-1}\right)$ but may be the result of a solely Raman active fluoride stretching mode. The fact that a coincident absorbance does not appear in the infrared excludes the possibility of this being the result of a $\mathrm{Cr}-\mathrm{O}-\mathrm{Cr}$ bridge stretch.

The infrared absorbances at 512 and $478 \mathrm{~cm}^{-1}$ fall in the region of fluoride-metal bridging. This mode is Raman inactive for linear $\mathrm{B-F}-\mathrm{M}$ bridges and weak for bent bridging systems. The weak Raman band at $485 \mathrm{~cm}^{-1}$ nay well be the result of a bent bridging vibration, coincident with the $478 \mathrm{~cm}^{-1}$ infrared peak. The bands below $400 \mathrm{~cm}^{-1}$ are generally accepted 
as deformation modes. These would include $\mathrm{O}-\mathrm{Cr}-\mathrm{F}$ and $\mathrm{F}-\mathrm{Cr}-\mathrm{F}$ bending vibrations, but definite assignments are not possible.

Chromium oxide trifluoride was found to react with antimany pentaPltworicie to form a purple solution. An absorption syectruin of the SbF solution in the quartz reaction vessel shoved maxina at $550,470,320$, and $270 \mathrm{~nm}$. Upon removal of volatile materials at room temperature a yellow-orange solute became evident in the excess $\mathrm{SbF}_{5}$ pumped off the non-volatile product. This solute displayed absorption bands at 465 , 320 , and $218 \mathrm{~nm}$ which corresponded well to those of the $1: 2$ adduct of $\mathrm{CrO}_{2} \mathrm{~F}_{2}$ and $\mathrm{SbF}_{5}$ (see Table $\mathrm{XX}$ ). The remaining peak at $550 \mathrm{~nm}$ is in the region which is characteristic of $\mathrm{Cr}(\mathrm{V})$ species (82). Other pentavalent chromínm examples are also listed in table XX.

The non-volatile product of the reaction is a purple solid with a composition of $\mathrm{CrOF}_{3} \cdot 2 \mathrm{SbF}_{5}$. It is formed in yields less than 1008 due to formation of $\mathrm{CrO}_{2} \mathrm{~F}_{2}$, perhaps as a result of glass attack, with its subsequent removal as the silightly volatile $\mathrm{CrO}_{2} \mathrm{~F}\left(\mathrm{Sb}_{2} \mathrm{~F}_{11}\right)$ (51). Formation of chromyl fluoride from $\mathrm{CrOF}_{3}$ woutd logical1y also produce $\mathrm{Cr}$ (III) fluorides or oxide fluorides which account perhaps for the relatively poor chemical analysis. The adduct attacks glass slowiy at room temperature and is rigorously hydrolyzed by water to form a yellow-green solution. $\mathrm{CrOF}_{3}+2 \mathrm{SbF}_{5}$ melts from $120-125^{\circ}$ and decomposes above $130^{\circ}$ to a brown solid with the evolution as a gas, probably oxygen. The magnetic susceptibility was measured as 2.27 Bolur Magnetons; a value which is rather high for a compound with one unpaired electron (theoretical spin-only value; 1.73 B.M.) but the presence of $\operatorname{Cr}$ (III) in the sarole would account for the high value. Data from an infrared spectrum of $\mathrm{CrOF}_{3} \cdot 2 \mathrm{SbF}_{5}$ are presented in Table XX1. The spectrum is of moderate quality due to attack on the salt plates: 


\section{TABLE XX}

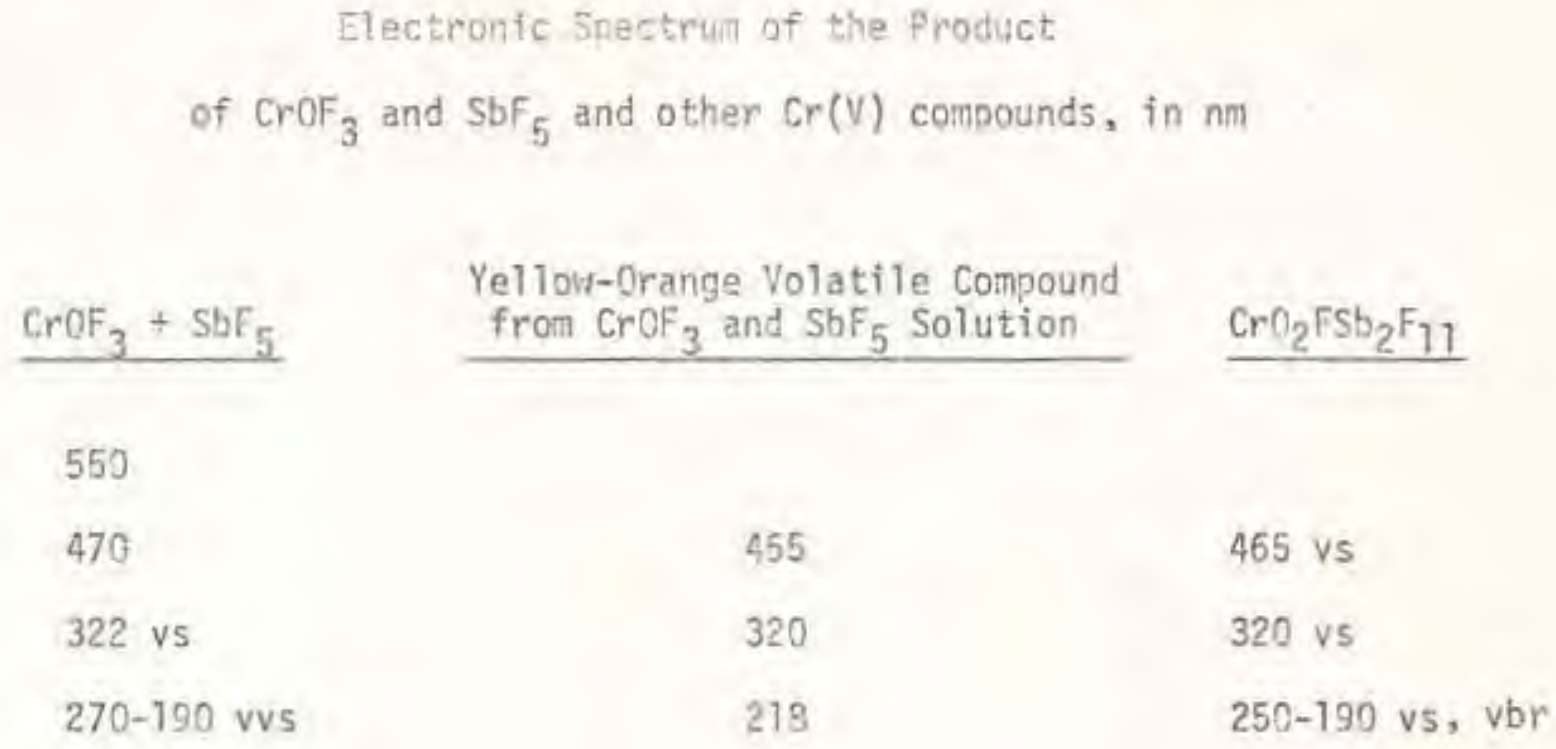

$\mathrm{KCrO}(\mathrm{PFP})_{2}(82)$

574

319
$\mathrm{CrOCl}_{3}(\mathrm{C4})$

520

390 
however, certain assignnents can be made. The peaks at 650 and $695 \mathrm{~cm}^{-1}$ are very similar to those found in the infrared spectrum of $\mathrm{CrF}_{5} \cdot 2 \mathrm{SbF}_{5}$ (61) which were assigned to Sb-F stretching modes of the $\mathrm{Sb}_{2} \mathrm{~F}_{11}{ }^{-}$ion. The broad bands at $540 \mathrm{~cm}^{-1}$ is in the region reasonably assigned to fluorine bridging but it is not possible to tell whether it involves antimony, chromium, or both. In $\mathrm{CrF}_{4} \mathrm{Sb}_{2} \mathrm{~F}_{11}$ a broad peak at $525 \mathrm{~cm}^{-1}$ was assigned to $\mathrm{Sb}-\mathrm{F}-\mathrm{Sb}$ stretch. The symetry to a $\mathrm{CrOF}_{2}{ }^{+}$species would be of particular interest but only one other fluorine stretching mode is observed. The shoulder at $760 \mathrm{~cm}^{-1}$ is thus assigned to $\mathrm{Cr}-\mathrm{F}$ stretch. The absorbance at $990 \mathrm{~cm}^{-1}$ originates from the $\mathrm{Cr}=0$ stretching mode. A Raman spectrum was not attempted.

$\mathrm{Cr}_{0} \mathrm{~F}_{2} \mathrm{Sb}_{2} \mathrm{~F}_{11}$ does not react with oxygen up to $80^{\circ}$. This is compared to $\mathrm{CrF}_{4} \mathrm{Sb}_{2} \mathrm{~F}_{11}$ which forms $\mathrm{O}_{2} \mathrm{CrF}_{4} \mathrm{Sb}_{2} \mathrm{~F}_{11}$ at room temperature (61).

Reaction of $\mathrm{CrOF}_{3}$ with fluorine at $180^{\circ}$ yields $\mathrm{CrF}_{5}$. This provides a good preparation for this compound under relatively mild conditions. 


\section{TABLE XXI}

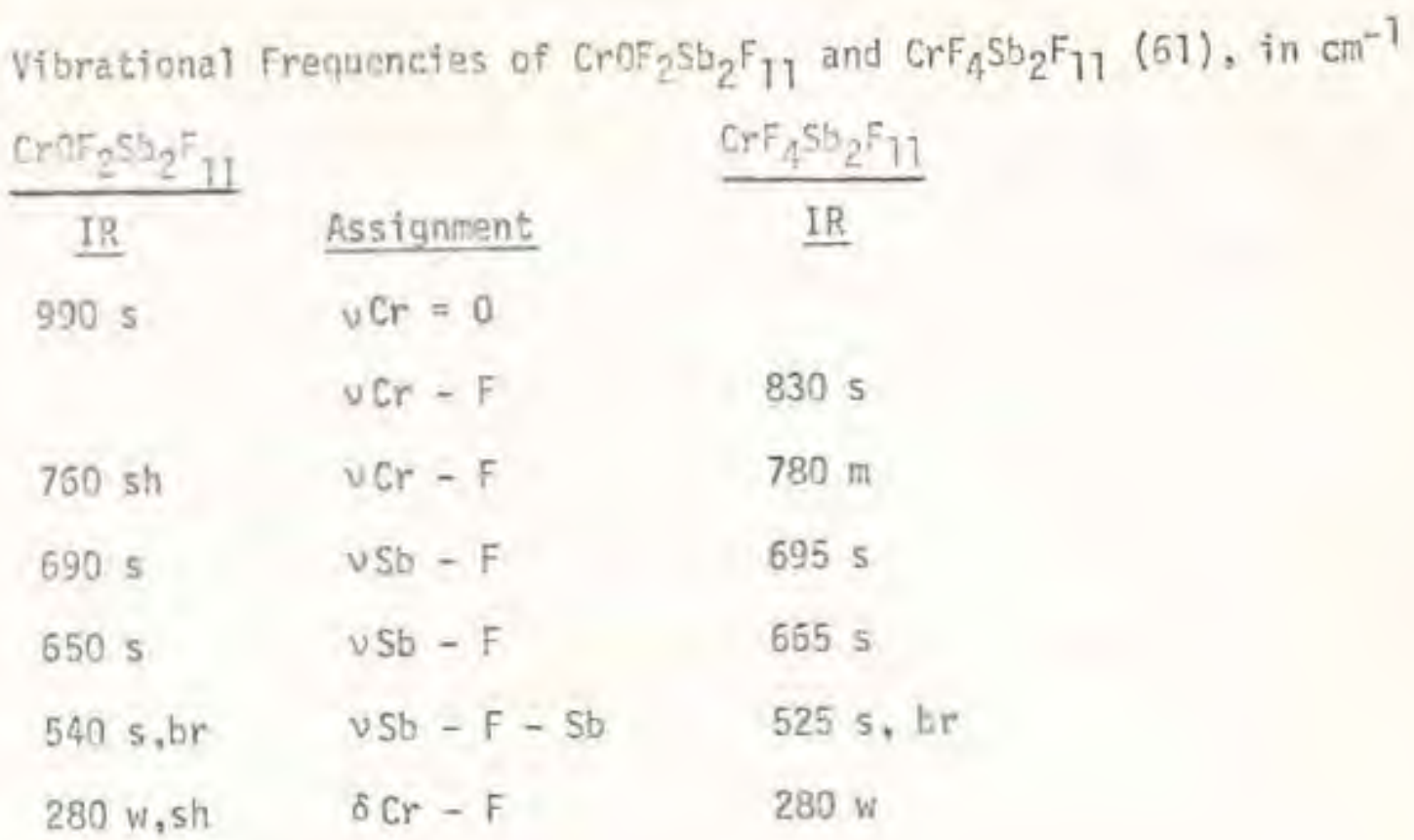




\section{BIBL TOGRAPHY}

1. O. Unvardorben. Amnalen Hin. (8) 1,135 (1927).

2. D.I. Mendelejeff, Princioies of Chemistry, German Edition, 5t. Petersburg, (1892), P. 59 .

3. K. Fredenhagen, Z. Anorg. Allgem. Chem., 247, 135 (1941).

4. H.V. Wartenterg, Z. Anorg. Al1gem. Chem., 247, 135 (1941).

5. A. Engelbrecht, A.V. Grosse, J. An. Chem. Soc., 74, 5262 (1952).

6. A. J. Edwards, W.E. Falconer, W.A. Sunder, 3. Chen. Soc. A., 541 (1974).

7. H.L. Krauss, F. Schwarzbach, Chem, Ber, 94, 1205 (1961).

8. G.D. Flesh, H.T. Sver, I. An. Chem. Soc., 89, 3189 (1958).

9, E.E. Aynsley, R. Nichois, P.L. Robinson, J. Chem. Soc, , 623 (1953).

10. H.C. Clark, Chem. Pev. 58, 869 (1958).

11. H. Meinert, 2 . Chen, , 7, 41 (1957).

12. D.E. Young, L.R. Anderson, D.E. Gould, W. B. Fox, J. An. Chem. Soc., 92, 2313 (1970).

13. C.J. Schark, R.D. Nilson, Inorg. Chem., 9, 311 (1970).

14. J.P. Faust, A.W. Jache. A.J. K1anica, U.S. Patent $3,545,924, D$ December 8, 1970.

15. J.F, E1115, C.M. Forrest, J., Inorg. Nucl. Chem,, 16, 150 (1960).

15. R.C. Shrewsberry, E.L. Williamson, J. Inorg. Nucl. Chem,, 28, $2535(1966)$.

17. M. Luce, 0. Hartmanshenn, J. Inorg. Nuc1. Chert, 29, 2826 (1967).

13. M.J. Heras, P.J. Aymonino, 11.J. Schumacher, Z. Phys. Chem., 22, 161 (1353).

19. R. Benoit, G. Besnard, O. Martmanshenn, M. Luce, J. Mongin, J. Pelissie, Commis. Energ. At. .Rapp., (1970) CEA-R-3953 (Chem Abs.. 27651 c. 
20. J.J. Pitts, A.W. Jache, Inorg. Chem. 7, 1561 (1958).

21. C. Lau, 1. Passmore, 1. Fluor. Chem., 6, 77 (1975).

22. C. Lau, J. Passmore, Inorg Chen., 13, 2275 (1974).

23. HC Clark, Y.11. Sadana, Can. J. Chem., 42, 50 (1964).

24. H.C. Clark, Y.M. Sadana, Can, 1. Chem., 42, 702 (1964),

25. A.S. Sharpe, A.A. Noolf, I. Chem. Soc., 798 (1951)

26. T.A. O'Donne11, D.F. Stewart, Inorg. Chem., 5, 1434 (1966).

27. F.S. Fawcett, A.L. McClelland, U.S. Patent 3,097,067, July 9, 1963.

28. A.L. McCelland, F.S. Fawcett, D.D. Coffman, unpublished work cited in "Preparative Inorganic Reactions", Interscience, W.C. Jolly, 1965 , vol, 2, D. 285.

29. F.S. Fawcett, C.W. Tullock, D.D. Coffman, 3. Am, Chem. Soc., 84, 4275 (1962).

30. H. Eilingsfeld, M. Seefelder, H. Weidinger, Angew. Cheri., 72, 836 (1960).

31. R. Adams, C.H. Ulich, J. Am. Chem. Soc., 92, 599 (1920).

32. H.S. Fry, 3. An, Chem. Soc., 33, 698 (1911).

33. A.A. Opalovsky, E.U. Lobkav, ‥ Fluor. Cheil., 5, 181 (1975).

34. J.R. Case, F, Nyman, Nature, 193, 473, Feb. 3, 1962.

35. D.K. Padria, A.R. Vasudera Murthy, ․ Fluor. Chem., 5, 181 (1975)

36. K.0. Christe, Inorg, Chem., 11, 1220 (1972).

37. E.T. McHale, G. von Elbe, 1. Phys. Chem., 72, 1849 (1968).

38. W.R. Hasek, W.C. Sinith, V.A. Engethardt, J. An. Chem. Soc., B2, $543(1950)$.

39. G.H. Cady, G.B. Hargreaves, J. Chem. Soc.., 1568 (1961).

40. A.J. Edvards, B.R. Steventon. J. Chem. Soc. A, 2503 (1958). 
41. W.E. Hohbs, J. Chan. Phys., 28, 1220 (1958)-

42. E.A. Jones, T.F. Parkinson, T.G. Burke, ‥ Chem. Phys., 18. $235(1950)$.

43. 0.F. Snitil, 5.1\%. Xejun, 14.17. Fletcher, Spec. Ácta, 20, 1753 (1964).

44. A.H. Uielson, P.d.H. Woitz, 1. Chem, Phys, 20, 1878 (195i).

45. 0. Liverdorben, Ainn. Physik, Chem., 7, 311 (1826).

46. W.H. Hartford, M. Darrin, Chem. Rev., 58, 1 (1958).

47. W.V. Rochat, J.N. Gerlach, G.L. Gard, Inorg. Chem., 9,998 (1970).

48. C.D. Garner, R. Maher, Chem. Corm., 633 (1973).

49. S.D. Brown, G.L. Gard, T.K. Loehr, submitted to I. Chem. Phys,., (1975).

50. A.J. Edwards, P. Taylor, Chem. Comm., 1474 (1970).

51. S.D. Brown, P.J. Greer, G.L. Gard, J. Fluorine Chein., 5,203 (1975).

52. S.D. Brown, G.L. Gard, Inorg. Chem., 12, 483 (1975).

53. R.C. Makhija, R.A. Stairs, Can. J. Chem., 46, 1255 (1968).

54. A.L. Etard, Bul1 Soc. Chin,, 27, 249-51 (1877) and references in Chem. Rey., 58, 25 (1958).

55. C.C. Hobbs, B. Houston, ‥ 프. Chen. Soc., 76, 1254 (1954).

56. R.A. Stairs, D.G.M. Diaper, A.L. Gatzke, Can. J. Chen., 41, 1059, (1963).

57. I. Necsoui, A.T. Balaben, I. Pascaru, E. S1iam, M. Elían, C.D. Nenitzescu, Tetrahedron, 19, 1133 (1963).

58. O.H. Wheeler, Can. J. Chen, , 38, 2137 (1960).

59. G.G. Belenku, L.S. German, I.L. Knunyants, Izv Akad Nauk SSSR, Ser Khum, 2, 379 (1970).

60. L.S. German, I.L. Knunyants, DokI Akad Nauk SSSR, 166, 502 (1966),

61. S.D. Brown, Master's Thesis, Portland State University, 1975.

62. T.G. Burke, D,F, Smith, R.H. Wielsen, 3. Chem. Phys., 20, 447 , (1952). 
63. J.4. Simons, ed., "Fluorine Chenistry", Vol. 2, Academic Press, llew York, 1954, p. 498.

64. D.C. Beriutt, R.M. Willer, I.C. Histasune, Spectrochim Acta, 23 A, 237 (1967).

65. P.J.H. Woltz, E.A. Jones, A.H. Nielsen, J. Chem. Phys., 20, 378, (1952).

66. R.R. Ryan, S.H. Mastin, 17.J. Risefeld, Acta Cryst, 827, 1270 (1971).

67. G. Pansewang, K. Dehnicke, $\underline{2}$. Anorg. Allgem, Chem., 269, 265 (1969),

68. L.0. Atormyan, O.N. Krasochka, N.Ya. RehTin, Chem, Corm, 610 (1961).

69. R. Mattes, G. Muller, H.J. Becher, Z. Anorg. Al Igem, Chem., 389, 177 (1972.

70. M.P. Griffith, S. Chem, Soc, A., 211 (1969).

71. J.R. Soulen, W.F. Schwartz, 1. Phys, Chem., 55, 2066 (1952).

72. R. Teranshi, J. Decius, ․․ Chem. Phys., 22, 877 (1953).

73. F.P. Gortsema, R.H. Toeniskoetter, Inorg. Chem, , 5, 1217 (1966).

74. D.C. Kepert, R.S. Nyholm, I. Chem. Soc., 2872, (1955).

75. D.G. B1ight, R.C. Deutscher, D.C. Kepert, J. Chem. Soc. Dalton, 88, (1972).

76. H.C. Dufin, R.B. Tucker, Chen, Ind, 1252 (1956).

77. M.J. Leigh, J.A. Stricken, J. Chem. Soc. Perkin II, 1476 (1973).

78. M. Greenblatt, E. Bank5, B. Pest, Acta Cryst., 23, 166 (1967).

79. E. Banks, 1. Greenblatt, B.R. McGarney, J. Chem. Phys., 47, 377, (1967).

80. R. Scholder, H. Schwartz, Z. Anorg. Allgem. Chen,, 326, 1 (1963).

81. H.B. Gray, C.R. Hare, Inorg. Chem., 1, 363 (1962).

82. C.J. Nillis, Chem, Comm, 944 (1972).

83. H.C. Krauss, G. Munster, Z. Haturforschg. 176, 344 (1962). 
84. H.C. Krauss, H. Leder, G. Munster, Chem. Ber., 96, 3098 (1963).

85. R.B. Johannesen. H.C. Krauss, Chem. Ber., 97, 2094 (1954).

B5. 0, Glemser, H. Roesky, K.H. Hellberg, Aagew. Chenl, Int. Ed, 2. 266, (1953).

87. J. Sviliuk, B. Zemva, z. Anorg. Allgem. Chem., 385, 137 (1971).

88. H.J. Emeleus, A.A. Moolf, ․ Chem. Soc., 164 (1950).

89. S. Blanchard, ㄴ. Chem, Phys, 61, 747 (1964).

90. R.J. Gillespie, M.J. Mortan, Inorg. Chem., 9, 811 (1970).

91. K.0. Christe, W. Sayadny, J.P. Guertin, Inarg. Chem., 6, 1159. (1967).

92. K.0. Christe, C.J. Sehack, D. Piliponch, Inorg. Chent., 8, 2489, (1969).

93. J.H. Canterford, R. Colton, 1.B. Tomkins, Inorg, Hucl. Chem, Letters, 4, 471, (1968).

94. I.R. Beattie, K.M.S. Livingston, D.J. Reynolds, G.A. Ozin, JChem. Soc. A., 1210, (1970).

95. R.J.H. Clark, P.D. Mitche11, 1. Chern. Soc. A., 2429 (1972).

96. G,E, Blokhina, I.N. Belyaer, A. Opatovski, L.I. Belan, Russ. J. Inorg. Chem., 17, 1113 (1972).

97. P.W. Frais, C.J.L. Lock, Chear. Comm., 75 (1971).

98. G.W.A. Fowtes, J.L. Frost, Chen. Comm., 252 (1966).

99. D. Brown, J. Chen. Soc, 4944 (1964).

100. K. Dehnicke, Naturyiss., 52, 58 (1965).

101. D.E. Sands, A. Zalkin, R.E. Elson, Acta. Cryst., 12, 21 (1959).

102. P.C. Crouch, G.M.A. Fowles, J.L. Frost, P.R. Marsha11, R.A. Walton, I. Chem. Soc. A., 105i, (1968).

103. M. Mercer, J. Chem. Soc. A., 2019 (1959).

104. N.G.B. Drew, 1.B. Tomkins, 1. Chem. Soc. A. 22 (1970). 
105. J.H. Canterford, R. Cotton, "Malides of the Second and Third Row Transition Metals", Wiley-Interscience, New York, 1968, p. 51,

106. G.A. Ozin, A.J. Reynolds, Chen, Conm., 884 (1969).

107. I.P. Peattie, Chemi- Sac. Reve, 4, 107 (1975).

108. D.H.A. Sharp, J. Thorley, J. Chem. Soc., 3557 (1963).

109. P.N. Gates, E.F. Mooney, J. Inorg, Nucl, Chem., 30, 839 (1958).

110. "Sadtler Standard Spectra", Sadtler Research Laboratories, 1955, \$9197.

111. S.J. Cristol, K.R. Eł1ar, J. Am. Chen. Soc., 72, 4353 (1950).

112. A.M. Akena, D.S. Brown, D.G. Tuck, Can, J. Chem., 49, 1505 (1971).

113. R.T. ConTey, "Infrared Spectroscopy", AlTyn and Bacon, Inc.. Boston, 1972, p. 187.

114. P. Vankateswarlee, J. Chem. Phys., 19, 293 (1951). 